\title{
No Double Standards: Quantifying the Impact of Standard Harmonization on Trade
}

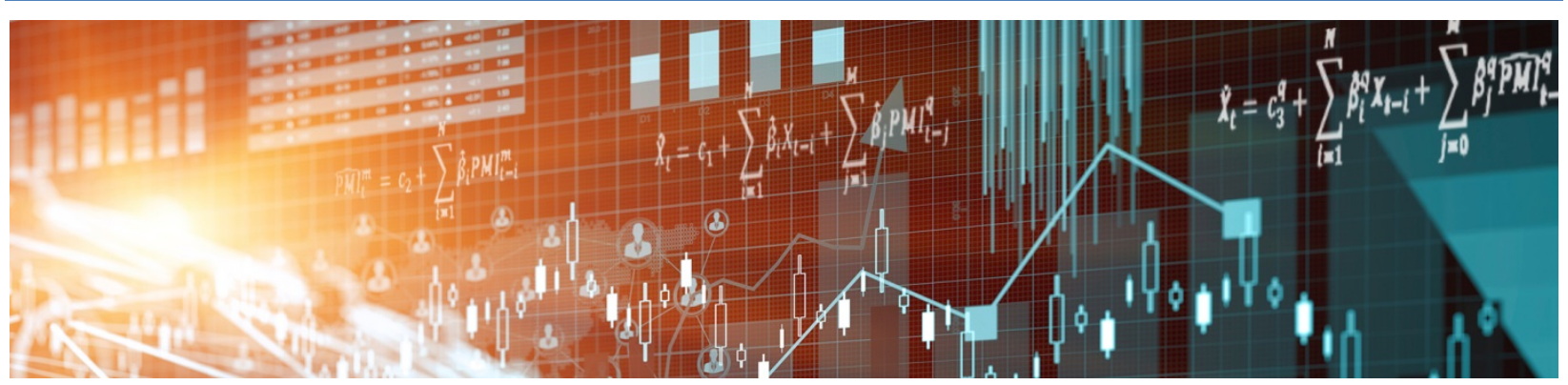

by Julia Schmidt and Walter Steingress 
Bank of Canada Staff Working Paper 2019-36

September 2019

\title{
No Double Standards: Quantifying the Impact of Standard Harmonization on Trade
}

\author{
by \\ Julia Schmidt ${ }^{1}$ and Walter Steingress ${ }^{2}$ \\ ${ }^{1}$ Banque de France \\ International Macroeconomics Division \\ 75049 Paris Cedex 01, France \\ julia.schmidt@banque-france.fr \\ 2International Economic Analysis Department \\ Bank of Canada \\ Ottawa, Ontario, Canada K1A OG9 \\ wsteingress@bank-banque-canada.ca
}




\section{Acknowledgements}

We would like to thank Juan Esteban Carranza-Romero, Christian Fons-Rosen, Lionel Fontagné, Vanessa Gunnella, Margaret Kyle, Philippe Martin, Keith Maskus, Thierry Mayer, Ralph Ossa, Dan Trefler and seminar participants at the Searle Center Northwestern University, MINES ParisTech, EEA Lisbon, DEGIT Paris, ETSG Florence, Université de Montréal, PRONTO Vienna, InsTED Syracuse, Midwest International Trade Conference, CEPII, Banque de France, Bank of Canada, Banco de la Republica in Cali, CEBRA Annual Conference, Geneva Trade and Development Workshop, Standards Council of Canada, BdF-PSE Macro-Trade Workshop and CAED for helpful comments and discussions. Special thanks to the team of the Searle Center on Law, Regulation, and Economic Growth, Northwestern University, for helping us with the data. The views expressed in this paper are those of the authors and do not reflect those of the Banque de France and the Bank of Canada. 


\begin{abstract}
Product standards are omnipresent in industrialized societies. Though standardization can be beneficial for domestic producers, divergent product standards have been categorized as a major obstacle to international trade. This paper quantifies the effect of standard harmonization on trade flows and characterizes the extent to which it changes the cost and demand structure of exporting. Creating a novel and comprehensive database on crosscountry standard equivalences, we identify standard harmonization events at the document level. Our results show that the introduction of harmonized standards increases trade through a larger sales volume of existing exporters (intensive margin) and more entry (extensive margin). These findings are consistent with a multi-country heterogeneous firm model featuring endogenous standard adoption. Because of additional demand, standard harmonization raises firms' incentives to produce varieties in accordance with the standard despite high sunk investment costs. Firms' export sales expand and entry into foreign markets is encouraged.
\end{abstract}

Bank topic: Econometric and statistical methods, International topics

JEL classification : F13, F14, F15, L15

\title{
Résumé
}

Les normes de produits sont omniprésentes dans les sociétés industrialisées. Bien que la normalisation puisse être bénéfique pour les producteurs nationaux, les normes de produits divergentes entre pays ont été classées comme un obstacle majeur au commerce international. Le présent document quantifie l'effet de l'harmonisation des normes sur les flux commerciaux et caractérise l'ampleur des changements qu'elle entraîne sur la structure des coûts et de la demande d'exportations. À l'aide d'une base de données de notre cru sur les équivalences des normes d'un pays à l'autre, nous faisons ressortir les activités d'harmonisation au niveau des documents normatifs. Nos résultats montrent que l'introduction de normes harmonisées fait augmenter les échanges commerciaux grâce à un volume de ventes plus important chez les exportateurs existants (marge intensive) et à l'entrée en scène de nouveaux exportateurs (marge extensive). Ces résultats sont cohérents avec un modèle multipays renfermant des entreprises hétérogènes avec adoption endogène des normes. En raison de la demande supplémentaire de produits qu'elle génère, l'harmonisation des normes incite les entreprises à produire des variétés conformes à celles-ci, malgré d'importants coûts d'investissement irrécupérables. Les ventes à l'exportation des entreprises augmentent et l'entrée sur les marchés étrangers est encouragée.

Sujets : Méthodes économétriques et statistiques, Questions internationales

Codes JEL : F13, F14, F15, L15 


\section{Non-technical summary}

Product standards are a defining feature of industrial processes and citizens' everyday lives. From environmental or safety standards to technological standards that ensure the compatibility of different devices and inputs, standardization is widespread and affects production processes in virtually all industries. While standards assure a better synergy between inputs and products in a domestic context, they are among the first to be listed as barriers to trade. Cross-country standard harmonization can be an effective trade policy tool to reduce these non-tariff barriers, but its use is subject to debate in policy and academic circles alike.

Data limitations and econometric challenges have prevented a thorough assessment of the effects of product standards and their harmonization on international trade. The existing evidence concentrates on specific sectors and regulatory trade barriers such as sanitary and phytosanitary (SPS) measures. In addition, the literature has largely ignored the fact that most product standards are voluntary. This paper intends to fill this gap and analyzes the impact of standard harmonization on aggregate trade flows.

We track the accreditation of foreign and international standards at the document level and construct a novel bilateral product-level database of standard harmonization. Indeed, harmonized standard releases are omnipresent and concern more products than traditional barriers to trade. The extensive sectoral coverage of our dataset enables us to provide new evidence on the quantitative importance of standard harmonization.

To measure the impact on trade, we compare trade flows of harmonized versus nonharmonized products following a difference-in-difference approach. Our results show that, on average, standard harmonization increases product-level trade flows by $0.67 \%$. This increase is driven by higher sales of existing varieties, while the positive contribution of more entry is minor. We further show that the increase in trade flows is a result of greater quantities being sold rather than a change in prices.

To translate our result into comparable economic outcomes, we compute ad-valorem tariff equivalents: that is, we ask what the hypothetical percentage point change is in the tariff rate that would yield the same effect as a harmonization event. We find that the impact of standard harmonization on trade flows corresponds to a tariff reduction of 2.1 percentage points. This marginal effect is amplified by the fact that over $40 \%$ of bilateral product-level trade flows are subject to standard harmonization every year. Overall, we estimate the average increase in world trade to be $0.27 \%$ per year, which is more than twice the contribution of tariff reductions.

To shed light on the underlying economic mechanisms, we build a multi-country model of heterogeneous firms and allow for endogenous standard adoption: i.e. firms decide to produce a standardized or a non-standardized variety of a differentiated product. Product standards capture product attributes, such as quality, safety or environmental aspects, which result in higher consumer demand. At the same time, producing standardized varieties requires sunk investment costs and higher marginal costs, which both increase with the severity of the standard. The presence of sunk costs implies a selection effect 
where only high-productivity firms are able to produce in accordance with the standard while low-productivity firms choose to produce the non-standardized variety.

Our results speak in favor of the presence of sunk investment costs and higher demand effects: standard harmonization gives firms the incentive to invest in the standard mainly by generating additional demand, such as through reducing information asymmetries and/or ensuring the compatibility of inputs and devices across markets.

Overall, the presence of these positive externalities highlights the benefits from policy coordination between countries when deciding product standards and underscores the importance of international standard-setting organizations in facilitating the development of common product standards. 


\section{Introduction}

Product standards are a defining feature of industrial processes and citizens' everyday lives. From environmental or safety standards to technological standards that ensure the compatibility of different devices and inputs, standardization is widespread and affects production processes in virtually all industries (ISO, 2016). While standards assure a better synergy between inputs and products in a domestic context, they may constitute an obstacle for producers from countries that are not subject to the same standards. ${ }^{1}$ Not surprisingly, product standards are therefore among the first to be listed as barriers to trade. Cross-country standard harmonization can be an effective trade policy tool to reduce these non-tariff barriers. However, such policies are subject to controversial debate, both in policy circles and among citizens. ${ }^{2}$

Data limitations and econometric challenges have prevented a thorough assessment of product standards and their harmonization (Goldberg and Pavcnik, 2016; Ederington and Ruta, 2016). The existing evidence concentrates on specific sectors and regulatory trade barriers such as Sanitary and Phytosanitary (SPS) and Technical Barriers to Trade (TBT) measures. However, the literature has largely ignored the fact that the majority of product standards are voluntary. ${ }^{3}$ The widespread use of product standards and increasing crossborder harmonization efforts might have a large impact on trade flows. As figure 1 shows, harmonized standard releases are omnipresent and concern more products than traditional barriers to trade. However, little is known about how these harmonized standards affect trade flows.

To fill this gap, we track the accreditation of foreign and international standards at the document level and construct a novel bilateral product-level database of standard harmonization. The extensive sectoral coverage of our dataset enables us to provide new evidence on the quantitative importance of standard harmonization. To measure the impact on trade, we compare trade flows of harmonized versus non-harmonized products following a difference-in-difference approach. Our results show that, on average, standard harmonization increases product-level trade flows by $0.67 \%$, which corresponds to a reduction of 2.1 percentage points in ad-valorem tariff equivalents. This marginal effect is amplified by the fact that over $40 \%$ of bilateral product-level trade flows are subject to standard harmonization every year. Overall, we estimate the average contribution to world trade to be $0.27 \%$ per year, which is more than twice the contribution of tariff reductions.

How does the harmonized release of a standard affect trade flows? Do we see more trade because of a larger number of varieties traded (extensive margin), or because the

\footnotetext{
${ }^{1}$ See, for example, Essaji (2008), Fontagné et al. (2015) and Fernandes et al. (2019).

${ }^{2}$ The public protests against recent US-European free trade negotiations are one example of citizens' mobilization against policy efforts that concern product standards. For instance, 180,000-320,000 people protested against TTIP and CETA in Germany in September 2016.

${ }^{3}$ For example, the International Organization for Standardization (ISO) stresses that its standards are voluntary. In a similar vein, European standards, even though sometimes requested by the European Commission, remain voluntary. In the case of Canada, for example, it is estimated that approximately two-thirds of standards are voluntary (see http://www.ic.gc.ca/eic/site/oca-bc.nsf/eng/ca01579.html).
} 
Figure 1: Harmonizations vs. tariffs, 1995-2014

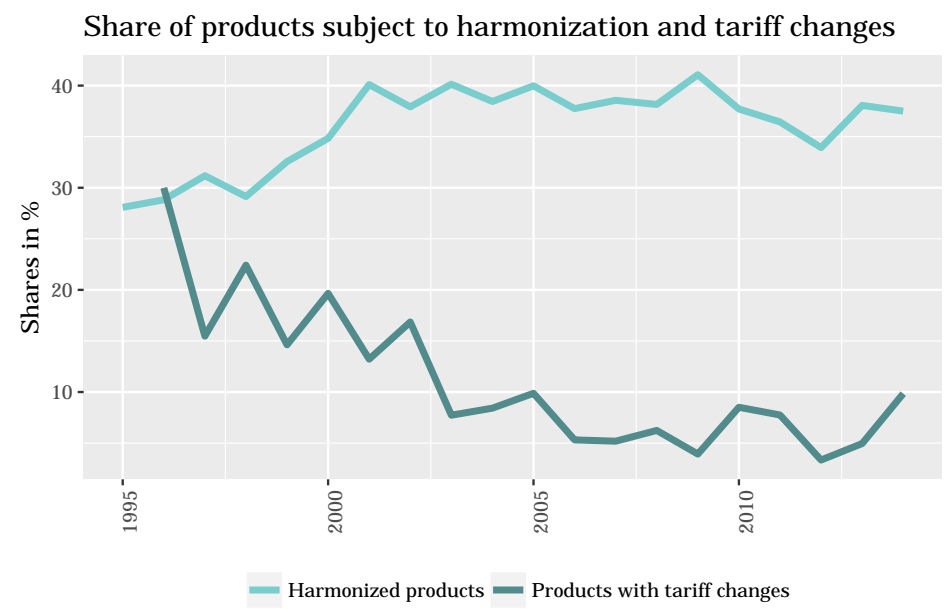

Notes: The figure displays the share of bilateral trade flows measured at the HS 4-digit level that are subject to standard harmonization or subject to tariff changes.

sales of already-exported product varieties increase (intensive margin)? Our results show that the change in trade flows is driven by an increase in sales of existing varieties (74\%), while the positive contribution of more entry is minor (26\%). Decomposing the intensive margin into a price (unit value) and quantity component shows that the increase is a result of more quantities being sold rather than a change in prices.

To shed light on the underlying economic channels, we build a multi-country model of international trade with heterogeneous firms and allow for endogenous standard adoption, i.e. firms decide to produce a standardized or a non-standardized variety of a differentiated product. Product standards are exogenously given and capture product attributes, such as quality, safety or environmental aspects, which result in higher consumer demand. At the same time, producing standardized varieties requires sunk investment costs and higher marginal costs, which both increase in the severity of the standard. ${ }^{4}$ The presence of sunk costs implies a selection effect where only high-productivity firms are able to produce in accordance with the standard while low-productivity firms choose to produce the non-standardized variety. The release of a harmonized standard increases the incentives for firms to adopt the standard, mainly by generating additional demand: for example, through the reduction of information asymmetries and/or by ensuring the compatibility of inputs and devices. ${ }^{5}$ Average sales of firms (intensive margin) increase because firms producing the harmonized variety see the demand for their products increase. Entry into exporting (extensive margin) is encouraged as low-productivity firms producing the non-standardized variety also profit from a general equilibrium effect that increases overall demand.

\footnotetext{
${ }^{4}$ These features are consistent with recent models on product standards, such as Baldwin et al. (2000), Costinot (2008), Mei (2017) and Macedoni and Weinberger (2018), as well as empirical evidence by Fontagné et al. (2015) and Fernandes et al. (2019).

${ }^{5}$ This effect is reminiscent of a reduction in uncertainty that encourages firm entry investment, as in Handley and Limão (2017).
} 
In our model, standard harmonization essentially acts as a demand shifter. While standardization reduces negative externalities (see, for example, Costinot, 2008), standard harmonization may lead to additional demand effects if it reduces information asymmetries or creates positive externalities such as network effects. ${ }^{6}$ To provide empirical support for this view, we corroborate our analysis with French firm-level data. While bilateral product-level data allow us to simultaneously control for sector-specific demand and supply effects, the interpretation of our results could be flawed by composition effects between firm and product entry within a sector. Running our baseline specification with the corresponding decomposition at the firm level confirms our previous results. Firm-level sales increase, mainly through more quantities being sold. The increase in quantities despite a small increase in firm-level prices (unit values) supports our interpretation of a positive demand effect (e.g. a reduction in information asymmetries) rather than lower variable trade cost (e.g. by facilitating border processing).

Concerning the robustness of our results, we first want to point out that trade policies almost always concern product standards, but not all product standards are formulated with a trade objective in mind. The standards in our database are released for a variety of reasons (such as to ensure the compatibility of technological devices or to address health concerns) and do not necessarily target exporters or importers. ${ }^{7}$ Ex ante it is not clear that harmonization has a positive effect on trade flows. Still, our estimated results are subject to endogeneity concerns. We address these concerns in a number of robustness checks. First, we show that our difference-in-difference estimator does not pick up different pre-trends between harmonized and non-harmonized products. Second, we present evidence that our results are not driven by the fact that harmonization may primarily happen in product categories with larger trade flows. Lastly, we mitigate the concern that special interest groups drive the results: we instrument country-specific harmonization events by accreditations of neighboring countries (as in Kee and Nicita, 2016) and take advantage of mandatory harmonization of supranational standards.

This paper contributes to the literature on the quantitative impact of non-tariff measures (NTMs) on international trade. International standards have become the center of attention in the international trade policy discussion: see, for example, OECD (2005) and World Trade Report (2012). With an average tariff of $1.5 \%$ on goods imported by developed countries in 2016 (see UNCTAD, 2016), estimates from recent studies suggest that NTMs are now the main trade barrier between countries. In this paper, we follow Kee et al. (2009) and compute the gains from standard harmonization as the equivalent to a reduction in the tariff rate. However, little is known about the economic channels of lowering these barriers (Goldberg and Pavcnik, 2016; Ederington and Ruta, 2016). Theory

\footnotetext{
${ }^{6}$ See Leland (1979) for the seminal paper on the reduction of information asymmetries, Farrell and Saloner (1985) and Katz and Shapiro (1985) for network externalities from standardization, and Swann (2000) for an overview of this early theoretical literature.

${ }^{7}$ As such, SPS and TBT regulation can be used for trade policy purposes. Examples of such policies can be found in the World Trade Organization (WTO) database on specific trade concerns, which contains information on product standards that member states notify as a measure that has a significant effect on trade; see World Trade Report (2012).
} 
can guide these reflections. One example is Arkolakis et al. (2016), who use a structural micro-founded general-equilibrium model of multi-product firms to generate counterfactual predictions for how a reduction in market access costs (NTMs) affects trade patterns. Mei (2017) and Parenti and Vannoorenberghe (2019) study optimal product regulation in the presence of a negative consumption externality and show that international cooperation in standard setting increases international trade. ${ }^{8}$

In general, the empirical literature on standards as a non-tariff barrier to trade focuses on the economic effect of the introduction of standards on trade flows; see Swann et al. (1996) for the seminal contribution and Swann (2010) for a literature review. More recently, Fontagné et al. (2015), Fernandes et al. (2019) and Macedoni and Weinberger (2018) analyze firm dynamics and show that restrictive regulatory standards have a detrimental impact on trade flows, but less so for larger firms. There are a few notable exceptions that specifically analyze the effect of cross-country standard harmonization on trade flows for specific regulations within a subset of industries. Chen and Mattoo (2008) use information on EU/EFTA harmonization and mutual recognition agreements and find that trade flows increase between participating countries, but exports of excluded countries can actually decrease. Disdier et al. (2015) also show that harmonization between Northern and Southern countries is associated with increasing trade flows and point out the trade-deflecting effect on South-South trade. Another study to use firm-level data is Reyes (2011). He shows that the harmonization of EU electronics standards led to an increase of the number of US firms exporting to the EU in that sector. Contrary to this literature, we are able to derive aggregate implications due to the use of a novel database with extensive sectoral and country coverage.

A final contribution of this paper is to shed light on the relative importance of the various economic channels suggested by the theoretical literature on the harmonization of product standards. Standard harmonization can increase consumer demand by reducing distortions due to information frictions (Leland, 1979; Atkeson et al., 2014) or by creating positive network externalities from more users (Katz and Shapiro, 1985; Farrell and Klemperer, 2007). On the supply side, harmonization can reduce market-specific fixed and marginal costs (Mei, 2017) or facilitate border processing and decrease trade costs (Kieck, 2010). At the same time, producing in accordance with a standard can entail sunk investment costs (Fischer and Serra, 2000; Maskus et al., 2005). ${ }^{9}$ To disentangle these different effects, we build a multi-country heterogeneous firm model and use the estimated responses on the different trade margins to infer changes in costs and demand due to the harmonization of product standards. Overall, our results favor the interpretation of a positive demand effect as the dominant channel, while the cost-reducing channel plays only a minor role.

\footnotetext{
${ }^{8}$ For a theoretical discussion of the introduction of non-harmonized standards and their impact on trade flows, see Gandal and Shy (2001), Fischer and Serra (2000), Ganslandt and Markusen (2001).

${ }^{9}$ These costs are termed "compliance costs" in Maskus et al. (2005), "adaption costs" in Maur and Shepherd (2011) and Toulemonde (2013), "conversion costs" in Gandal and Shy (2001) and "setup costs" in Fischer and Serra (2000).
} 
The rest of the paper is organized as follows. Section 2 explains the data and stylized facts on cross-country standard harmonization. Section 3 discusses our empirical strategy and presents the main results. In section 4, we present a theoretical framework that we use to interpret the results and discuss the different expected effects of standard harmonization on trade. In section 5, we further investigate these economic channels, while section 6 provides robustness checks. The last section concludes.

\section{Cross-country standard harmonization and data}

We start by describing some features of the standard-setting process. Standards are released by different standard-setting organizations (SSOs). An SSO can be organized at the national level (for example, the German Institute for Standardization, DIN, or the Standards Council of Canada, SCC), can be an international standard-setting body (such as the International Organization for Standardization, ISO) or an industry association (such as the Institute of Electrical and Electronics Engineers, IEEE). Many SSOs are non-profit, non-governmental organizations. SSOs elaborate standards in working groups and technical committees that are composed of industry experts. For example, in ISO, there are technical committees on a variety of issues such as screw threads (ISO/TC 1), cosmetics (ISO/TC 217) or blockchain technologies (ISO/TC 307). The experts in those committees participate on behalf of private firms, non-governmental and governmental agencies.

SSOs elaborate standards on a large range of aspects beyond the regulatory TBT and SPS concerns that are usually discussed in the trade literature. One can distinguish between quality standards, compatibility standards, conformity assessment standards or technical standards. ${ }^{10}$ Of course, a certain standard can be categorized into more than one of these types, and the standards in our database actually often fulfill several of these purposes.

Standards are by definition voluntary, and the majority of product standards remain so. They can become de jure binding when a governmental regulation references a standard. For example, the standard IEC 331:1970 that deals with fire-resisting characteristics of electrical cables has been incorporated by reference into the U.S. Code of Federal Regulations. In certain cases, standards are elaborated to support and interpret government regulation, but their use often remains voluntary. ${ }^{11}$ In addition, a large number of standards are de facto binding as market forces constrain firms in the production of goods. For example,

\footnotetext{
${ }^{10}$ There exists no official categorization of the different standard types. See, for example, the discussion in Swann (2000). Quality standards also comprise product attributes such as safety aspects or environmental concerns. Compatibility standards ensure the interoperability of devices and compatibility of inputs. Conformity assessment or testing standards describe the procedures by which producers must prove that their product complies with regulatory provisions. Standards whose aim it is to reduce variety are elaborated to allow for economies of scale.

${ }^{11}$ Legal texts often leave it to firms to determine how they comply with a certain regulation. In this respect, standards can help businesses in achieving this goal, but firms are free to choose other means of compliance; the standard thus remains voluntary. See, for example, the standardization requests by the European Commission: https://ec.europa.eu/growth/single-market/european-standards/requests_en.
} 
consumers expect a printer to be compatible with A4 paper size (ISO 216:2007) or letter size (ANSI/ASME Y14.1) despite there being no official law on paper dimensions for printers.

We track the standard releases of each standard-setting organization within the Searle Center Database on Technology Standards, Industry Consortia and Innovation (see Baron and Spulber (2018)). Its main source is Perinorm, a bibliographical repository of standard documents. We specifically rely on Perinorm's information on standard equivalences in order to identify cross-country standard harmonization. In addition, the dataset contains the date of release, the International Classification for Standards (ICS) category and the nationality of the SSO.

An SSO can release a standard developed by its own technical committee, but can also release a standard developed by another SSO. ${ }^{12}$ In order to identify relevant harmonization events, we restrict the sample to those standards that constitute the first publication ("original") across all SSOs/nationalities as well as the accreditation of these original standards by SSOs of different nationality. On average, a harmonized standard is accredited by 6.4 countries. In the data, we define harmonization as follows: an SSO of the importing country releases a standard that was also released by an SSO of the exporting country (either in the same year or before). There are two means via which product standards are harmonized across countries. Either an SSO decides to accredit the standard of an SSO of another nationality ("bilateral standard harmonization") or two SSOs of different nationality accredit a standard originating in an international SSO ("international standard harmonization"). More details on the database construction can be found in appendix C.

Table 1: Means of accreditation: bilateral vs. international

\begin{tabular}{crr}
\hline Number of standards in subset & 695724 & in \% \\
\hline of which: original bilateral standards & 10541 & 1.5 \\
of which: accreditations of bilateral standards & 45493 & 6.5 \\
of which: by national SSOs & 39885 & 5.7 \\
of which: by international SSOs & 5608 & 0.8 \\
of which: original international standards & 98987 & 14.2 \\
of which: accreditations of international standards & 540703 & 77.7 \\
\hline
\end{tabular}

Table 1 expresses the population of original standards and accreditations in percentages. Three quarters of all standard releases are accreditations of standards from international SSOs by national SSOs. A large amount of this international dimension of standard harmonization is due to the European integration process and the accompanying dominance of European SSOs among international SSOs. National SSOs play only a minor role. Only $6 \%$ of the standard releases in our data are accreditations of standards that originate in national SSOs.

\footnotetext{
${ }^{12}$ This is, for example, the case when a standard released by an international SSO such as the International Organization for Standardization (ISO) is published by a national SSO such as the British Standards Institution (BSI).
} 
In this paper, our definition of standard harmonization comprises both standard releases that concern aspects that were previously not the subject of a product standard (either because there was no standard or because the product/technology did not yet exist) or standard harmonization in the strict sense where conflicting standards are replaced by one common, harmonized version. We designate the term "standard harmonization" to apply both to the release of a new, harmonized standard as well as to the replacement of conflicting standards.

Another form of reducing diverging product standards is mutual recognition. In this case, two countries have divergent product standards and allow the sales of products under both standards. We are not able to identify mutual recognition events in the data. This would require knowing that the accreditation of a trading partner's standard was specifically part of a mutual recognition procedure. An alternative form of mutual recognition, as in the case of the EU, does not necessarily involve the formal accreditation of a trading partner's product standards and consequently does not show up in our dataset.

In terms of sectoral heterogeneity, standards are categorized according to the International Classification for Standards (ICS). ${ }^{13}$ Table 2 shows that cross-country standard harmonization is very prevalent in materials technologies, electronics and ICT as well as engineering technologies. We note that standardization is common in all types of industries and extends beyond health, safety and environmental concerns such as SPS and TBT. SSOs constantly update their standards in order to reflect state-of-the-art technology. Many standards are released in bundles whenever they concern interrelated issues and are often categorized in several ICS classes. As a result, thousands of standards are released each year.

Table 2: Releases of harmonized standards, by major ICS categories

\begin{tabular}{lrr}
\hline Field & Number & in $\%$ \\
\hline Agriculture and food technologies & 34818 & 3.3 \\
Construction & 99263 & 9.4 \\
Electronics, information technology and telecommunications & 172479 & 16.3 \\
Engineering technologies & 188497 & 17.8 \\
Generalities, infrastructures and sciences & 121210 & 11.4 \\
Health, safety and environment & 115374 & 10.9 \\
Materials technologies & 178873 & 16.9 \\
Special technologies & 37212 & 3.5 \\
Transport and distribution of goods & 111945 & 10.6 \\
\hline Total & 1059671 & 100 \\
\hline
\end{tabular}

Notes: The Table displays the number of standard releases, broken down by major ICS categories, after having excluded within-country accreditations. The categories are Agriculture and food technology [ICS 65-67]; Construction [ICS 91-93]; Electronics and ICT [ICS 31-37]; Engineering technologies [ICS 17-29 and 39]; Generalities, infrastructures and sciences [ICS 01-07]; Health, safety and environment [ICS 11-13]; Materials technologies [59-61 and 71-87]; Special technologies [95-97]; and Transport and distribution of goods [ICS 43-55]. A number of standards belong to more than one ICS class (disaggregated at the 5-digit level). The data are summed over the years 1960-2018 and all SSOs.

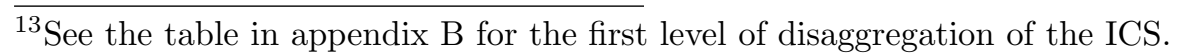


The next step is to relate the standard releases to economic outcomes. Standards are classified according to the International Classification for Standards (ICS) system, while tradable products are categorized according to the Harmonized System (HS) established by the World Customs Organization (WCO). The non-existence of a concordance is one of the main reasons why previous papers in the literature cover only certain sectors: see Moenius (2006), Reyes (2011) or Fontagné et al. (2015).

We tackle the concordance issue in two ways. First, we use a newly developed concordance table from the WTO with the drawback that some links between key standard categories and products might be missing. As a second step, we develop a new all-industry concordance table using keyword-matching techniques and describe our methodological approach in a companion paper (Han et al., 2019). ${ }^{14}$ The main advantage of this table is that it covers all ICS and HS categories. Both concordance tables create links between the 5-digit ICS standard categories and 4-digit HS product categories. We link the standard harmonization events at the country-pair level to the corresponding product and aggregate all harmonization events within an HS 4-digit product. The resulting dataset varies by exporter, importer, product and year and is the basis for our empirical analysis. In the following, we present results based on the WTO concordance table. Results using the concordance based on keyword-matching techniques can be found in appendix E.E.

\section{Empirical framework and results}

In this section we discuss the econometric framework to quantify the importance of standard harmonization on international trade. The data source for bilateral trade flows is the BACI database developed by the CEPII; see Gaulier and Zignago (2010). BACI reconciles export and import declarations of values and volumes in the United Nations COMTRADE database by giving precedence to countries with more reliable trade statistics. The data cover the years 1995 to 2014 and include 5,000 HS 6-digit product categories for more than 160 countries. In our analysis, we work on the HS 4-digit level (1250 different categories) and use the disaggregate HS 6-digit level to measure product entry (extensive margin) and average sales (intensive margin) within an HS 4-digit sector. We further split the intensive margin into a price component and a quantity component, which is the ratio of average sales over average price. The total sample size consists of all bilateral sector linkages between the 26 countries $^{15}$ for the period 1995-2014 and results in 6.7 million observations with a positive trade flow. Of these observations, $44 \%$ are subject to at least one standard harmonization.

\footnotetext{
${ }^{14}$ We describe the details of both approaches in appendix D.

${ }^{15}$ These countries are Australia, Austria, Brazil, Canada, China, Czech Republic, Denmark, Finland, France, Germany, Italy, Jordan, Japan, Korea, Netherlands, Norway, Poland, Russia, Slovak Republic, South Africa, Spain, Sweden, Switzerland, Turkey, United Kingdom and the United States.
} 


\subsection{Econometric specification and definitions}

The empirical framework is a product-level gravity equation, which maps directly to the theoretical framework that we will introduce in section 4 . The estimation equation takes the following form:

$$
\log \left(X_{i j k t}\right)=\beta h_{i j k t}+f_{i k t}+f_{j k t}+f_{i j t}+f_{i j k}+\varepsilon_{i j k t}
$$

Bilateral trade flows (exports of products in sector $k$ from country $i$ to country $j$ at time $t), X_{i j k t}$, are a log-linear function of standard harmonization, $h_{i j k t}$, as well as a number of fixed effects. In particular, we include product-specific supply effects, $f_{i k t}$, product-specific demand effects, $f_{j k t}$, time-invariant exporter-importer-product effects, $f_{i j k}$, as well as time-varying shocks that affect both importer and exporter, $f_{i j t}$. This rich set of fixed effects ensures that the identification in equation 1 is entirely coming from within-bilateral-product variation and is unrelated to product-specific supply and demand shocks or the possible introduction of non-harmonized (national) product standards in the exporter or the importer country. In all regression specifications, standard errors are clustered at the exporter-product level.

The identification of the impact of standard harmonization on trade relies on a difference-in-difference approach with multiple treatments. $h_{i j k t}$ is a dummy variable that equals one whenever there is at least one standard that the importing country $j$ harmonizes with the exporting country $i$ in product $k$ at time $t .{ }^{16}$ Note that this definition also alleviates endogeneity concerns, as exporters have arguably less influence on the importing countries' SSOs. The dummy remains one until the end of the sample period, except if there is an additional harmonization event in the same product category between the same countries. In this case, the dummy is augmented by one increment. Given this definition, $h_{i j k t}$ measures the average treatment effect of an additional standard harmonization event.

Next, we decompose the bilateral trade flow into the product of the extensive and intensive margin. The decomposition in combination with our theoretical framework will shed light on the underlying channels through which standard harmonization affects bilateral trade. We define the intensive margin as the average trade value per 6 -digit HS product $\left(\bar{x}_{i j k t}=X_{i j k t} / M_{i j k t}\right)$ and the extensive margin as the number of unique 6 -digit HS products $\left(M_{i j k t}\right)$ within the HS 4-digit sector. We further decompose the intensive margin into the average price per HS 6-digit product $\left(\tilde{p}_{i j k t}\right)$ within one HS 4-digit sector and a quantity $\left(\tilde{c}_{i j k t}\right)$ component. The average price is calculated as a trade-weighted geometric average of the HS 6-digit unit value. ${ }^{17}$ The average quantity is defined as the ratio of the average sales per HS 6-digit product divided by the corresponding average price. Given

\footnotetext{
${ }^{16}$ Note that our baseline specification does not exploit the number of standard documents that have been harmonized within a year. The reason is that a higher number of harmonized standards within the product group does not necessarily imply that the economic effect of harmonization should be larger. This argument is supported by our analysis. Including the log of the number of harmonized documents as an additional control variable does not have a significant effect on our results.

${ }^{17}$ We use information on kilograms to compute quantities.
} 
these definitions, the complete decomposition equals

$$
X_{i j k t}=M_{i j k t} \bar{x}_{i j k t}=M_{i j k t} \tilde{p}_{i j k t} \tilde{c}_{i j k t} .
$$

All dependent variables are included in logs.

Before discussing the empirical results, we want to stress that even though the Searle Center Database is a comprehensive database covering the most important industrialized countries, we cannot exclude under-reporting for specific countries and SSOs. In the regression analysis, we therefore consistently use fixed effects to minimize the risks from under-reporting. As we measure the explicit release of harmonized standard documents, our results should thus be interpreted as pertaining explicitly to formal harmonization.

\subsection{Baseline results}

Standard harmonization is generally associated with a positive overall impact on trade flows. A first glance at the data confirms this intuition. We plot the average growth rate of trade flows before and after a harmonization event in figure 2 and compare this growth rate to trade flows that were never subject to standard harmonization. One notices a significantly higher growth rate for bilateral exports after the importer accredited a standard from an exporter. Before the harmonization event, we do not observe any significant differences in the growth rates between the treatment ("Harmonization") and the control group ("Non-harmonization").

Figure 2: Growth of trade flows around harmonizations

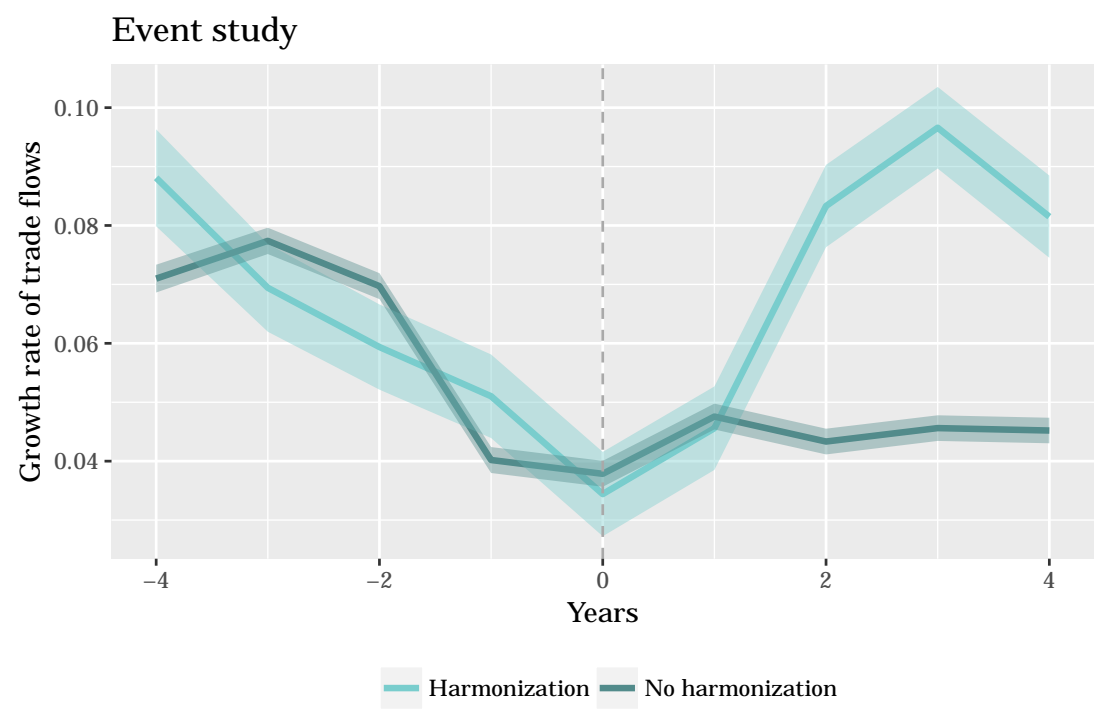

Notes: This figure plots the mean growth rate before and after a harmonization event for harmonized trade flows (treatment group) and non-harmonized trade flows (control group). Only the first harmonization event for each exporter-importer-product combination is considered. The control group only comprises exporter-importer-product combinations that were never harmonized. The point 0 denotes the timing of the event. The sample covers the years 1999-2010 and has been restricted to only include observations with positive trade flows in the preceding four years. Growth rates below the 2.5 th and above the 97.5 th percentiles are excluded from the calculations.

To provide more formal evidence on the relationship plotted in figure 2, we start by 
running regression equation 1 with the full battery of fixed effects. Column (1) in table 3 shows the results and confirms the suggested positive effect of harmonization on trade flows in figure 2. The estimated coefficient of 0.0067 is statistically significant at the $1 \%$ level and suggests that, on average, a harmonization event increases trade flows by $0.67 \%$. Column (2) and column (3) in table 3 decompose the overall trade flows into the extensive and the intensive margin. The latter is then further decomposed into price (column (4)) and quantity (column (5)) contributions. The results suggest that the overall effect is mainly driven by the intensive margin, which itself is driven by an increase in quantities. The response of the extensive margin is positive, but considerably smaller in magnitude than the response of the intensive margin. These results form the basis for the analysis of the economic channels discussed in section 4 and 5. Before doing so, we investigate the quantitative importance of our results and translate them into comparable economic effects.

Table 3: Regression results / Baseline specification

\begin{tabular}{lccccc}
\hline & $(1)$ & $(2)$ & $(3)$ & $(4)$ & $(5)$ \\
& Total & Ext. margin & Int. margin & Price & Quantity \\
\hline Harm. & $0.00667^{* * *}$ & $0.00176^{* * *}$ & $0.00491^{* * *}$ & $-0.00408^{* * *}$ & $0.00899^{* * *}$ \\
& {$[0.000]$} & {$[0.000]$} & {$[0.002]$} & {$[0.000]$} & {$[0.000]$} \\
\hline Observations & 5848855 & 5848855 & 5848855 & 5848855 & 5848855 \\
$R^{2}$ & 0.88 & 0.90 & 0.86 & 0.85 & 0.86 \\
Adjusted $R^{2}$ & 0.85 & 0.87 & 0.82 & 0.81 & 0.83 \\
\hline
\end{tabular}

Notes: Regression of the respective dependent variable (designated in column headers) on harmonization indicator. Fixed effects are included as described in the regression specification 1. Standard errors are clustered at the exporter-product level. P-values are reported in brackets. ${ }^{* *},{ }^{* *}$ and ${ }^{*}$ indicate respectively $1 \%, 5 \%$ and $10 \%$ significance levels.

\subsection{Ad-valorem equivalents and contribution to trade growth}

The results from our baseline regression suggest that a harmonization event increases trade flows, on average, by $0.67 \%$. But how does this increase in trade flows compare to observable changes in trade costs? To answer this question, we calculate the average ad-valorem equivalent (AVE) of tariffs following Kee and Nicita (2016). They define the ad-valorem equivalent (AVE) in non-tariff measures (in our case, standard harmonization) as the equivalent of the ad-valorem tariff that induces the same proportionate change in the quantity traded

$$
A V E=\frac{\left(\exp \left(\beta_{2}\right)-1\right)}{\left(\exp \left(\beta_{1}\right)-1\right)}
$$

where $\beta_{1}$ and $\beta_{2}$ are the estimated coefficients from a quantity regression that includes the average tariff rate $\left(t_{i j k t}\right)$ at the HS 4 -digit level as a control variable. The advantage of this definition of AVE is that we do not need to know the sector-specific import demand 
elasticity $\left(\sigma_{k}\right){ }^{18}$ Including the full set of fixed effects, the corresponding estimation equation is written as

$$
\log \left(\tilde{q}_{i j k t}\right)=\beta_{1} \log \left(1+t_{i j k t}\right)+\beta_{2} h_{i j k t}+f_{i k t}+f_{j k t}+f_{i j t}+f_{i j k}+\varepsilon_{i j k t} .
$$

We use these regression coefficients in combination with the "delta method" to compute the point estimate of the AVE together with the standard errors. Table 4 shows the regression output for all dependent variables. Note that the number of observations compared to the baseline regression drops because of missing information on tariff rates for some data points. The estimated coefficients for the harmonization dummy drop slightly, but the coefficients remain statistically significant.

Table 4: Regression results / Ad-valorem equivalent

\begin{tabular}{lccccc}
\hline & $(1)$ & $(2)$ & $(3)$ & $(4)$ & $(5)$ \\
& Total & Ext. margin & Int. margin & Price & Quantity \\
\hline Harm. & $0.00487^{* * *}$ & $0.00121^{* * *}$ & $0.00366^{* *}$ & $-0.00408^{* * *}$ & $0.00774^{* * *}$ \\
& {$[0.008]$} & {$[0.002]$} & {$[0.036]$} & {$[0.001]$} & {$[0.000]$} \\
Ln(1+tariff $)$ & $-0.67837^{* * *}$ & $-0.04621^{* * *}$ & $-0.63216^{* * *}$ & $-0.15568^{* * *}$ & $-0.47648^{* * *}$ \\
& {$[0.000]$} & {$[0.008]$} & {$[0.000]$} & {$[0.002]$} & {$[0.000]$} \\
\hline Observations & 4692889 & 4692889 & 4692889 & 4692889 & 4692889 \\
$R^{2}$ & 0.89 & 0.91 & 0.87 & 0.87 & 0.88 \\
Adjusted $R^{2}$ & 0.86 & 0.88 & 0.83 & 0.83 & 0.84 \\
\hline Ad-valorem equivalent tariff & & & & $-2.090^{* * *}$ \\
& & & & & {$[0.002]$} \\
\hline
\end{tabular}

Notes: Regression of the respective dependent variable (designated in column headers) on harmonization indicator and tariffs. Fixed effects are included as described in the regression specification 1. Standard errors are clustered at the exporter-product level. P-values are reported in brackets. ${ }^{* * *},{ }^{* *}$ and $*$ indicate respectively $1 \%, 5 \%$ and $10 \%$ significance levels.

What is the hypothetical percentage point change in the tariff rate that would yield the same effect as a harmonization event? In the bottom line of table 4, we present the ad-valorem equivalent from the quantity regression (column (5)). The increase in traded quantities after a standard harmonization event can be associated with an equivalent tariff reduction of 2.09 percentage points.

The AVE estimate in table 4 is an average and masks significant heterogeneity across the 1250 different 4-digit HS products. For this reason, we first estimate equation 4 on the level of each individual HS 4-digit product and include exporter, importer and time-fixed effects. Second, we substitute the obtained product-specific coefficients for tariffs and the harmonization dummy into equation 3 and compute the corresponding AVE.

Figure 3 shows that for the majority of sectors, a standard harmonization event is equivalent to a reduction in tariffs (observations with a negative AVE coefficient).

\footnotetext{
${ }^{18}$ As Kee and Nicita (2016) note, there are other ways to define AVEs, such as the equivalent tariff that induces the same change in quantities imported, or the equivalent tariff that induces the same rate ratio change in quantities imported. Kee et al. (2009) define the corresponding AVE for those cases as follows $A V E_{k}=\left(\left(\exp \left(\beta_{2}\right)-1\right)\right) / \sigma_{k}$, where $\beta_{2}$ is the estimated coefficient of the standard harmonization variable and $\sigma_{k}$ is the sector-specific import demand elasticity.
} 
The cross-sector average AVE is -2.9 percentage points and slightly higher in magnitude compared to our average estimate from the full sample. ${ }^{19}$

Figure 3: Ad-Valorem Equivalents (AVE)

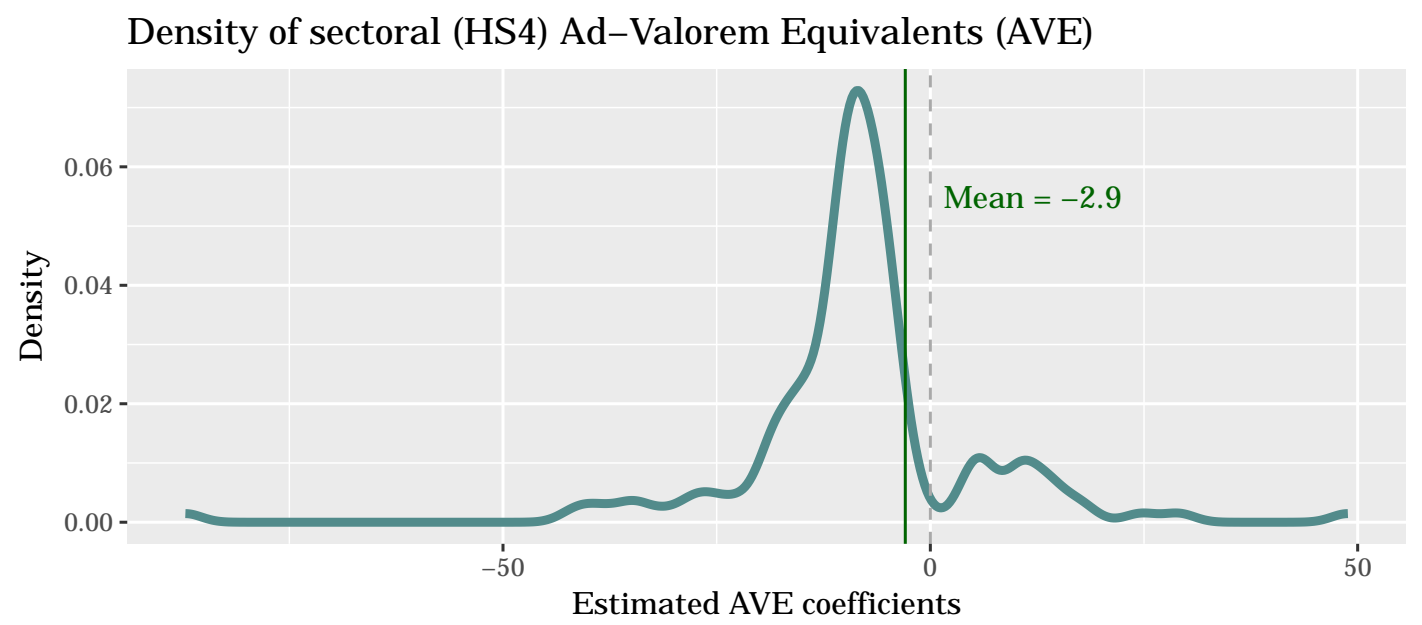

Notes: This figure plots the kernel density estimate of the product-specific AVE estimates at the HS 4-digit level. Only statistically significant AVE estimates are included in the plot. The vertical line displays the mean AVE estimate (taking into account both statistically significant and not significant AVE estimates).

Next, we use the point estimates of the harmonization indicator to calculate the implied increase in trade flows among the countries in our sample that is due to harmonization. We simply multiply the harmonization dummy by either (1) the point estimate in column (1) of table 3 or (2) the sectoral point estimates used to construct figure 3 and calculate the trade-weighted average increase in trade flows between the countries in our sample. Figure 4 plots the estimated increase due to standard harmonization for both set of estimates. Based on the aggregate coefficient ("agg. estimate"), the average implied increase is $0.27 \%$, while the sectoral coefficients imply an increase of $0.73 \%$ of trade flows ("sector estimate"). Given that the average growth rate of trade in our sample is $5.9 \%$, these estimates suggest that up to $12.4 \%$ of this increase is due to standard harmonization. The reason for this considerable change in trade despite the low point estimates is that $44 \%$ of our products are harmonized within a given year. For comparison, we also include the implied change in trade flows due to tariff reductions. The associated increase in trade flows is smaller, amounting to only $0.12 \%$. Overall, these estimates reveal that standard harmonization among the industrialized countries in our sample contributed significantly more to higher trade flows compared to reductions of traditional trade barriers such as tariffs.

Taken together, our empirical results suggest that standard harmonization has a significant and positive effect on trade flows in terms of the number of harmonization events. The increase in trade flows operates mainly through higher average product sales (changes in the intensive margin) brought about by a larger trading volume (quantities) while prices decline. The effect of product entry (extensive margin) on overall trade flows is only minor. Next, we develop a theoretical framework and discuss the underlying economic

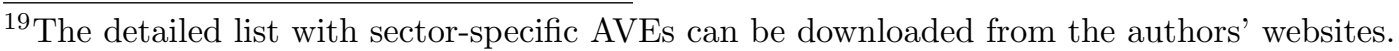


channels of standard harmonization.

Figure 4: Increase in trade flows due to standard harmonization

\section{Estimated change in trade flows (partial equilibrium)}

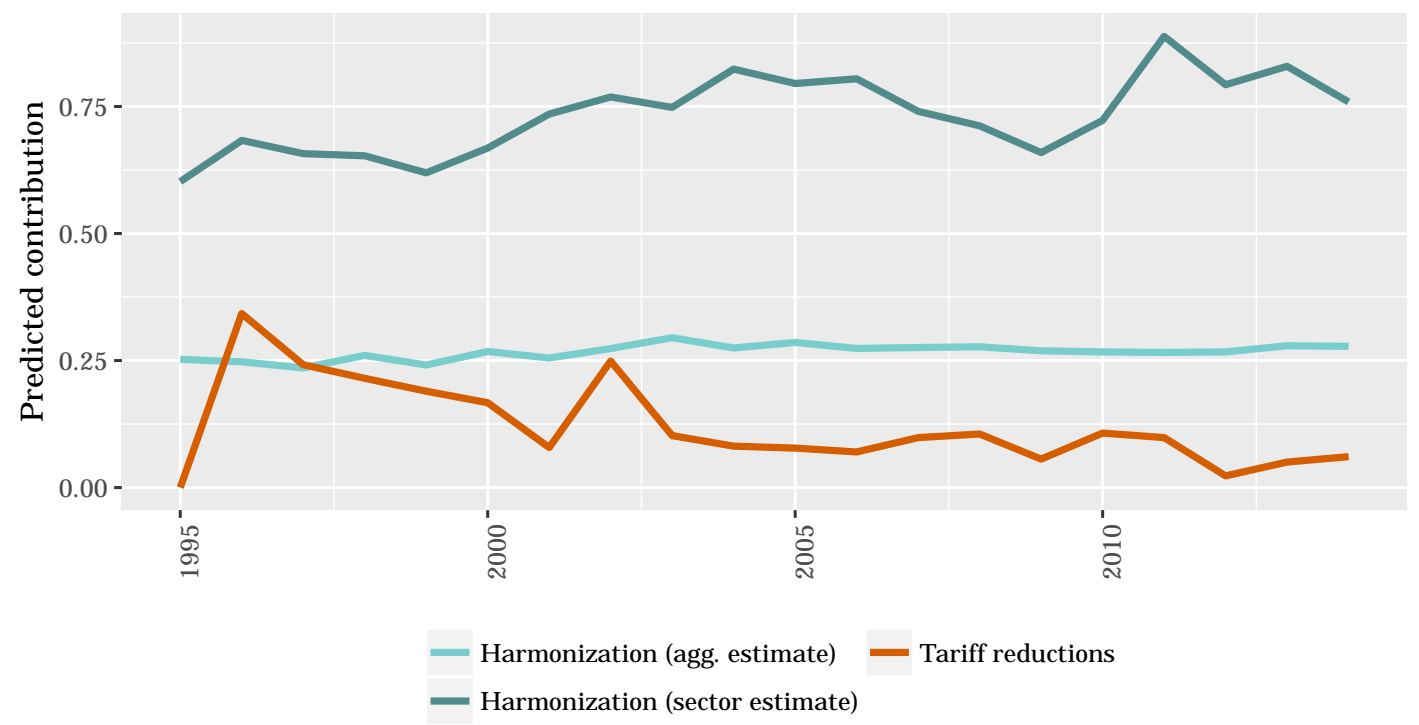

Notes: This figure plots the contribution of standard harmonization and tariff changes to the growth rate of trade flows among the countries in our sample. The estimates are based on a regression of total trade flows on standard harmonization and tariffs.

\section{Model}

Standard harmonization is commonly associated with a reduction in the fixed costs of exporting. In a workhorse model of international trade with heterogeneous firms à la Melitz (2003) where firm productivity follows a Pareto distribution as in Chaney (2008), a reduction in fixed costs of exporting leads to a reduction in the intensive margin and an increase in the extensive margin, which exceeds the former. The empirical evidence of section 3 , however, shows that the higher export sales associated with standard harmonization are mainly driven by a higher intensive margin.

In this section, we present a theoretical framework that can be used to interpret the empirical evidence presented so far. In particular, we introduce the notion that firms endogenously choose whether to adopt a standard. For expositional purposes, we first present the choice problem that exporting firms face when product standards are tightened in the destination country. We then discuss the specific case of standard harmonization and show via which channels it impacts the different margins of trade.

\subsection{Theoretical framework}

Our theoretical framework is a modified version of the Melitz (2003) framework that incorporates producer choice about standard adoption. Heterogeneous firms face a sector $k$ specific CES demand elasticity, fixed costs of exporting from country $i$ to country $j$, as well as variable iceberg trade costs. There are two sector-specific demand elasticities. The 
first one is $\gamma_{k}$ and describes the elasticity of substitution across consumption baskets from different exporting countries, and the second one, $\sigma_{k}$, denotes the elasticity of substitution between different sector-specific varieties. Quantities exported from country $i$ to country $j$ in sector $k$ are denoted by $c_{i j k}$. (This includes domestically produced goods $c_{i j k}$.) Preferences for sector-specific bilateral quantities are given by ${ }^{20}$

$$
C_{i j k}=\left[\int_{\omega \in \Omega_{i j k}}\left(d_{i j k}(\omega)\right)^{\frac{1}{\sigma_{k}}}\left(z_{i j k}(\omega) c_{i j k}(\omega)\right)^{\frac{\sigma_{k}-1}{\sigma_{k}}} d \omega\right]^{\frac{\sigma_{k}}{\sigma_{k}-1}}
$$

where $z_{i j k}$ denotes the product standard in sector $k$ between countries $i$ and $j$. It represents product attributes such as technical specifications, environmental regulation, health or safety requirements and is expressed in terms of demand equivalents. In this version of the model, the standard introduced by $i$ and $j$ concerning product $k$ is not mandatory. Firms have the choice to produce freely (which is equal to the case $z_{i j k}=1$ ) or to produce according to the standard $\left(z_{i j k}>1\right)$.

We also introduce a demand shifter $d_{i j k}$. The purpose of the demand shifter is to allow for variety-specific changes in consumer preferences. Consumers value certain varieties more because their consumption brings them more utility. In the context of standardization, we have in mind the creation of positive externalities such as network effects when standardized varieties are compatible with each other. Another rationale behind this demand shifter is that consumers face search or "information acquisition" costs when looking for goods (Matveenko, 2017).

Across exporting countries, quantities are aggregated via CES:

$$
C_{j k}=\left[\sum_{i=1}^{N} C_{i j k}^{\frac{\gamma_{k}-1}{\gamma_{k}}}\right]^{\frac{\gamma_{k}}{\gamma_{k}-1}}
$$

where $\gamma_{k}$ is the elasticity of substitution across exporting countries. We assume that demand for goods produced in different sectors $k$ is determined by the following utility function:

$$
U_{j}=\sum_{k=0}^{K} \beta_{k} \log C_{j k} \quad, \quad \sum_{k=0}^{K} \beta_{k}=1, \quad \beta_{k}>0 .
$$

Using $Y_{j}$ to denote aggregate income in $j$, utility maximization implies that consumers in $j$ spend $X_{j k}=\beta_{k} Y_{j}$ on goods from sector $k$. Demand for variety-specific exports from country $i$ to country $j$ in sector $k$ is given by

$$
c_{i j k}(\omega)=d_{i j k}(\omega) A_{i j k} z_{i j k}^{\sigma_{k}-1}(\omega) p_{i j k}^{-\sigma_{k}}(\omega),
$$

where $A_{i j k}=P_{i j k}^{\sigma_{k}-\gamma_{k}} P_{j k}^{\gamma_{k}-1} X_{j k}$ summarizes destination-specific sector demand and the

\footnotetext{
${ }^{20}$ With respect to the empirical exercise, we think of a sector $k$ as a HS 4-digit category in the trade data.
} 
corresponding price indices, which are defined as follows:

$$
\begin{aligned}
P_{i j k} & =\left(\int_{\omega \in \Omega_{i j}} d_{i j k}(\omega)\left(\frac{p_{i j k}(\omega)}{z_{i j k}(\omega)}\right)^{1-\sigma_{k}} d \omega\right)^{\frac{1}{1-\sigma_{k}}} \\
P_{j k} & =\left(\sum_{i=1}^{N} P_{i j k}^{1-\gamma_{k}}\right)^{\frac{1}{1-\gamma_{k}}}
\end{aligned}
$$

Firms maximize profits by choosing prices as well as whether to adopt the standard $z_{i j k}$ or not. Firm costs are affected by $z_{i j k}$ in two ways. First, the implementation of a new product standard $z_{i j k}$ necessitates sunk investment costs $z_{i j k}^{a_{k}}$. These capture the idea that a new product standard requires firms to change existing production structures to adapt to the new regulation (Maskus et al., 2005; Fischer and Serra, 2000). Second, marginal production costs $z_{i j k}^{t_{k}}$ also depend on the stringency of the product attribute. Note that the choice of functional forms for sunk investment costs and marginal production costs are similar to Flach and Unger (2018). However, the model is flexible and its predictions do not depend on these specific choices. ${ }^{21}$ Firms face variable iceberg costs of exporting $\tau_{i j k}$ as well as fixed costs of exporting $f_{i j k}$. They differ in their productivity $\varphi$ to produce their respective variety and choose whether to produce the standardized $\left(z_{i j k}>1\right)$ or non-standardized variety $\left(z_{i j k}=1\right)$. In the following, we index firms by $\varphi$ and drop the firm-specific indices on $d_{i j k}$ and $z_{i j k}$, as we assume them to be the same for all firms belonging to one of the two respective groups of firms producing either the standardized or non-standardized variety.

Firms producing the standardized variety. These firms' profit maximization problem is as follows: ${ }^{22}$

$$
\max _{p_{i j k}^{z}} \pi_{i k}^{z}(\varphi)=\sum_{j=1}^{N} p_{i j k}^{z} c_{i j k}-\frac{\tau_{i j k} z_{i j k}^{t_{k}}}{\varphi} c_{i j k}-f_{i j k}-z_{i j k}^{a_{k}} \quad ; a_{k}>\sigma_{k}-1 ; 0<t_{k}<1
$$

The parameter $t_{k}$ captures the elasticity of marginal costs with respect to the standard. Firms then choose their optimal price given the product standard, demand and their idiosyncratic productivity:

$$
p_{i j k}^{z}(\varphi)=\frac{\sigma_{k}}{\sigma_{k}-1} \frac{\tau_{i j k} z_{i j k}^{t_{k}}}{\varphi}
$$

\footnotetext{
${ }^{21}$ Given that marginal costs (and hence the price) depend on the product attribute, our main framework considers the case of vertical product differentiation (i.e. quality). However, the model captures the case of horizontal product differentiation simply by setting the parameter $t_{k}$ to zero.

${ }^{22}$ Without loss of generality, we normalize the sector-specific factor price of labor input to one.
} 
Substituting for product demand and the optimal price, we obtain firm sales:

$$
x_{i j k}^{z}(\varphi)=d_{i j k} A_{i j k}\left(\frac{\sigma_{k}}{\sigma_{k}-1} \frac{\tau_{i j k}}{\varphi}\right)^{1-\sigma_{k}} z_{i j k}^{\left(\sigma_{k}-1\right)\left(1-t_{k}\right)}
$$

Substituting back into the profit function, we can write profits of firm $\varphi$ selling to market $j$ as follows:

$$
\pi_{i j k}^{z}(\varphi)=\frac{x_{i j k}^{z}(\varphi)}{\sigma_{k}}-f_{i j k}-z_{i j k}^{a_{k}}
$$

Firms producing the non-standardized variety. Firms that do not produce in accordance with the standard save on sunk investment costs (i.e. $z_{i j k}^{a_{k}}=0$ ) and lower marginal costs, but forgo demand effects. Their total sales are given by

$$
x_{i j k}(\varphi)=d_{i j k} A_{i j k}\left(\frac{\sigma_{k}}{\sigma_{k}-1} \frac{\tau_{i j k}}{\varphi}\right)^{1-\sigma_{k}} .
$$

The corresponding profit function equals

$$
\pi_{i j k}(\varphi)=\frac{x_{i j k}(\varphi)}{\sigma_{k}}-f_{i j k}
$$

Heterogeneity in firm productivity implies that not all firms are willing to pay the sunk investment costs to produce the standardized variety. For this reason, some (the ones with low productivity) choose to produce freely, whereas others (high-productivity firms) choose to produce according to the standard. There are two productivity cut-offs: a zero-profit condition for the first firm that enters the export market and produces freely (denoted by $\bar{\varphi}_{i j k}$ ) and a condition for the first firm that is indifferent between producing freely or according to the standard (denoted by $\bar{\varphi}_{i j k}^{z}$ ). These cut-offs are respectively

$$
\begin{aligned}
& \bar{\varphi}_{i j k}=\frac{\sigma_{k}}{\sigma_{k}-1} \tau_{i j k}\left(\frac{\sigma_{k} f_{i j k}}{d_{i j k} A_{i j k}}\right)^{\frac{1}{\left(\sigma_{k}-1\right)}} \\
& \bar{\varphi}_{i j k}^{z}=\frac{\sigma_{k}}{\sigma_{k}-1} \tau_{i j k}\left(\frac{\sigma_{k} z_{i j k}^{a_{k}}}{d_{i j k} A_{i j k}\left(z_{i j k}^{\left(\sigma_{k}-1\right)\left(1-t_{k}\right)}-1\right)}\right)^{\frac{1}{\left(\sigma_{k}-1\right)}} .
\end{aligned}
$$

Figure 5 shows the corresponding productivity cut-offs and the implied relationship with export profits and export status. Given $z_{i j k}>1$, the cut-off for the non-standardized good is smaller than the cut-off for the standardized good, $\bar{\varphi}_{i j k}<\bar{\varphi}_{i j k}^{z}$. The extensive margin of exports is defined by the marginal firm that is indifferent between exporting and non-exporting in equation 17. Assuming a Pareto distribution with density $g(\varphi)=\xi_{k} \varphi^{-\xi_{k}-1}$ and support $[1, \infty]$, we can derive analytical expressions for total sales $\left(X_{i j k}\right)$, the extensive 
Figure 5: Firm-level sales with voluntary product standard $z_{i j k}$

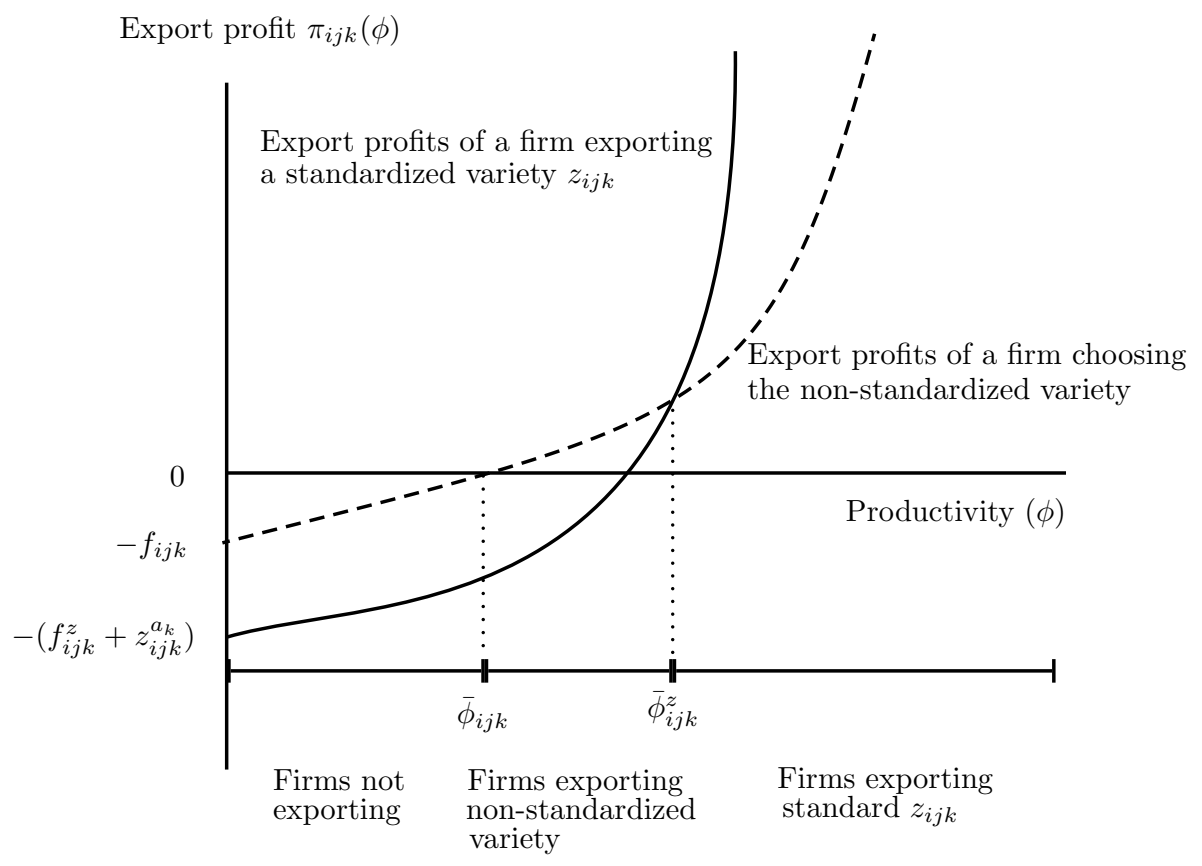

$\left(M_{i j k}\right)$ and the intensive margin $\left(\bar{x}_{i j k}\right)$ at the bilateral sector level

$$
\begin{aligned}
& X_{i j k}= \underbrace{\left(\frac{\sigma_{k}}{\sigma_{k}-1} \tau_{i j k}\left(\frac{\sigma_{k} f_{i j k}}{d_{i j k} A_{i j k}}\right)^{\frac{1}{\sigma_{k}-1}}\right)^{-\xi_{k}} M_{i k}}_{\text {Extensive margin }}, \\
& \underbrace{\Gamma_{1 k} f_{i j k}\left(1-w_{i j k}^{1-\frac{\sigma_{k}-1}{\xi_{k}}}+w_{i j k}^{1-\frac{\sigma_{k}-1}{\xi_{k}}} z_{i j k}^{\left(1-t_{k}\right)\left(\sigma_{k}-1\right)}\right)}_{\text {Intensive margin }},
\end{aligned}
$$

where $M_{i k}$ is the total number of exporters in sector $k$ and $\Gamma_{1 k}=\frac{\xi_{k} \sigma_{k}}{\xi_{k}-\left(\sigma_{k}-1\right)}$ is a function of the parameters $\sigma_{k}$ and $\xi_{k}$. The intensive margin is a weighted average of the share of firms that sell the standardized and the non-standardized variety. $w_{i j k}$ is equal to the share of firms that invest into the standard and is given by the following expression:

$$
w_{i j k}=\frac{\left(1-G\left(\bar{\varphi}_{i j k}^{z}\right)\right) M_{i k}}{\left(1-G\left(\bar{\varphi}_{i j k}\right)\right) M_{i k}}=\left(\frac{\frac{z_{i j k}^{a_{k}}}{f_{i j k}}}{z_{i j k}^{\left(\sigma_{k}-1\right)\left(1-t_{k}\right)}-1}\right)^{\frac{-\xi_{k}}{\sigma_{k}-1}}
$$

where $G\left(\bar{\varphi}_{i j k}^{z}\right)$ and $G\left(\bar{\varphi}_{i j k}\right)$ are the Pareto distribution function evaluated at the cut-off productivities of firms producing the standardized and non-standardized variety respectively. 
In a similar vein, we can derive the corresponding expressions for the average quantity and price of firms:

$$
\begin{aligned}
& \tilde{p}_{i j k}=\Gamma_{2, k}\left(d_{i j k} A_{i j k}\right)^{\frac{1}{\sigma_{k}-1}} f_{i j k}^{\frac{1}{1-\sigma_{k}}}\left(1-w_{i j k}^{1-\frac{\sigma_{k}-1}{\xi_{k}}}+w_{i j k}^{1-\frac{\sigma_{k}-1}{\xi_{k}}} z_{i j k}^{\left(1-t_{k}\right)\left(\sigma_{k}-1\right)}\right)^{\frac{1}{1-\sigma_{k}}} \\
& \tilde{c}_{i j k}=\Gamma_{3, k}\left(d_{i j k} A_{i j k}\right)^{\frac{1}{1-\sigma_{k}}} f_{i j k}^{\frac{\sigma_{k}}{\sigma_{k}-1}}\left(1-w_{i j k}^{1-\frac{\sigma_{k}-1}{\xi_{k}}}+w_{i j k}^{1-\frac{\sigma_{k}-1}{\xi_{k}}} z_{i j k}^{\left(1-t_{k}\right)\left(\sigma_{k}-1\right)}\right)^{\frac{\sigma_{k}}{\sigma_{k}-1}}
\end{aligned}
$$

where $\Gamma_{2, k}$ and $\Gamma_{3, k}$ are constants at the sectoral level. ${ }^{23}$ The detailed derivations of equations 19 to 22 can be found in appendix A.

\subsection{Strengthening the product standard}

The above model outlines the linkages between firm behavior and product standards and derives the corresponding gravity equation with a decomposition into an extensive and intensive margin as well as average prices and quantities. In order to highlight how standardization affects firm choices, we consider first the case of an increase in the stringency of the product standard.

The strengthening of a product standard increases product demand and, at the same time, entails marginal and sunk investment costs. The cost effect, which dominates the demand effect, has a direct impact on the number of firms that can afford to produce the standardized variety, thus reducing the share $w_{i j k}$. In addition, there is an indirect equilibrium effect via the price index $P_{i j k}$. Marginal costs for firms producing the standardized variety increase and so do their prices. This upward pressure on $P_{i j k}$ is counterbalanced by the fact that the share of firms producing the standardized variety drops. The former effect dominates and $P_{i j k}$ increases.

The rise in $P_{i j k}$ determines the extensive margin by shifting the cut-off for the least productive firm that exports $\left(\bar{\varphi}_{i j k}\right)$; see equation 17 . Within sector $k$, low-productivity firms profit from the increase in $P_{i j k}$ as their products become cheaper relative to standardized products. The magnitude of the effect depends on the within-sector elasticity of substitution $\sigma_{k}$. At the same time, the increase in the sectoral price index $P_{i j k}$ shifts consumers' demand away from country $i$. This effect is governed by the cross-country elasticity of substitution $\gamma_{k}$. The overall effect on the extensive margin depends on the relative strength of these elasticities.

With respect to the intensive margin (see equation 19), the change on average sales depends on two opposing effects. First, there exists a direct positive effect on the intensive margin because firms have to sell more in order to cover the higher sunk investment costs. The second effect is a negative composition effect. An increase in $z_{i j k}$ reduces the share of firms that opt to produce the standard $\left(w_{i j k}\right)$. Instead, these firms choose to produce the non-standardized variety, which require lower sales as they only need to cover the

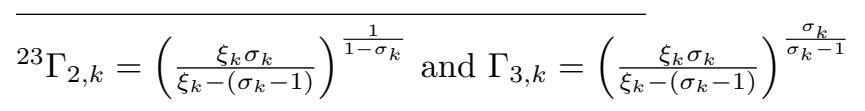


fixed costs to export. The combined effect depends on conditions on the parameters $\left(a_{k}, t_{k}, \sigma_{k}, \xi_{k}\right)$ that determine the relative strength of these opposing effects, which we derive in appendix $\mathrm{A}$. The change in the intensive margin also defines the response of average prices and quantities. The average price has a negative elasticity (see equation 21), while the average quantity has a positive elasticity (see equation 22).

Concerning the parameters of our model, we follow the empirical literature on the introduction of product standards. The literature finds that the introduction of standards reduces the number of exporters (extensive margin) and has either a negative effect (Fontagné et al., 2015) or no effect (Fernandes et al., 2019) on average export sales (intensive margin). Fontagné et al. (2015) also find that average prices increase and quantities exported decrease. Our framework reproduces these moments if consumers are less likely to substitute between a standardized and non-standardized product than between product baskets from different exporting countries, i.e. $\gamma_{k}>\sigma_{k}$. For the remainder of the analysis, we assume that this condition is satisfied. Table 5 summarizes the predicted effects on the various margins of trade when product standards are strengthened.

Table 5: Predicted effects when increasing the severity of a standard

\begin{tabular}{|c|c|c|c|c|}
\hline & (1) & $(2)$ & $(3)$ & $(5)$ \\
\hline \multicolumn{5}{|c|}{ Bilateral sector-level data } \\
\hline & $\partial X_{i j k}$ & $\partial M_{i j k}$ & $\partial X_{i j k} / M_{i j k} \partial \tilde{c}_{i j k}$ & $\partial \tilde{p}_{i j k}$ \\
\hline$\partial z_{i j k}$ & $<0$ & $<0$ & $<0$ & $>0$ \\
\hline
\end{tabular}

\subsection{Harmonizing a product standard}

We outlined above the different channels via which standardization can affect the decision of firms to export. Next, we consider the harmonization of a standard between two trading partners. Generally, the harmonization of standards is expected to reduce barriers to trade. Table 6 summarizes the different economic effects that standard harmonization can have for production, market transactions and users of standardized products. ${ }^{24}$

The first dimension concerns fixed costs to export from country $i$ to country $j$. The harmonization of product standards may facilitate market access by reducing the need to change production structures in order to adapt the product to destination-specific requirements of the export market (for example, certification, testing requirements or other compliance costs; see Shepherd, 2007). Similarly, firms can exploit cost complementarities that arise from synergies in the production of destination-specific goods. We thus associate the introduction of a harmonized standard with lower fixed costs of exporting.

The second dimension can be summarized as demand effects. Standards are widely used in technological applications to ensure the compatibility of different devices. The

\footnotetext{
${ }^{24}$ See also Baron and Schmidt (2014) and Baron and Spulber (2015) for a general discussion on the economic impact of standardization. Swann (2000) presents a broad overview of the economics of standardization and categorizes the economic effects in a similar way as presented in table 6 .
} 
Table 6: Economic effects of standard harmonization

\begin{tabular}{lll}
\hline Dimension & Impact on firms & Potential economic effects \\
\hline $\begin{array}{l}\text { Fixed costs } \\
\text { of exporting }\end{array}$ & $\begin{array}{l}\text { Production structures } \\
\text { (blueprints, machines) } \\
\text { Compliance costs }\end{array}$ & $\begin{array}{l}\text { Easier market access } \\
\text { Need to certify compliance with } \\
\text { standard only once }\end{array}$ \\
\hline Demand & Compatibility & $\begin{array}{l}\text { Network effects (larger number of } \\
\text { users) }\end{array}$ \\
& Complementary goods & $\begin{array}{l}\text { Economies of scale and scope } \\
\text { Reduction of information costs }\end{array}$ \\
\hline Variable & Common definitions & $\begin{array}{l}\text { Lower transaction costs between } \\
\text { producer and user/buyer }\end{array}$ \\
\hline
\end{tabular}

positive externalities associated with this interoperability should increase the demand for such products (Katz and Shapiro, 1985; Farrell and Saloner, 1985). In a similar vein, standardization can lead to economies of scale and scope when complementary intermediate goods are used for a large variety of final products. While some of these demand effects pertain to standardization in general, the harmonization of standards across trade partners should result in higher demand for products from harmonizers than for products from non-harmonizers. In particular, consider that countries $i$ and $j$ each have a product standard that brings customers the same amount of utility (i.e. the value of $z$ is the same), but the specifications in $i$ and $j$ differ, which makes the products incompatible. The harmonization of the product standard enables compatibility. This creates additional demand effects captured by a rise in $d_{i j k}$.

Standard harmonization might also lead to lower variable costs of exporting from $i$ to $j$ (third dimension in table 6 ). One of the most basic purposes of standardization is the use of common definitions. The reduction in associated information asymmetries lowers transaction costs between producers and buyers of a product (Swann et al., 1996; Maur and Shepherd, 2011). Similarly, border processing costs might be reduced when standards are harmonized.

Potential benefits from harmonization alter the choice problem for firms. As described above and summarized in table 6 , the firms producing the harmonized variety face different fixed costs of exporting (denoted by $f_{i j k}^{z}$ ), variable costs of exporting $\left(\tau_{i j k}^{z}\right)$ and demand $\left(d_{i j k}^{z}\right)$ than firms producing the non-standardized variety. As a consequence, the cut-off expressed in equation 18 changes:

$$
\bar{\varphi}_{i j k}^{z}=\frac{\sigma_{k}}{\sigma_{k}-1} \tau_{i j k}\left(\frac{\sigma_{k}\left(f_{i j k}^{z}-f_{i j k}+z_{i j k}^{a_{k}}\right)}{d_{i j k} A_{i j k}\left(\frac{d_{i j k}^{z}}{d_{i j k}}\left(\frac{\tau_{i j k}^{z}}{\tau_{i j k}}\right)^{1-\sigma_{k}} z_{i j k}^{\left(\sigma_{k}-1\right)\left(1-t_{k}\right)}-1\right)}\right)^{\frac{1}{\left(\sigma_{k}-1\right)}}
$$

To shed light on the relevance of the different economic effects described in table 6 , we define wedges that allow us to reconcile the empirical findings on the various trade 
margins with our theoretical model. These wedges capture differences in costs and demand of firms producing the standardized variety relative to firms that produce freely. More precisely, we define the wedge in fixed costs to export $\left(\triangle_{i j k}^{f}=f_{i j k}^{z} / f_{i j k}\right)$, the wedge in variable trade costs $\left(\triangle_{i j k}^{\tau}=\tau_{i j k}^{z} / \tau_{i j k}\right)$ as well as the demand wedge $\triangle_{i j k}^{d}=d_{i j k}^{z} / d_{i j k}$. Using these definitions, we can rewrite total exports as a function of $\triangle_{i j k}^{f}, \triangle_{i j k}^{\tau}$ and $\triangle_{i j k}^{d}$ :

$$
\begin{aligned}
X_{i j k}= & \underbrace{\left(\frac{\sigma_{k}}{\sigma_{k}-1} \tau_{i j k}\left(\frac{\sigma_{k} f_{i j k}}{d_{i j k} A_{i j k}}\right)^{\frac{1}{\sigma_{k}-1}}\right)^{-\xi_{k}} M_{i k}}_{\text {Extensive margin }} \\
& \underbrace{\Gamma_{1 k} f_{i j k}\left(1-w_{i j k}^{1-\frac{\sigma_{k}-1}{\xi_{k}}}+w_{i j k}^{1-\frac{\sigma_{k}-1}{\xi_{k}}} \triangle_{i j k}^{d}\left(\triangle_{i j k}^{\tau}\right)^{1-\sigma_{k}} z_{i j k}^{\left(\sigma_{k}-1\right)\left(1-t_{k}\right)}\right)}_{\text {Intensive margin }}
\end{aligned}
$$

The share of firms producing the standardized variety is

$$
w_{i j k}=\left(\frac{\left(\frac{z_{i j k}^{a_{k}}}{f_{i j k}}+\triangle_{i j k}^{f}-1\right)}{\triangle_{i j k}^{d}\left(\triangle_{i j k}^{\tau}\right)^{1-\sigma_{k}}\left(z_{i j k}^{\left(\sigma_{k}-1\right)\left(1-t_{k}\right)}-1\right)}\right)^{\frac{-\xi_{k}}{\sigma_{k}-1}}
$$

and the corresponding expressions for the average quantity and price of firms are

$$
\begin{aligned}
\tilde{p}_{i j k}= & \Gamma_{2, k}\left(d_{i j k} A_{i j k}\right)^{\frac{1}{\sigma_{k}-1}} f_{i j k}^{\frac{1}{1-\sigma_{k}}} \\
& \left(1-w_{i j k}^{1-\frac{\sigma_{k}-1}{\xi_{k}}}+w_{i j k}^{1-\frac{\sigma_{k}-1}{\xi_{k}}} \triangle_{i j k}^{d}\left(\triangle_{i j k}^{\tau}\right)^{1-\sigma_{k}} z_{i j k}^{\left(1-t_{k}\right)\left(\sigma_{k}-1\right)}\right)^{\frac{1}{1-\sigma_{k}}} \\
\tilde{c}_{i j k}= & \Gamma_{3, k}\left(d_{i j k} A_{i j k}\right)^{\frac{1}{1-\sigma_{k}}} f_{i j k}^{\frac{\sigma_{k}}{\sigma_{k}-1}} \\
& \left(1-w_{i j k}^{1-\frac{\sigma_{k}-1}{\xi_{k}}}+w_{i j k}^{1-\frac{\sigma_{k}-1}{\xi_{k}}} \triangle_{i j k}^{d}\left(\triangle_{i j k}^{\tau}\right)^{1-\sigma_{k}} z_{i j k}^{\left(1-t_{k}\right)\left(\sigma_{k}-1\right)}\right)^{\frac{\sigma_{k}}{\sigma_{k}-1}} .
\end{aligned}
$$

Harmonization incentivizes firms to invest in the standard, as the firms profit from lower fixed costs of exporting $\left(\triangle_{i j k}^{f} \downarrow\right)$, lower variable costs $\left(\triangle_{i j k}^{\tau} \downarrow\right)$ and higher demand $\left(\triangle_{i j k}^{d} \uparrow\right)$.

Table 7 summarizes the marginal effect of these parameters on the various margins. Note that aggregate changes in demand and supply, captured by changes in $M_{i k}$ or $A_{j k}$, will be absorbed by product-specific time-varying importer and exporter fixed effects. Column (2) in table 7 shows the changes in the extensive margin and column (3) on the intensive margin. A reduction in fixed or marginal costs or higher demand for firms producing the harmonized variety increases overall trade through an increase of both the extensive and the intensive margin. 
Table 7: Predicted effects

\begin{tabular}{llllll}
\hline & $(1)$ & $(2)$ & $(3)$ & $(4)$ & $(5)$ \\
\hline \multicolumn{5}{c}{ Bilateral sector-level data } \\
\hline & $\partial X_{i j k}$ & $\partial M_{i j k}$ & $\partial X_{i j k} / M_{i j k}$ & $\partial \tilde{c}_{i j k}$ & $\partial \tilde{p}_{i j k}$ \\
\hline$\partial \triangle_{i j k}^{f}$ & $<0$ & $<0$ & $<0$ & $<0$ & $>0$ \\
$\partial \triangle_{i j k}^{\tau}$ & $<0$ & $<0$ & $<0$ & $<0$ & $>0$ \\
$\partial \triangle_{i j k}^{d}$ & $>0$ & $>0$ & $>0$ & $>0$ & $<0$ \\
\hline \multicolumn{5}{c}{ Firm-level data } \\
\hline \multicolumn{5}{c}{$\partial c_{i j k}$} \\
\hline$\partial f_{i j k}$ & $=0$ & \multicolumn{5}{c}{$\partial p_{i j k}$} \\
$\partial \tau_{i j k}$ & $<0$ & & $<0$ & $>0$ \\
$\partial d_{i j k}$ & $>0$ & $>0$ & $=0$ \\
\hline
\end{tabular}

Regarding the intensive margin, firms producing the harmonized variety directly profit from more demand as consumers value this variety more. As a result, average sales per firm increase. Similarly, lower variable costs of exporting $\triangle_{i j k}^{\tau}$ allow firms to produce the standardized variety because they sell at a lower price: the average price (see column (4)) falls and the average quantity being sold increases; see column (5). In addition, there is an indirect composition effect that increases the intensive margin: a reduction in fixed and variable costs of exporting as well as higher demand incentivize more firms to produce the harmonized variety for which average sales are higher.

Harmonization decreases the sectoral price index $P_{i j k}$ as consumers obtain one unit of utility more easily. This determines the reaction on the extensive margin (see equation 17). Given that $\gamma_{k}>\sigma_{k}$, the fall in the price index implies that the substitution of demand from other countries towards the exporting country with which the standard is harmonized is stronger than the substitution away from the non-standardized variety towards the standardized variety. In other words, the net effect on $A_{i j k}$ for non-standardized varieties is positive and more firms enter the export market.

\section{Further investigations on economic channels}

The model presented above serves as a means to shed light on the empirical results obtained in section 3. In this section, we attempt to further test some of the predictions of the theoretical framework presented above.

\subsection{Timing of harmonization}

An important ingredient in our model is the sunk investment cost that firms have to pay when they adopt a standard. In order to evaluate the relevance of these costs, we look at the time period between the original introduction of the standard and the harmonization event. To illustrate the point, suppose a country introduces a new standard. Several years 
later, another country decides to accredit this particular standard. Firms operating in the standard-originating country have already adapted their production process to the standard and are likely to incur few additional costs when exporting to the country that accredits the standard. On the other hand, if both the exporting and the importing country introduce the same standard in the same year, exporters have to pay high sunk investment costs at the time of harmonization. In order to investigate the role of these investment costs, we therefore measure the time elapsed between the release of the standard by the exporter and the release of the same standard by the importer. This variable is denoted as the "time lag" of harmonization.

Table 8: Distribution of time lag

\begin{tabular}{lrr}
\hline Time lag & Harmonization events & $\%$ \\
\hline 0 & 4369398 & 53.6 \\
1 & 1348197 & 16.5 \\
2 & 468078 & 5.7 \\
3 & 320694 & 3.9 \\
4 & 236094 & 2.9 \\
$>=5$ & 1407316 & 17.3 \\
\hline Notes: The time lag is calculated as the mean number of \\
years that have passed since the importing country accredited \\
a standard already accredited by the exporting country. If \\
both accredit a harmonized standard within the same year, \\
this time lag is zero.
\end{tabular}

Table 8 shows the distribution of the time lag variable. The majority of harmonization events actually concern harmonizations where the standard is released by both countries at the same time. One should, however, keep in mind that, by construction, a harmonization event with a time lag equal to zero is counted twice in the dataset: once for the exports from A to B and once for the exports from B to A. For any harmonization event with a time lag strictly larger than zero, we consider the importer's accreditation of a standard already released by an exporter to represent a harmonization event but not vice versa. ${ }^{25}$

In table 9, we include the time lag of harmonization as an additional variable. We notice that a higher time lag is associated with a positive effect on both the intensive and extensive margin; the effect is higher on the former than on the latter. Though the model presented in section 4 is not a dynamic one, the positive response of both margins to higher time lags can be interpreted within the stylized framework of the model: investment costs are sunk and thus hit exporters when first implemented. However, if the majority of exporters have already paid these sunk investment costs in the past (i.e. when the time lag is high), the accreditation of the same standard in the destination country leads to a decrease in fixed costs of exporting, higher demand and/or lower variable costs while sunk investment costs are negligible.

\footnotetext{
${ }^{25}$ See appendix E for more details.
} 
Table 9: Regression results / Controlling for time lag

\begin{tabular}{lccccc}
\hline & $(1)$ & $(2)$ & $(3)$ & $(4)$ & $(5)$ \\
& Total & Ext. margin & Int. margin & Price & Quantity \\
\hline Harm. & $0.00618^{* * *}$ & $0.00166^{* * *}$ & $0.00452^{* * *}$ & $-0.00408^{* * *}$ & $0.00860^{* * *}$ \\
& {$[0.000]$} & {$[0.000]$} & {$[0.006]$} & {$[0.000]$} & {$[0.000]$} \\
Time lag & $0.00009^{* * *}$ & $0.00002^{* * *}$ & $0.00007^{* * *}$ & 0.00000 & $0.00007^{* *}$ \\
& {$[0.000]$} & {$[0.001]$} & {$[0.001]$} & {$[0.947]$} & {$[0.015]$} \\
\hline Observations & 5848855 & 5848855 & 5848855 & 5848855 & 5848855 \\
$R^{2}$ & 0.88 & 0.90 & 0.86 & 0.85 & 0.86 \\
Adjusted $R^{2}$ & 0.85 & 0.87 & 0.82 & 0.81 & 0.83 \\
\hline
\end{tabular}

Notes: Regression of the respective dependent variable (designated in column headers) on harmonization indicator and the time lag of harmonization. The time lag is defined as the interaction between $h_{i j k t}$ and the mean time lag across all standard harmonizations that define one harmonization event. Fixed effects are included as described in the regression specification 1. Standard errors are clustered at the exporter-product level. P-values are reported in brackets. ${ }^{* *},{ }^{* *}$ and ${ }^{*}$ indicate respectively $1 \%, 5 \%$ and $10 \%$ significance levels.

\section{$5.2 \quad$ Firm-level evidence}

As a second test, we use firm-level data to compare these outcomes with our model predictions. Overall, the product-level results in section 3 are consistent with the cost and demand effects described in table 6 , but do not allow us to disentangle their relative importance. As table 7 shows, an increase in firm-level sales $x_{i j k}$ implies that demand effects due to harmonization $\left(\triangle_{i j k}^{d} \uparrow\right)$ or lower variable costs $\left(\triangle_{i j k}^{\tau} \downarrow\right)$ are driving the results at the firm level. Decomposing the intensive margin into prices and quantities, we are able to distinguish between the relative contribution of those two effects. Using firm-level data, we are able to shed more light on the contribution of the described cost and demand channels.

We match our standard harmonization database at the HS 4-digit level with French firm-level data obtained from French custom declarations for the period 1995-2014. In section 4 , we refer to sector $k$ as an HS 4-digit category while varieties $\omega$ correspond to a firm producing an HS 6-digit product. ${ }^{26}$ In line with the theoretical set-up, we now consider the alternative interpretation with firms as the appropriate unit of observation and work on the HS 6-digit level. We have information on the euro value of exports by each firm and restrict the sample to the 25 importing countries in our standard database. In order to reduce any potential bias arising from the presence of occasional exporters, we follow Fontagné et al. (2015) and only include firm-product-importer combinations with at least 5 years of positive exports over the time period in question. The firm-level regression specification is

$$
Y_{f j n t}=\beta h_{j n t}+f_{f j n}+f_{f j t}+\varepsilon_{f j n t},
$$

where $f$ designates a firm, $n$ the HS 6-digit product level, $j$ the importing country and $t$ the year of observation. We measure the extensive margin ("export status") by specifying $Y_{\text {fjnt }}$

\footnotetext{
${ }^{26}$ This assumption is quite realistic given the moments of French firm-level data: for a given combination of firm, HS4-category, destination country and year, 75\% of firms export only one HS6 6-digit product.
} 
to be a dummy variable that equals one if the firm has positive exports and zero otherwise. In addition, we count the number of $\mathrm{CN}$ (Combined Nomenclature) 8-digit products per firm as a measure of the extensive margin within the firm. As a third variable we include total export sales per firm $f$ in an HS 6-digit category $n$ to importing country $j$ in year $t$ (in logs). For the reasons laid out in section 4 (see table 7 ), we decompose total sales into prices (proxied by unit values in terms of kilograms shipped) and quantities, which are both included in logs. Equation 28 includes fixed effects on the firm-importer-HS6 level $\left(f_{f j n}\right)$ as well as the firm-importer-year level $\left(f_{f j t}\right) .{ }^{27}$

Table 10: Regression results: Firm-level data

\begin{tabular}{lccccc}
\hline & $\begin{array}{c}(1) \\
\text { Export } \\
\text { status }\end{array}$ & $\begin{array}{c}(2) \\
\text { Number of } \\
\text { products }\end{array}$ & $\begin{array}{c}(3) \\
\text { Sales }\end{array}$ & $\begin{array}{c}(4) \\
\text { Price }\end{array}$ & $\begin{array}{c}(5) \\
\text { Quantity }\end{array}$ \\
\hline Harm. & 0.00084 & $0.00150^{*}$ & $0.00586^{* * *}$ & $0.00188^{*}$ & $0.00398^{* *}$ \\
& {$[0.185]$} & {$[0.054]$} & {$[0.002]$} & {$[0.080]$} & {$[0.044]$} \\
\hline Observations & 12634460 & 5285380 & 4506939 & 4506939 & 4506939 \\
$R^{2}$ & 0.63 & 0.77 & 0.86 & 0.94 & 0.90 \\
Adjusted $R^{2}$ & 0.55 & 0.68 & 0.80 & 0.91 & 0.86 \\
\hline
\end{tabular}

Notes: Regression of the respective dependent variable (designated in column headers) on harmonization indicator. Columns (3)-(5) are based on a regression sample containing only observations for which information on quantities is available. Fixed effects are included as described in the regression specification 28. Standard errors are clustered at the HS6-year level. P-values are reported in brackets. ***, ** and * indicate respectively $1 \%, 5 \%$ and $10 \%$ significance levels.

The results shown in table 10 are similar to the results obtained from bilateral productlevel data (see table 3). Standard harmonization is associated with an increase of total sales (column (3)) by $0.59 \%$. Concerning the extensive margin, the positive contribution is driven by a higher number of products per firm (column (2)) while there is little evidence of new firm entry (column (1)). Compared to the baseline results, table 10 shows that firms sell larger volumes despite charging higher prices; see column (4) and column (5). ${ }^{28}$ These results favor the interpretation that standard harmonization increases product demand, for example, by making intermediate inputs compatible or by reducing information asymmetries. We do not find much evidence that a reduction in variable costs, which should result in lower prices, drives the results.

\subsection{Differentiated vs. homogeneous products}

One possible reason why product demand increases in response to standard harmonization relates to the reduction of information asymmetries. In particular, the use of a common standard renders extensive product descriptions obsolete, as producers can simply refer

\footnotetext{
${ }^{27}$ We also ran our firm-level regressions with a less demanding fixed-effects set-up as in Fontagné et al. (2015) by including HS2-destination-year $\left(f_{H S 2, j, t}\right)$ and firm $\left(f_{f}\right)$ fixed effects. In this case, all coefficients for export status, the number of products and total sales as well as prices and quantities are positive and significant.

${ }^{28}$ Higher firm-level prices can be reconciled with lower product-level prices in our bilateral regressions as the number of product varieties increases when existing firms expand their product range.
} 
to the standard to convince importers of the properties of their product. Following Matveenko (2017), we associate differentiated products with higher search barriers to trade (and thus a higher reduction of these barriers when standards are harmonized). In particular, Matveenko (2017) provides micro-foundations for the demand shifter $d_{i j k}$ that we introduced in section 4: rational inattentive consumers with CES utility have to choose the optimal amount of time to search for products. The resulting demand for a product is defined by the ex-ante probability of searching for the good and the elasticity of substitution. Thus, one should observe that changes in the search probability, as, for example, brought about by a reduction in information asymmetry through standard harmonization, increase demand more for low-elasticity products compared to high-elasticity products (or in other words, differentiated goods, which have a low elasticity of substitution, should react more than non-differentiated goods).

We also expect that any effects of standard harmonization that affect the complementarity and compatibility of products should apply to a larger extent to differentiated than to homogeneous products. So-called network effects, arising either through consumption externalities where a larger number of users increases individual consumption benefits or through compatibility effects where one component (i.e. software) can be used in combination with another (i.e. hardware), are typically associated with technology-intensive and manufactured goods rather than commodities (see the discussion in Gandal, 2002).

Table 11: Regression results / Rauch classification

(a) Differentiated products

\begin{tabular}{lccccc}
\hline & $(1)$ & $(2)$ & $(3)$ & $(4)$ & $(5)$ \\
& Total & Ext. margin & Int. margin & Price & Quantity \\
\hline Harm. & $0.00764^{* * *}$ & $0.00143^{* * *}$ & $0.00621^{* * *}$ & $-0.00412^{* * *}$ & $0.01033^{* * *}$ \\
& {$[0.000]$} & {$[0.001]$} & {$[0.001]$} & {$[0.003]$} & {$[0.000]$} \\
\hline Observations & 3521175 & 3521175 & 3521175 & 3521175 & 3521175 \\
$R^{2}$ & 0.89 & 0.90 & 0.87 & 0.83 & 0.87 \\
Adjusted $R^{2}$ & 0.86 & 0.88 & 0.84 & 0.79 & 0.83 \\
\hline
\end{tabular}

(b) Homogeneous products

\begin{tabular}{lccccc}
\hline & $(1)$ & $(2)$ & $(3)$ & $(4)$ & $(5)$ \\
& Total & Ext. margin & Int. margin & Price & Quantity \\
\hline Harm. & 0.00123 & 0.00077 & 0.00046 & -0.00261 & 0.00307 \\
& {$[0.753]$} & {$[0.305]$} & {$[0.901]$} & {$[0.290]$} & {$[0.513]$} \\
\hline Observations & 1781512 & 1781512 & 1781512 & 1781512 & 1781512 \\
$R^{2}$ & 0.86 & 0.89 & 0.84 & 0.83 & 0.84 \\
Adjusted $R^{2}$ & 0.82 & 0.86 & 0.78 & 0.77 & 0.79 \\
\hline
\end{tabular}

Notes: Regression of the respective dependent variable (designated in column headers) on harmonization indicator, splitting the sample in differentiated and homogeneous products according to the Rauch (1999) classification. Fixed effects are included as described in the regression specification 1 . Standard errors are clustered at the exporter-product level. P-values are reported in brackets. ***,** and * indicate respectively $1 \%, 5 \%$ and $10 \%$ significance levels.

In order to test these hypotheses, we use the classification by Rauch (1999), which 
categorizes products as either being differentiated or homogeneous. ${ }^{29}$ Table 11 shows that the previously positive results are entirely driven by differentiated products. We do not find any such effects for homogeneous products, leading us to interpret this as suggestive evidence that standard harmonization can reduce information asymmetries or increase complementarity/compatibility and thus can act as a demand shifter. This interpretation of our results is similar to Brynjolfsson et al. (2018), who show that a reduction in search costs, as in the case of language barriers, increases trade flows, and that this effect is even more pronounced for differentiated products.

\subsection{Reallocation of sales}

One implication of the model is that the positive effects from standard harmonization increase the incentives for firms to invest in the standardized variety. This increases the share of firms producing the standard and reduces the differences in sales between the most productive and the average firm. In addition, there is more firm entry within the sector due to general equilibrium effects. We should thus observe a reduction in the concentration of sales among exporters following a harmonization event. To test this prediction, we calculate several concentration measures: the Herfindahl-Hirschman Index (HHI), the normalized HHI and the concentration ratio, which is defined as the market share of the product with the largest export sales within a sector. The regression specification is identical to equation $1 .{ }^{30}$ We simply replace the sector-specific bilateral trade flow with sector-specific bilateral concentration measures. The results displayed in table 12 show that standard harmonization decreases all concentration measures significantly and therefore supports the predictions of the model.

Table 12: Regression results / Concentration of export sales

\begin{tabular}{lccc}
\hline & $(1)$ & $(2)$ & $(3)$ \\
& HHI & HHI norm. & Concentration ratio \\
\hline Harm. & $-0.0834^{* * *}$ & $-0.1015^{* * *}$ & $-0.0689^{* * *}$ \\
& {$[0.001]$} & {$[0.007]$} & {$[0.005]$} \\
\hline Observations & 3593693 & 3593693 & 3593693 \\
$R^{2}$ & 0.69 & 0.58 & 0.65 \\
Adjusted $R^{2}$ & 0.59 & 0.44 & 0.53 \\
\hline
\end{tabular}

Notes: Regression of the respective dependent variable (designated in column headers) on harmonization indicator. Only sectors that have at least two products are included. Fixed effects are included as described in the regression specification 1. Standard errors are clustered at the exporter-product level. P-values are reported in brackets. ${ }^{* * *},{ }^{* *}$ and $*$ indicate respectively $1 \%, 5 \%$ and $10 \%$ significance levels.

\footnotetext{
${ }^{29}$ Rauch (1999) distinguishes between products traded on organized exchanges or products that have a reference price. In our exercise, we summarize these categories in one.

${ }^{30}$ We include only sectors where at least two HS6 products are exported, but results are quantitatively similar and significant when considering the entire sample.
} 


\section{Endogeneity}

This section addresses potential endogeneity concerns. The first concern is that harmonization primarily happens in product categories where trade flows are generally large; higher trade flows after standard harmonization are thus simply a result of the preference of SSOs to standardize more important product categories. Second, special interest groups or firms may lobby for the accreditation of a standard in the anticipation of higher sales. In order to address these concerns, we want to point out that all our regressions include a rich set of fixed effects that controls for any non-discriminatory standard common to all exporters or importers. In addition, we resort to several robustness tests below, namely (1) estimating our regression model in differences, thus ruling out the size effect of large trade flows, (2) testing for the existence of pre-trends, (3) assuring that the standards in question have a supranational and thus largely exogenous character (by testing so-called European Standards) and (4) using the harmonization events of neighboring countries as an instrument for a country's own events.

\subsection{Difference equation}

One key identification concern is that our main results in table 3 are driven by the fact that standard harmonization is primarily done in sectors where exporters are already present and where trade volumes are high. To address part of these concerns, we specify our baseline regression in terms of first differences:

$$
\Delta X_{i j k t}=\beta \Delta h_{i j k t}+f_{i k t}+f_{j k t}+f_{i j t}+\varepsilon_{i j k t}
$$

The variable of interest, $\Delta h_{i j k t}$, is the first difference of the cumulative measure of standard harmonization $h_{i j k t}$. $\Delta h_{i j k t}$ is a binary indicator that equals one in the year the standard harmonization took place and zero otherwise. In addition, we follow Baier et al. (2014) and allow for multi-year differences. The regression equation looks as follows:

$$
\Delta_{m} X_{i j k t}=\beta \Delta_{m} h_{i j k t}+f_{i k t}+f_{j k t}+f_{i j t}+\varepsilon_{i j k t},
$$

where $\Delta_{m}$ indicates differencing the dataset by $m$ years. The reasons for multi-year differencing are twofold. When differencing the data by several years, the reference year in the control and treatment group is shifted back in the past. As a consequence, the regression set-up (1) is picking up some of the longer-run effects and (2) is safeguarding against anticipation effects (if any effect of standard harmonization is already present in the year before the actual release, differencing by several years makes the result more robust to such an anticipation effect).

The results are presented in table 13 for one-, two-, three- and four-year differences. While the one-year and two-year differences hardly show any significant results, differencing over three and four years shows the same results as the baseline regression, i.e. standard harmonization leads to an increase of the trade flow driven by the intensive margin, which itself is primarily driven by an increase in the quantities sold. These results suggest that 
the effect of standard harmonization needs time to develop. The coefficients in column (1) of the various specifications are consistent with this interpretation. After one year, the estimate on the growth rate of total trade flows is not statistically significant from zero. After two years, the effect increases to $0.3 \%$ and remains significant at around $0.6 \%$ after three and four years. Note that the fact that standard harmonization is only significant in the regression with multi-year differences is compatible with the results from the baseline difference-in-difference set-up (table 3 ), where the dummy variable $h_{i j k t}$ takes on the value of one at the time of the harmonized standard release and for the following years (until the next harmonization event), thus also measuring long-run effects.

Table 13: Regression results / Multi-year differences

(a) First differences

\begin{tabular}{lccccc}
\hline & $(1)$ & $(2)$ & $(3)$ & $(4)$ & $(5)$ \\
& $\Delta$ Total & $\Delta$ Ext. & $\Delta$ Int. & $\Delta$ Price & $\Delta$ Quantity \\
& & margin & margin & & \\
\hline Harm. & -0.00132 & 0.00004 & -0.00136 & -0.00096 & -0.00040 \\
& {$[0.533]$} & {$[0.945]$} & {$[0.501]$} & {$[0.620]$} & {$[0.885]$} \\
\hline Observations & 5017031 & 5017031 & 5017031 & 5017031 & 5017031 \\
$R^{2}$ & 0.22 & 0.19 & 0.22 & 0.23 & 0.23 \\
Adjusted $R^{2}$ & 0.08 & 0.03 & 0.07 & 0.09 & 0.08 \\
\hline
\end{tabular}

(b) Two-year differences

\begin{tabular}{lccccc}
\hline & $(1)$ & $(2)$ & $(3)$ & $(4)$ & $(5)$ \\
& $\Delta$ Total & $\begin{array}{c}\Delta \text { Ext. } \\
\text { margin }\end{array}$ & $\begin{array}{c}\Delta \text { Int. } \\
\text { margin }\end{array}$ & $\Delta$ Price & $\Delta$ Quantity \\
\hline Harm. & $0.00301^{*}$ & 0.00077 & 0.00224 & -0.00158 & $0.00382^{*}$ \\
& {$[0.094]$} & {$[0.105]$} & {$[0.192]$} & {$[0.291]$} & {$[0.091]$} \\
\hline Observations & 4676493 & 4676493 & 4676493 & 4676493 & 4676493 \\
$R^{2}$ & 0.25 & 0.21 & 0.25 & 0.25 & 0.25 \\
Adjusted $R^{2}$ & 0.11 & 0.06 & 0.10 & 0.11 & 0.10 \\
\hline
\end{tabular}

(c) Three-year differences

\begin{tabular}{lccccc}
\hline & $(1)$ & $(2)$ & $(3)$ & $(4)$ & $(5)$ \\
& $\Delta$ Total & $\Delta$ Ext. & $\Delta$ Int. & $\Delta$ Price & $\Delta$ Quantity \\
& & margin & margin & & \\
\hline Harm. & $0.00630^{* * *}$ & $0.00116^{* * *}$ & $0.00514^{* * *}$ & 0.00024 & $0.00490^{* *}$ \\
& {$[0.000]$} & {$[0.006]$} & {$[0.002]$} & {$[0.854]$} & {$[0.022]$} \\
\hline Observations & 4370967 & 4370967 & 4370967 & 4370967 & 4370967 \\
$R^{2}$ & 0.27 & 0.24 & 0.27 & 0.27 & 0.26 \\
Adjusted $R^{2}$ & 0.13 & 0.09 & 0.12 & 0.13 & 0.12 \\
\hline
\end{tabular}

(d) Four-year differences

\begin{tabular}{lccccc}
\hline & $(1)$ & $(2)$ & $(3)$ & $(4)$ & $(5)$ \\
& $\Delta$ Total & $\begin{array}{c}\Delta \text { Ext. } \\
\text { margin }\end{array}$ & $\begin{array}{c}\Delta \text { Int. } \\
\text { margin }\end{array}$ & $\Delta$ Price & $\Delta$ Quantity \\
\hline Harm. & $0.00573^{* * *}$ & $0.00120^{* * *}$ & $0.00453^{* * *}$ & -0.00062 & $0.00515^{* *}$ \\
& {$[0.001]$} & {$[0.003]$} & {$[0.006]$} & {$[0.621]$} & {$[0.014]$} \\
\hline Observations & 4078732 & 4078732 & 4078732 & 4078732 & 4078732 \\
$R^{2}$ & 0.30 & 0.26 & 0.29 & 0.29 & 0.28 \\
Adjusted $R^{2}$ & 0.16 & 0.11 & 0.15 & 0.15 & 0.14 \\
\hline
\end{tabular}

Notes: Regression of the respective dependent variable (designated in column headers) on harmonization indicator. Regression model corresponds to the differenced version of the baseline model (regression specification 30). Standard errors are clustered at the exporter-product level. Fixed effects are included as described in the regression specification 30. P-values are reported in brackets. $* * *$, ** and * indicate respectively $1 \%, 5 \%$ and $10 \%$ significance levels. 


\subsection{Pre-trends}

Another identification concern is that our difference-in-difference estimator picks up different pre-trends between harmonized and non-harmonized products. Different pretrends arise if harmonization primarily happens in product categories where trade flows are large or when firms anticipate future standardization efforts and thus react prior to the actual harmonization event. Given that we have multiple harmonization events within an exporter-importer-product triplet, we focus only on observations that did not have any standard harmonization four years prior to the first harmonization event. ${ }^{31}$ The regression specification with pre-trends looks as follows:

$$
\log \left(X_{i j k t}\right)=\beta_{h} h_{i j k t}+\sum_{n=1}^{4} \beta_{n} d_{i j k t-n}^{1 s t}+f_{i k t}+f_{j k t}+f_{i j t}+f_{i j k}+\varepsilon_{i j k t},
$$

where the variable $d_{i j k t-n}^{1 s t}$ represents a dummy that is equal to one $n$ years prior to the first harmonization event. Results are displayed in table 14. The magnitudes are comparable to the baseline specification. Once again, total trade, the extensive and intensive margin and quantities are positively affected, while prices decrease. Pre-trend dummies for these regressions are not significant at any margin.

Table 14: Regression results / Controlling for pre-trends

\begin{tabular}{lccccc}
\hline & $(1)$ & $(2)$ & $(3)$ & $(4)$ & $(5)$ \\
& Total & Ext. margin & Int. margin & Price & Quantity \\
\hline Harm. & $0.00791^{* * *}$ & $0.00203^{* * *}$ & $0.00588^{* * *}$ & $-0.00425^{* * *}$ & $0.01013^{* * *}$ \\
& {$[0.000]$} & {$[0.000]$} & {$[0.002]$} & {$[0.003]$} & {$[0.000]$} \\
1st Harm. $(\mathrm{t}+1)$ & -0.00319 & -0.00032 & -0.00287 & -0.00618 & 0.00332 \\
& {$[0.510]$} & {$[0.788]$} & {$[0.533]$} & {$[0.130]$} & {$[0.588]$} \\
1st Harm. (t+2) & -0.00665 & -0.00174 & -0.00491 & 0.00264 & -0.00755 \\
& {$[0.232]$} & {$[0.195]$} & {$[0.352]$} & {$[0.569]$} & {$[0.288]$} \\
1st Harm. (t+3) & -0.00458 & -0.00240 & -0.00217 & -0.00123 & -0.00094 \\
& {$[0.457]$} & {$[0.108]$} & {$[0.709]$} & {$[0.812]$} & {$[0.904]$} \\
1st Harm. (t+4) & 0.00061 & -0.00127 & 0.00187 & 0.00761 & -0.00574 \\
& {$[0.926]$} & {$[0.431]$} & {$[0.763]$} & {$[0.174]$} & {$[0.494]$} \\
\hline Observations & 4580633 & 4580633 & 4580633 & 4580633 & 4580633 \\
$R^{2}$ & 0.89 & 0.90 & 0.86 & 0.86 & 0.87 \\
Adjusted $R^{2}$ & 0.85 & 0.87 & 0.82 & 0.81 & 0.83 \\
\hline
\end{tabular}

Notes: Regression of the respective dependent variable (designated in column headers) on harmonization indicator and dummy variables for the first harmonization event shifted in time. Standard errors are clustered at the exporter-product level. Fixed effects are included as described in the regression specification 31. P-values are reported in brackets. ${ }^{* * *},{ }^{* *}$ and $*$ indicate respectively $1 \%, 5 \%$ and $10 \%$ significance levels.

\subsection{Endogeneity and European Standards (EN)}

In order to address the question of endogeneity of harmonization efforts, we exploit the fact that the European Commission officially works with three European SSOs,

\footnotetext{
${ }^{31}$ Since our sample starts in 1996, we do not consider any observations that experience a harmonization event prior to the year 2000 .
} 
namely the European Committee for Standardisation (CEN), the European Committee for Electrotechnical Standardization (CENELEC) and the European Telecommunications Standards Institute (ETSI), as providers of so-called European Standards. These can be used to support EU legislation. Once a standard is qualified as a European Standard (identified through the reference code containing the letters "EN"), it "carries with it the obligation to be implemented at national level by being given the status of a national standard and by withdrawal of any conflicting national standard" (CEN-CENELEC Internal Regulations $\left.^{32}\right)$.

Figure 6: European Standards, 1990-2014

European (EN) and remaining standards

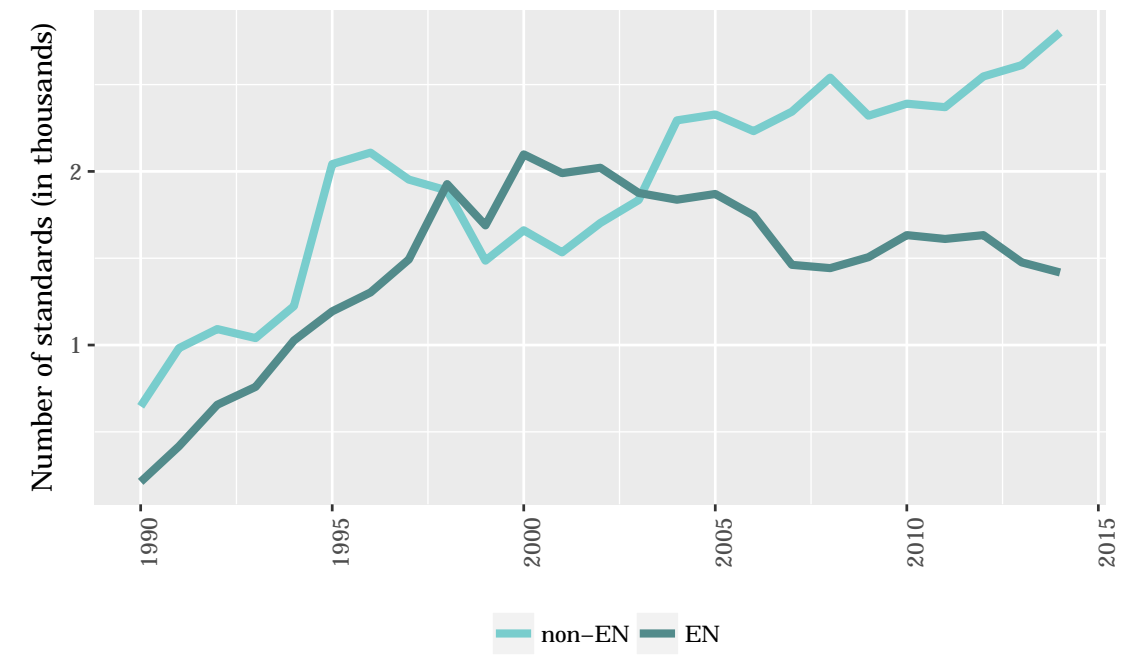

Notes: The figure displays the number of original standard releases of all harmonized standards, broken down by the year of their original release as well as whether they constitute a European Standard or not.

The European Commission actively supports the development of European Standards. Figure 6 displays the number of original releases of all harmonized standards, broken down by their categorization as a European Standard (EN) or another standard. As is obvious from figure 6, European standardization efforts picked up over the 1990s and even outnumbered other standards to a considerable extent.

The supranational character of these European standards reduces endogeneity concerns. Even if one were to make the argument that European standards are primarily released in fields where one expects a lot of trade, fixed effects will take up these $k t$-specific factors, and identification therefore only comes from the cross-country variation as well as the timing of implementation of European into national standards. In our dataset, non-European countries also accredit European Standards (EN), although to a considerably smaller extent than EU/EFTA members. Whereas the accreditations of EN standards by national SSOs take place in the same year as the original release in approximately $46 \%$ of all cases, the remaining $54 \%$ have a time lag of one year or longer.

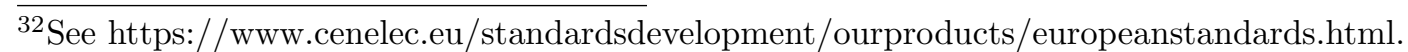


We run the same regression model as before, but limit the construction of the harmonization indicator to European standards. The results are displayed in table 15. The results are quantitatively and qualitatively very similar to the baseline specification. In line with the statistics presented in table 1, cross-country standardization is largely a process supported by international and European SSOs, which helps reduce endogeneity concerns.

Table 15: Regression results / European Standards

\begin{tabular}{lccccc}
\hline & $(1)$ & $(2)$ & $(3)$ & $(4)$ & $(5)$ \\
& Total & Ext. margin & Int. margin & Price & Quantity \\
\hline Harm. & $0.00528^{* * *}$ & 0.00064 & $0.00464^{* *}$ & $-0.00354^{* * *}$ & $0.00818^{* * *}$ \\
& {$[0.009]$} & {$[0.130]$} & {$[0.015]$} & {$[0.009]$} & {$[0.001]$} \\
\hline Observations & 6194987 & 6194987 & 6194987 & 6194987 & 6194987 \\
$R^{2}$ & 0.88 & 0.90 & 0.86 & 0.85 & 0.86 \\
Adjusted $R^{2}$ & 0.85 & 0.87 & 0.82 & 0.82 & 0.83 \\
\hline
\end{tabular}

Notes: Regression of the respective dependent variable (designated in column headers) on harmonization indicator that only takes into consideration EN standards. Fixed effects are included as described in the regression specification 1. Standard errors are clustered at the exporter-product level. P-values are reported in brackets. ${ }^{* * *},{ }^{* *}$ and $*$ indicate respectively $1 \%, 5 \%$ and $10 \%$ significance levels.

\subsection{IV regressions}

We resort to instrumental variable techniques to further analyze to what extent our results are robust to endogeneity bias, for example due to the possibility that the accreditation of standards is subject to special interest groups. A commonly used instrument for the home trade policy, in the literature on non-tariff measures, is the trade policies of its neighboring countries (see, for example, Kee and Nicita, 2016). The underlying idea is that trade policies of neighboring countries, due to similarities in terms of economic structure, geographic characteristics or membership in supranational organizations, are a good predictor of a country's own policies, but are not the target of lobbying efforts by domestic firms.

Using CEPII's GeoDist database (Mayer and Zignago, 2011), we identify an exporting country's neighbors among the countries in our database and calculate the mean number of harmonization events with respect to each importing country. If this average is larger than or equal to 0.5 , we code it as a harmonization event $\left(h_{i j k t}^{I V}=1\right)$. We consider a country to be a neighbor if it shares a common language or a land border with another country. ${ }^{33}$

The results are displayed in table 16. The upper panel displays the results of the first stage: the mean standard harmonizations of neighboring countries constitute a relevant predictor of a country's own harmonizations and the F-statistic dismisses the possibility that the IV estimates are biased due to weak instruments. The second-stage results,

\footnotetext{
${ }^{33}$ A certain number of countries do not share a language or border with any of the rest of the countries in our database: Brazil, Japan, Jordan, South Korea and Turkey. For Japan and South Korea, we consider the countries with which they share a maritime border as neighbors. For Brazil, Jordan and Turkey, we define the three closest countries in our database as neighbors.
} 
displayed in the lower panel of table 16, show that the results hold across all dependent variables: overall trade increases, due to both an increase in the extensive and the intensive margin, whereas the decomposition of the intensive margin shows again a decrease in prices and an increase in quantities.

Table 16: Regression results / Instrumental variables

(a) First stage

\begin{tabular}{lc}
\hline & $(1)$ \\
& Harm. \\
\hline Harm. neighbors & $0.23846^{* * *}$ \\
& {$[0.000]$} \\
\hline Observations & 5848855 \\
F-statistic & 3811 \\
\hline
\end{tabular}

(b) Second stage

\begin{tabular}{lccccc}
\hline & $(1)$ & $(2)$ & $(3)$ & $(4)$ & $(5)$ \\
& Total & Ext. & Int. margin & Price & Quantity \\
& & margin & & & \\
\hline Harm. & $0.01861^{* *}$ & $0.00401^{* * *}$ & $0.01459^{* *}$ & $-0.02107^{* * *}$ & $0.03566^{* * *}$ \\
& {$[0.013]$} & {$[0.010]$} & {$[0.040]$} & {$[0.000]$} & {$[0.000]$} \\
\hline Observations & 5848855 & 5848855 & 5848855 & 5848855 & 5848855 \\
\hline
\end{tabular}

Notes: Instrumental variables regression of the respective dependent variable (designated in column headers) on harmonization indicator where harmonization is instrumented by neighbors' harmonization. Panel a shows the first-stage results and panel b shows the second-stage results. Fixed effects are included as described in the regression specification 1. Standard errors are clustered at the exporter-product level. $\mathrm{P}$-values are reported in brackets. $* * *, * *$ and $*$ indicate respectively $1 \%, 5 \%$ and $10 \%$ significance levels.

In terms of economic magnitudes, the IV estimates are larger than the OLS ones. However, for columns (1)-(3) of table 16, the Durbin-Wu-Hausman test shows that we cannot reject the null hypothesis of the OLS estimator yielding consistent estimates; we thus conclude that there are no statistically significant differences between the OLS and IV estimates. Under the assumption that our instrument is indeed exogenous and given that the OLS estimator is more efficient, we consider OLS our preferred estimation method.

Overall, the evidence presented in this section suggests that our results are robust to endogeneity concerns. We can exclude that the results are driven by the size effect of large trade flows. Including pre-trends into the analysis shows that these are not significant. Finally, addressing potential endogeneity bias with IV techniques and using a measure of largely exogenous, supranational standards yields results that are consistent with the baseline approach.

\section{Conclusion}

Based on a novel dataset of harmonized standard releases across 26 countries, this paper contributes to the literature by quantifying the effects of standard harmonization on international product trade flows. Our results show that harmonizing standards leads to a $0.67 \%$ increase in trade flows. This increase is predominantly driven by the intensive 
margin and to a smaller extent by the extensive margin. An additional decomposition of the price and quantity changes shows that quantity effects are the main determinant for the changes of the intensive margin. In terms of ad-valorem equivalents, our results imply a trade-promoting effect comparable to a reduction of tariffs by 2.1 percentage points (on impact).

By decomposing trade flows into their different margins, we are able to analyze the channels through which the presumed gains from standard harmonization materialize. To this end, we build a heterogeneous firm model with endogenous standard adoption. Our results speak in favor of the presence of sunk investment costs and higher demand effects: standard harmonization incentivizes firms to invest in the standard by increasing demand for harmonized products.

Data limitations and econometric challenges have prevented academics and policymakers from thoroughly analyzing the economic consequences of standardization and its increasing cross-border harmonization. This paper attempts to fill this gap by quantifying the impact on international trade and its different margins, but does not investigate why standards are harmonized between certain countries and in specific sectors while others remain in the hands of national regulation. We also do not touch upon interesting issues such as the link of standard harmonization with preferential trade agreements or welfare calculations, nor do we analyze firm-level dimensions, such as to what extent the release of a harmonized standard affects market shares. We leave these questions to further research. 


\section{References}

Arkolakis, Costas, Sharat Ganapati and Marc-Andreas Muendler (2016): The Extensive Margin of Exporting Products: A Firm-level Analysis. Cowles Foundation Discussion Papers 2028, Cowles Foundation for Research in Economics, Yale University.

Atkeson, Andrew, Christian Hellwig and Guillermo Ordoñez (2014): Optimal regulation in the presence of reputation concerns. The Quarterly Journal of Economics, 130(1), pp. 415-464.

Baier, Scott L., Jeffrey H. Bergstrand and Michael Feng (2014): Economic integration agreements and the margins of international trade. Journal of International Economics, 93(3), pp. 339-350.

Baldwin, Richard E., John McLaren and Arvind Panagariya (2000): Regulatory protectionism, developing nations, and a two-tier world trade system [with comments and discussion]. In: Brookings Trade Forum, pp. 237-293. JSTOR.

Baron, J. and J. Schmidt (2014): Technological Standardization, Endogenous Productivity and Transitory Dynamics. Working papers 503, Banque de France.

Baron, Justus and Daniel Spulber (2015): Technology Standards and Standard Setting Organizations: Introduction to the Searle Center Database. Working Paper No. 006, Searle Center on Law, Regulation, and Economic Growth.

Baron, Justus and Daniel F. Spulber (2018): Technology standards and standard setting organizations: Introduction to the Searle Center Database. Journal of Economics \& Management Strategy, 27(3), pp. 462-503.

Brynjolfsson, Erik, Xiang Hui and Meng Liu (2018): Does Machine Translation Affect International Trade? Evidence from a Large Digital Platform. Working Paper 24917, National Bureau of Economic Research.

Chaney, T. (2008): Distorted gravity: The intensive and extensive margins of international trade. The American Economic Review, 98(4), pp. 1707-1721.

Chen, Maggie Xiaoyang and Aaditya Mattoo (2008): Regionalism in standards: Good or bad for trade? Canadian Journal of Economics, 41(3), pp. 838-863.

Costinot, Arnaud (2008): A comparative institutional analysis of agreements on product standards. Journal of International Economics, 75(1), pp. 197-213.

Disdier, Anne-Célia, Lionel Fontagné and Olivier Cadot (2015): North-South standards harmonization and international trade. World Bank Economic Review, 29(2), pp. $327-352$.

Ederington, J. and M. Ruta (2016): Nontariff Measures and the World Trading System. Handbook of Commercial Policy, vol. 1, pp. 211-277. North-Holland.

Essaji, Azim (2008): Technical regulations and specialization in international trade. Journal of International Economics, 76(2), pp. 166-176.

Farrell, Joseph and Paul Klemperer (2007): Coordination and lock-in: Competition with switching costs and network effects. Handbook of Industrial Organization, 3, pp. 1967-2072.

Farrell, Joseph von R. and Garth Saloner (1985): Standardization, compatibility, and innovation. The RAND Journal of Economics, 16(1), pp. 70-83. 
Fernandes, Ana M., Esteban Ferro and John S. Wilson (2019): Product standards and firms' export decisions. The World Bank Economic Review, 33(2), pp. 353-374.

Fischer, Ronald and Pablo Serra (2000): Standards and protection. Journal of International Economics, 52(2), pp. 377-400.

Flach, Lisandra and Florian Unger (2018): Quality and Gravity in International Trade. CEPR Discussion Papers 12602, Centre for Economic Policy Research.

Fontagné, Lionel, Gianluca Orefice, Roberta Piermartini and Nadia Rocha (2015): Product standards and margins of trade: Firm-level evidence. Journal of International Economics, 97(1), pp. 29-44.

Gandal, Neil (2002): Compatibility, standardization, and network effects: Some policy implications. Oxford Review of Economic Policy, 18(1), pp. 80-91.

Gandal, Neil and Oz Shy (2001): Standardization policy and international trade. Journal of International Economics, 53(2), pp. 363-383.

Ganslandt, Mattias and James R. Markusen (2001): Standards and Related Regulations in International Trade: A Modeling Approach. NBER Working Papers 8346, National Bureau of Economic Research, Inc.

Gaulier, Guillaume and Soledad Zignago (2010): BACI: International Trade Database at the Product-Level. The 1994-2007 Version. CEPII Working Paper, 2010-23.

Goldberg, Pinelopi K. and Nina Pavcnik (2016): The Effects of Trade Policy. Handbook of Commercial Policy, vol. 1, pp. 161-206. North-Holland.

Han, Xinfen, Julia Schmidt and Walter Steingress (2019): Constructing a Concordance Table between HS and ICS. Mimeo.

Handley, Kyle and Nuno Limão (2017): Policy uncertainty, trade, and welfare: Theory and evidence for China and the United States. American Economic Review, 107(9), pp. 2731-2783.

Hummels, D. and P.J. Klenow (2005): The variety and quality of a nation's exports. American Economic Review, 95(3), pp. 704-723.

ISO (2016): Annual Report: Navigating a World in Transition. Tech. rep., International Organization for Standardization, Geneva.

Katz, Michael L. and Carl Shapiro (1985): Network externalities, competition, and compatibility. The American Economic Review, 75(3), pp. 424-440.

Kee, Hiau Looi and Alessandro Nicita (2016): Trade Frauds, Trade Elasticities and Non-Tariff Measures. Mimeo.

Kee, Hiau Looi, Alessandro Nicita and Marcelo Olarreaga (2009): Estimating trade restrictiveness indices. The Economic Journal, 119(534), pp. 172-199.

Kieck, Erich (2010): Coordinated border management: Unlocking trade opportunities through one stop border posts. World Customs Journal, 4(1), pp. 3-13.

Leland, Hayne E (1979): Quacks, lemons, and licensing: A theory of minimum quality standards. Journal of Political Economy, 87(6), pp. 1328-1346.

Macedoni, Luca and Ariel Weinberger (2018): Quality Heterogeneity and Misallocation: The Welfare Benefits of Raising Your Standards. Mimeo.

Maskus, Keith E., Tsunehiro Otsuki and John S. Wilson (2005): The cost of compliance 
with product standards for firms in developing countries: An econometric study. Policy Research Working Paper Series 3590, The World Bank.

Matveenko, Andrei (2017): Logit, CES, and Rational Inattention. CERGE-EI Working Papers wp593, The Center for Economic Research and Graduate Education - Economics Institute, Prague.

Maur, Jean-Christophe and Ben Shepherd (2011): Product Standards. In: Jean-Pierre Chauffour and Jean-Christophe Maur (eds.), Preferential Trade Agreement Policies for Development, pp. 197-216. The World Bank.

Mayer, Thierry and Soledad Zignago (2011): Notes on CEPII's Distances Measures: The GeoDist Database. Working Papers 2011-25, CEPII.

Mei, Yuan (2017): Regulatory Protection and the Role of International Cooperation. Mimeo.

Melitz, M. J. (2003): The impact of trade on intra-industry reallocations and aggregate industry productivity. Econometrica, 71(6), pp. 1695-1725.

Moenius, Johannes (2006): The Good, the Bad and the Ambiguous: Standards and Trade in Agricultural Products. Mimeo.

OECD (2005): OECD Annual Report 2005. In: Annual Report, pp. 1-143. The Organisation for Economic Co-operation and Develoment (OECD).

Parenti, Mathieu and Gonzague Vannoorenberghe (2019): A Simple Theory of Deep Trade Integration. Mimeo.

Rauch, James E. (1999): Networks versus markets in international trade. Journal of International Economics, 48(1), pp. 7-35.

Reyes, José-Daniel (2011): International Harmonization of Product Standards and Firm Heterogeneity in International Trade. Policy Research Working Paper Series 5677, The World Bank.

Shepherd, Ben (2007): Product Standards, Harmonization, and Trade: Evidence from the Extensive Margin. Policy Research Working Paper Series 4390, The World Bank.

Swann, G. M. Peter (2010): International Standards and Trade: A Review of the Empirical Literature. OECD Trade Policy Papers 97, OECD Publishing.

Swann, Peter (2000): The Economics of Standardization. Final Report for Standards and Technical Regulations Directorate Department of Trade and Industry. Tech. rep., University of Manchester, Manchester, UK.

Swann, Peter, Paul Temple and Mark Shurmer (1996): Standards and trade performance: The UK experience. The Economic Journal, 106(438), pp. 1297-1313.

Toulemonde, Eric (2013): A welfare analysis of the principle of mutual recognition. European Economic Review, 60, pp. 1-16.

UNCTAD (2016): Key Statistics and Trends in Trade Policy 2016. Tech. Rep. UNCTAD/DITC/TAB/2016/2, UN Publishing.

World Trade Report (2012): Trade and public policies: A closer look at non-tariff measures in the 21st century. Tech. rep., World Trade Organization. 


\section{A Appendix: Model}

\section{Firm profits and sales}

Firms can produce a standardized or a non-standardized variety. Firm-level variables that are specific to firms producing the standardized variety are denoted by the superscript $z$. Throughout, we assume that the production of a standardized variety is associated with sunk fixed costs $z_{i j k}^{a_{k}}$. In the case of fixed costs of exporting being smaller for standardized varieties than for non-standardized varieties $\left(f_{i j k}^{z}<f_{i j k}\right)$, we assume in the below exposition that $f_{i j k}^{z}+z_{i j k}^{a_{k}}>f_{i j k} \cdot{ }^{34}$

Firms producing the non-standardized variety. Profits of firms that decide to produce a non-standardized variety are given by

$$
\pi_{i j k}(\varphi)=\frac{x_{i j k}(\varphi)}{\sigma_{k}}-f_{i j k}
$$

where sales are given by

$$
x_{i j k}(\varphi)=d_{i j k} A_{i j k}\left(\frac{\sigma_{k}}{\sigma_{k}-1} \frac{\tau_{i j k}}{\varphi}\right)^{1-\sigma_{k}},
$$

where $A_{i j k}=P_{i j k}^{\sigma_{k}-\gamma_{k}} P_{j k}^{\gamma_{k}-1} X_{j k}$.

Firms producing the standardized variety. Profits of firms producing a standardized good with productivity $\varphi$ from country $i$ selling to country $j$ and choosing the price optimally are given by

$$
\pi_{i j k}^{z}(\varphi)=\frac{x_{i j k}^{z}(\varphi)}{\sigma_{k}}-f_{i j k}^{z}-z_{i j k}^{a_{k}}
$$

where sales are given by

$$
x_{i j k}^{z}(\varphi)=d_{i j k}^{z} A_{i j k}\left(\frac{\sigma_{k}}{\sigma_{k}-1} \frac{\tau_{i j k}^{z}}{\varphi}\right)^{1-\sigma_{k}} z_{i j k}^{\left(\sigma_{k}-1\right)\left(1-t_{k}\right)},
$$

where $A_{i j k}=P_{i j k}^{\sigma_{k}-\gamma_{k}} P_{j k}^{\gamma_{k}-1} X_{j k}$.

\section{Productivity cut-offs}

There are two productivity cut-offs. The cut-off $\bar{\varphi}_{i j k}^{z}$ is given by the firm that is indifferent between producing the standardized and the non-standardized variety. It is obtained by

\footnotetext{
$\overline{{ }^{34} \text { Note that in the contrary case, i.e. } f_{i j k}^{z}}+z_{i j k}^{a_{k}}<=f_{i j k}$, all firms produce the standardized variety.
} 
setting their profits equal:

$$
\frac{d_{i j k} A_{i j k}\left(\frac{\sigma_{k}}{\sigma_{k}-1} \frac{\tau_{i j k}}{\varphi}\right)^{1-\sigma_{k}}}{\sigma_{k}}-f_{i j k}=\frac{d_{i j k}^{z} A_{i j k}\left(\frac{\sigma_{k}}{\sigma_{k}-1} \frac{\tau_{i j k}^{z}}{\varphi}\right)^{1-\sigma_{k}} z_{i j k}^{\left(\sigma_{k}-1\right)\left(1-t_{k}\right)}}{\sigma_{k}}-f_{i j k}^{z}-z_{i j k}^{a_{k}}
$$

The resulting productivity cut-off to produce standardized varieties is

$$
\bar{\varphi}_{i j k}^{z}=\left(\frac{\sigma_{k}\left(z_{i j k}^{a_{k}}+f_{i j k}^{z}-f_{i j k}\right)}{d_{i j k} A_{i j k}\left(\frac{d_{i j k}^{z}}{d_{i j k}}\left(\frac{\tau_{i j k}^{z}}{\tau_{i j k}}\right)^{1-\sigma_{k}} z_{i j k}^{\left(\sigma_{k}-1\right)\left(1-t_{k}\right)}-1\right)}\right)^{\frac{1}{\sigma_{k}-1}}\left(\frac{\sigma_{k}}{\sigma_{k}-1} \tau_{i j k}\right) .
$$

In addition, there is a cut-off productivity $\left(\bar{\varphi}_{i j k}\right)$ below which firms will not sell in country $j$ because the potential revenues cannot cover production and fixed costs of exporting to $j$. This cut-off is obtained by setting the profits of a non-standardized variety equal to zero:

$$
\bar{\varphi}_{i j k}=\frac{\sigma_{k}}{\sigma_{k}-1} \tau_{i j k}\left(\frac{\sigma_{k} f_{i j k}}{d_{i j k} A_{i j k}}\right)^{\frac{1}{\sigma_{k}-1}}
$$

Next, we define the wedge in fixed costs to export $\left(\triangle_{i j k}^{f}=f_{i j k}^{z} / f_{i j k}\right)$, the wedge in variable trade costs $\left(\triangle_{i j k}^{\tau}=\tau_{i j k}^{z} / \tau_{i j k}\right)$ as well as the demand wedge $\left(\triangle_{i j k}^{d}=d_{i j k}^{z} / d_{i j k}\right)$. Using the Pareto distribution, we can express the ratios of the cut-offs in terms of the share of firms that are exporting the standardized good:

$$
w_{i j k}=\frac{\left(1-G\left(\bar{\varphi}_{i j k}^{z}\right)\right) M_{i k}}{\left(1-G\left(\bar{\varphi}_{i j k}\right)\right) M_{i k}}=\left(\frac{\bar{\varphi}_{i j k}^{z}}{\bar{\varphi}_{i j k}}\right)^{-\xi_{k}}=\left(\frac{\frac{z_{i j k}^{a_{k}}}{f_{i j k}}+\triangle_{i j k}^{f}-1}{\triangle_{i j k}^{d}\left(\triangle_{i j k}^{\tau}\right)^{1-\sigma_{k}} z_{i j k}^{\left(\sigma_{k}-1\right)\left(1-t_{k}\right)}-1}\right)^{\frac{-\xi_{k}}{\sigma_{k}-1}}
$$

where $M_{i k}$ is the number of sector- $k$ firms in country $i$.

\section{Gravity equation}

We can write total bilateral export sales of country $i$ to country $j$ as

$$
X_{i j k}=\int_{\omega \in \Omega_{i j}} x_{i j k}(\omega) d G(\omega)
$$

as the sum of the sales of firms that produce the standardized varieties (firms with productivity in the interval $\left.\bar{\varphi}_{i j}^{z}<\varphi<\infty\right)$ and firms that produce the non-standardized 
variety (firms with productivity in the interval $\bar{\varphi}_{i j k}<\varphi<\bar{\varphi}_{i j k}^{z}$ ):

$$
\begin{aligned}
X_{i j k}= & A_{i j k}\left(\frac{\sigma_{k}}{\sigma_{k}-1}\right)^{1-\sigma_{k}} M_{i j k} \\
& \left(\frac{M_{i j k}^{n z}}{M_{i j k}} d_{i j k}\left(\tau_{i j k}\right)^{1-\sigma_{k}}\left(\tilde{\varphi}_{i j k}^{n z}\right)^{\sigma_{k}-1}+\frac{M_{i j k}^{z}}{M_{i j k}} d_{i j k}^{z}\left(\tau_{i j k}^{z}\right)^{1-\sigma_{k}} z_{i j k}^{\left(\sigma_{k}-1\right)\left(1-t_{k}\right)}\left(\tilde{\varphi}_{i j k}^{z}\right)^{\sigma_{k}-1}\right),
\end{aligned}
$$

where $M_{i j k}^{n z}$ is the number of firms producing the non-standardized varieties with average productivity $\tilde{\varphi}_{i j k}^{n z}$ and $M_{i j k}^{z}$ is the number of firms producing the standardized varieties with average productivity $\tilde{\varphi}_{i j k}^{z}$.

Firms producing the non-standardized variety. Average productivity for firms producing the non-standardized varieties is defined as

$$
\tilde{\varphi}_{i j k}^{n z}=\left(\int_{\bar{\varphi}_{i j k}}^{\bar{\varphi}_{i j k}^{z}} \varphi^{\sigma_{k}-1} d \frac{G(\varphi)}{G\left(\bar{\varphi}_{i j k}^{z}\right)-G\left(\bar{\varphi}_{i j k}\right)}\right)^{\frac{1}{\sigma_{k}-1}},
$$

which we can simplify to

$$
\begin{aligned}
\left(\tilde{\varphi}_{i j k}^{n z}\right)^{\sigma_{k}-1}= & {\left[\left(\bar{\varphi}_{i j k}^{z}\right)^{-\xi_{k}}-\left(\bar{\varphi}_{i j k}\right)^{-\xi_{k}}\right]^{-1} \frac{\xi_{k}}{\xi_{k}-\left(\sigma_{k}-1\right)} } \\
& {\left[\left(\bar{\varphi}_{i j k}^{z}\right)^{-\xi_{k}+\left(\sigma_{k}-1\right)}-\left(\bar{\varphi}_{i j k}\right)^{-\xi_{k}+\left(\sigma_{k}-1\right)}\right] . }
\end{aligned}
$$

Using the fact that we can express the cut-offs in terms of the share of exporters producing the standardized variety $\bar{\varphi}_{i j k}^{z}=\bar{\varphi}_{i j k} w_{i j k}^{-\frac{1}{\xi_{k}}}$, we get

$$
\left(\tilde{\varphi}_{i j k}^{n z}\right)^{\sigma_{k}-1}=\left(\bar{\varphi}_{i j k}^{n z}\right)^{\sigma_{k}-1} \frac{\xi_{k}}{\xi_{k}-\left(\sigma_{k}-1\right)} \frac{1-w_{i j k}^{1-\frac{\left(\sigma_{k}-1\right)}{\xi_{k}}}}{1-w_{i j k}} .
$$

Firms producing the standardized variety. Similarly, the average productivity for firms producing the standardized varieties is defined as

$$
\tilde{\varphi}_{i j k}^{z}=\left(\int_{\bar{\varphi}_{i j k}^{Z}}^{\infty} \varphi^{\sigma_{k}-1} d \frac{G(\varphi)}{1-G\left(\bar{\varphi}_{i j k}^{z}\right)}\right)^{\frac{1}{\sigma_{k}-1}}
$$

or, in terms of the cut-off

$$
\left(\tilde{\varphi}_{i j k}^{z}\right)^{\sigma_{k}-1}=\frac{\xi_{k}}{\xi_{k}-\left(\sigma_{k}-1\right)}\left(\bar{\varphi}_{i j k} w_{i j k}^{-\frac{1}{\xi_{k}}}\right)^{\sigma_{k}-1} .
$$


Plugging in the average productivities and substituting $w_{i j k}=M_{i j k}^{z} / M_{i j k}$ as well as $1-w_{i j k}=M_{i j k}^{n z} / M_{i j k}$, we get

$$
\begin{aligned}
X_{i j k}= & \left(\bar{\varphi}_{i j k}\right)^{-\xi} M_{i k} d_{i j k} A_{i j k}\left(\frac{\sigma_{k}}{\sigma_{k}-1} \frac{\tau_{i j k}}{\bar{\varphi}_{i j k}}\right)^{1-\sigma_{k}} \frac{\xi_{k}}{\xi_{k}-\left(\sigma_{k}-1\right)} \\
& \left(1-w_{i j k}^{1-\frac{\sigma-1}{\xi_{k}}}+\triangle_{i j k}^{d}\left(\triangle_{i j k}^{\tau}\right)^{1-\sigma_{k}} z_{i j k}^{\left(1-t_{k}\right)\left(\sigma_{k}-1\right)} w_{i j k}^{1-\frac{\sigma-1}{\xi_{k}}}\right) .
\end{aligned}
$$

Further simplification by substituting the expression for the cut-off from equation 38, the gravity equation with the extensive and intensive margin is written as

$$
\begin{aligned}
X_{i j k}= & \underbrace{\left(\frac{d_{i j k} A_{i j k}}{\sigma_{k} f_{i j k}}\right)^{\frac{\xi_{k}}{\left(\sigma_{k}-1\right)}}\left(\frac{\sigma_{k}}{\sigma_{k}-1} \tau_{i j k}\right)^{-\xi_{k}} M_{i k}}_{\text {Extensive margin }} \\
& \underbrace{\frac{\xi_{k} \sigma_{k} f_{i j k}}{\xi_{k}-\left(\sigma_{k}-1\right)}\left(1-w_{i j k}^{1-\frac{\sigma_{k}-1}{\xi_{k}}}+\triangle_{i j k}^{d}\left(\triangle_{i j k}^{\tau}\right)^{1-\sigma_{k}} z_{i j k}^{\left(1-t_{k}\right)\left(\sigma_{k}-1\right)} w_{i j k}^{1-\frac{\sigma_{k}-1}{\xi_{k}}}\right)}_{\text {Intensive margin }} .
\end{aligned}
$$

\section{The price index}

The price index is the weighted average of the prices of firms that export the standardized variety and those that do not:

$$
\begin{aligned}
P_{i j k}^{1-\sigma_{k}}=M_{i j k} & \frac{M_{i j k}^{n z}}{M_{i j k}} \underbrace{\int_{\bar{\varphi}_{i j k}^{z}}^{\bar{\varphi}_{i j k}} d_{i j k}\left(\frac{\sigma_{k}}{\sigma_{k}-1} \frac{\tau_{i j k}}{\varphi}\right)^{1-\sigma_{k}} d \frac{G(\varphi)}{G\left(\bar{\varphi}_{i j k}^{z}\right)-G\left(\bar{\varphi}_{i j k}\right)}}_{\left(\tilde{p}_{i j k}^{n z}\right)^{1-\sigma_{k}}} \\
& +M_{i j k} \frac{M_{i j k}^{z}}{M_{i j k}} \underbrace{\int_{\bar{\varphi}_{i j k}^{z}}^{\infty} d_{i j k}^{z}\left(\frac{\sigma_{k}}{\sigma_{k}-1} \frac{\tau_{i j k}^{z} z_{i j k}^{t_{k}-1}}{\varphi}\right)^{1-\sigma_{k}} d \frac{G(\varphi)}{1-G\left(\bar{\varphi}_{i j k}^{z}\right)}}_{\left(\tilde{p}_{i j k}^{z}\right)^{1-\sigma_{k}}}
\end{aligned}
$$

Firms producing the non-standardized variety. Their price index is defined as

$$
\begin{aligned}
\tilde{p}_{i j k}^{n z} & =\left(\left(G\left(\bar{\varphi}_{i j k}^{z}\right)-G\left(\bar{\varphi}_{i j k}\right)\right)^{-1} \int_{\bar{\varphi}_{i j k}}^{\bar{\varphi}_{i j k}^{z}} d_{i j k}\left(\frac{\sigma_{k}}{\sigma_{k}-1} \frac{\tau_{i j k}}{\varphi}\right)^{1-\sigma_{k}} d G(\varphi)\right)^{\frac{1}{1-\sigma_{k}}} \\
& =\left(d_{i j k}\right)^{\frac{1}{1-\sigma_{k}}}\left(\frac{\sigma_{k}}{\sigma_{k}-1} \tau_{i j k}\right)\left(\frac{\xi_{k}}{\xi_{k}-\left(\sigma_{k}-1\right)} \frac{1-w_{i j k}^{1-\frac{\sigma_{k}-1}{\xi_{k}}}}{1-w_{i j k}}\right)^{\frac{1}{1-\sigma_{k}}}\left(\bar{\varphi}_{i j k}\right)^{-1} .
\end{aligned}
$$


Firms producing the standardized variety. Their price index is defined as

$$
\begin{aligned}
\tilde{p}_{i j k}^{z} & =\left(\left(1-G\left(\bar{\varphi}_{i j k}^{z}\right)\right)^{-1} \int_{\bar{\varphi}_{i j k}^{Z}}^{\infty} d_{i j k}^{z}\left(\frac{\sigma_{k}}{\sigma_{k}-1} \frac{\tau_{i j k}^{z} z_{i j k}^{t_{k}-1}}{\varphi}\right)^{1-\sigma_{k}} d G(\varphi)\right)^{\frac{1}{1-\sigma_{k}}} \\
& =\left(d_{i j k}^{z}\right)^{\frac{1}{1-\sigma_{k}}}\left(\frac{\sigma_{k}}{\sigma_{k}-1} \tau_{i j k}^{z} z_{i j k}^{t_{k}-1}\right)\left(\frac{\xi_{k}}{\xi_{k}-\left(\sigma_{k}-1\right)}\right)^{\frac{1}{1-\sigma_{k}}}\left(\bar{\varphi}_{i j k} w_{i j k}^{-\frac{1}{\xi_{k}}}\right)^{-1} .
\end{aligned}
$$

Overall price index. Substituting for the price indices, we get

$$
P_{i j k}=\left(\left(1-G\left(\bar{\varphi}_{i j k}\right)\right) M_{i k}\right)^{\frac{1}{1-\sigma_{k}}}\left(\bar{\varphi}_{i j k}\right)^{-1}\left(\frac{\sigma_{k}}{\sigma_{k}-1} \tau_{i j k}\right)\left(\frac{\xi_{k} s_{i j k}}{\xi_{k}-\left(\sigma_{k}-1\right)}\right)^{\frac{1}{1-\sigma_{k}}},
$$

where

$$
s_{i j k}=\left(1-w_{i j k}^{1-\frac{\sigma_{k}-1}{\xi}}+w_{i j k}^{1-\frac{\sigma_{k}-1}{\xi}} \triangle_{i j k}^{d}\left(\triangle_{i j k}^{\tau}\right)^{1-\sigma_{k}} z_{i j k}^{\left(1-t_{k}\right)\left(\sigma_{k}-1\right)}\right) .
$$

Substitute for the cut-off $\bar{\varphi}_{i j k}$ :

$$
P_{i j k} M_{i k}^{\frac{1}{\sigma_{k}-1}}\left(\frac{\sigma_{k}}{\sigma_{k}-1} \tau_{i j k}\left(\frac{\sigma_{k} f_{i j k}}{d_{i j k} A_{i j k}}\right)^{\frac{1}{\sigma_{k}-1}}\right)^{1-\frac{\xi_{k}}{\sigma_{k}-1}}=\left(\frac{\sigma_{k}}{\sigma_{k}-1} \tau_{i j k}\right)\left(\frac{\xi_{k} s_{i j k}}{\xi_{k}-\left(\sigma_{k}-1\right)}\right)^{\frac{1}{1-\sigma_{k}}}
$$

and substitute for $A_{i j k}=P_{i j k}^{\sigma_{k}-\gamma_{k}} A_{j k}$ to take into account that the cut-off depends on the price index:

$$
\begin{aligned}
& M_{i k}^{\frac{1}{\sigma_{k}-1}}\left(\frac{\sigma_{k}}{\sigma_{k}-1} \tau_{i j k}\left(\frac{\sigma_{k} f_{i j k}}{d_{i j k} A_{j k}}\right)^{\frac{1}{\sigma_{k}-1}}\right)^{1-\frac{\xi_{k}}{\sigma_{k}-1}} P_{i j k}^{1-\frac{\sigma_{k}-\gamma_{k}}{\sigma_{k}-1}\left(1-\frac{\xi_{k}}{\sigma_{k}-1}\right)} \\
& =\left(\frac{\sigma_{k}}{\sigma_{k}-1} \tau_{i j k}\right)\left(\frac{\xi_{k} s_{i j k}}{\xi_{k}-\left(\sigma_{k}-1\right)}\right)^{\frac{1}{1-\sigma_{k}}} .
\end{aligned}
$$

Simplifying, we get the price index as a function of the weights, fixed costs, variable trade costs as well as exporter and importer industry-specific fixed effects $\left(M_{i k}\right.$ and $\left.A_{j k}\right)$ :

$$
P_{i j k}=\left(\frac{1}{M_{i k}}\left(\frac{\sigma_{k} f_{i j k}}{d_{i j k} A_{j k}}\right)^{\left(\sigma_{k}-1\right)-\xi_{k}}\left(\frac{\sigma_{k} \tau_{i j k}}{\sigma_{k}-1}\right)^{\xi_{k}}\left(\frac{\xi_{k}-\left(\sigma_{k}-1\right)}{\xi_{k} s_{i j k}}\right)\right)^{\frac{\left(\sigma_{k}-1\right)}{\left(\sigma_{k}-1\right)^{2}-\left(\gamma_{k}-\sigma_{k}\right)\left(\xi_{k}-\left(\sigma_{k}-1\right)\right)}}
$$

\section{Decomposition of the intensive margin}

The price index is defined as

$$
P_{i j k}=\left(\left(1-G\left(\bar{\varphi}_{i j k}\right)\right) M_{i k}\right)^{\frac{1}{1-\sigma_{k}}} \frac{\sigma_{k}}{\sigma_{k}-1} \frac{\tau_{i j k}}{\bar{\varphi}_{i j k}}\left(\frac{\xi_{k} s_{i j k}}{\xi_{k}-\left(\sigma_{k}-1\right)}\right)^{\frac{1}{1-\sigma_{k}}} .
$$


The average price is

$$
\begin{aligned}
\tilde{p}_{i j k} & =\frac{\sigma_{k}}{\sigma_{k}-1} \frac{\tau_{i j k}}{\bar{\varphi}_{i j k}}\left(\frac{\xi_{k} s_{i j k}}{\xi-\left(\sigma_{k}-1\right)}\right)^{\frac{1}{1-\sigma_{k}}} \\
& =\left(\frac{\sigma_{k} f_{i j k}}{d_{i j k} A_{i j k}}\right)^{\frac{1}{1-\sigma_{k}}}\left(\frac{\xi_{k} s_{i j k}}{\xi_{k}-\left(\sigma_{k}-1\right)}\right)^{\frac{1}{1-\sigma_{k}}} .
\end{aligned}
$$

The average quantity is the intensive margin divided by the average price:

$$
\begin{aligned}
\tilde{c}_{i j k}=\frac{\bar{x}_{i j k}}{\tilde{p}_{i j k}} & =\frac{\frac{\xi_{k}}{\xi_{k}-\left(\sigma_{k}-1\right)} \sigma_{k} f_{i j k} s_{i j k}}{\left(\frac{\xi_{k}}{\xi_{k}-\left(\sigma_{k}-1\right)}\right)^{\frac{1}{1-\sigma_{k}}}\left(\frac{\sigma_{k} f_{i j k}}{d_{i j k} A_{i j k}}\right)^{\frac{1}{1-\sigma_{k}}} s_{i j k}^{\frac{1}{1-\sigma_{k}}}} \\
& =\left(\frac{\xi_{k} \sigma_{k} f_{i j k}}{\xi_{k}-\left(\sigma_{k}-1\right)}\right)^{\frac{\sigma_{k}}{\sigma_{k}-1}}\left(d_{i j k} A_{i j k}\right)^{\frac{1}{1-\sigma_{k}}} s_{i j k}^{\frac{\sigma_{k}}{\sigma_{k}-1}}
\end{aligned}
$$

Derivatives w.r.t. $z_{i j k}$

Extensive margin:

$$
\begin{aligned}
& M_{i j k}=\bar{\varphi}_{i j k}{ }^{-\xi_{k}} M_{i k}=\left(\frac{\sigma_{k}}{\sigma_{k}-1} \tau_{i j k}\right)^{-\xi_{k}}\left(\frac{\sigma_{k} f_{i j k}}{d_{i j k} A_{i j k}}\right)^{\frac{-\xi_{k}}{\sigma_{k}-1}} M_{i k} \\
& \frac{\partial \log \left(\bar{\varphi}_{i j k}\right)^{-\xi_{k}}}{\partial \log z_{i j k}}=-\frac{\xi_{k}\left(\gamma_{k}-\sigma_{k}\right)}{\sigma_{k}-1} \frac{\partial \log P_{i j k}}{\partial \log z_{i j k}}
\end{aligned}
$$

Intensive margin:

$$
\begin{aligned}
& \bar{x}_{i j k}=\frac{\xi_{k} \sigma_{k} f_{i j k}}{\xi_{k}-\left(\sigma_{k}-1\right)} s_{i j k} \\
& \frac{\partial \log \bar{x}_{i j k}}{\partial \log z_{i j k}}=\frac{\partial \log s_{i j k}}{\partial \log z_{i j k}}
\end{aligned}
$$

Average price:

$$
\begin{aligned}
& \tilde{p}_{i j k}=\left(\frac{\sigma_{k} f_{i j k}}{d_{i j k} P_{i j k}^{\sigma_{k}-\gamma_{k}} A_{j k}}\right)^{\frac{1}{1-\sigma_{k}}}\left(\frac{\xi_{k} s_{i j k}}{\xi_{k}-\left(\sigma_{k}-1\right)}\right)^{\frac{1}{1-\sigma_{k}}} \\
& \frac{\partial \log \tilde{p}_{i j k}}{\partial \log z_{i j k}}=-\frac{\gamma_{k}-\sigma_{k}}{\sigma_{k}-1} \frac{\partial \log P_{i j k}}{\partial \log z_{i j k}}-\frac{1}{\sigma_{k}-1} \frac{\partial \log s_{i j k}}{\partial \log z_{i j k}}
\end{aligned}
$$


Average quantity:

$$
\begin{aligned}
& \tilde{c}_{i j k}=\left(\frac{\xi_{k} \sigma_{k} f_{i j k}}{\xi_{k}-\left(\sigma_{k}-1\right)}\right)^{\frac{\sigma_{k}}{\sigma_{k}-1}}\left(d_{i j k} P_{i j k}^{\sigma_{k}-\gamma_{k}} A_{i k}\right)^{\frac{1}{1-\sigma_{k}}} s_{i j k}^{\frac{\sigma_{k}}{\sigma_{k}-1}} \\
& \frac{\partial \log \tilde{c}_{i j k}}{\partial \log z_{i j k}}=\frac{\gamma_{k}-\sigma_{k}}{\sigma_{k}-1} \frac{\partial \log P_{i j k}}{\partial \log z_{i j k}}+\frac{\sigma_{k}}{\sigma_{k}-1} \frac{\partial \log s_{i j k}}{\partial \log z_{i j k}}
\end{aligned}
$$

Derivative of the price index:

$$
\begin{aligned}
& P_{i j k}=\left(\frac{1}{M_{i k}}\left(\frac{\sigma_{k} f_{i j k}}{A_{j k}}\right)^{\left(\sigma_{k}-1\right)-\xi_{k}}\left(\frac{\sigma_{k} \tau_{i j k}}{\sigma_{k}-1}\right)^{\xi_{k}}\left(\frac{\xi_{k}-\left(\sigma_{k}-1\right)}{\xi_{k} s_{i j k}}\right)\right)^{\frac{\left(\sigma_{k}-1\right)}{\left(\sigma_{k}-1\right)^{2}-\left(\gamma_{k}-\sigma_{k}\right)\left(\xi_{k}-\left(\sigma_{k}-1\right)\right)}} \\
& \frac{\partial \log P_{i j k}}{\partial \log z_{i j k}}=\frac{-\left(\sigma_{k}-1\right)}{\left(\sigma_{k}-1\right)^{2}-\left(\gamma_{k}-\sigma_{k}\right)\left(\xi_{k}-\left(\sigma_{k}-1\right)\right)} \frac{\partial \log s_{i j k}}{\partial \log z_{i j k}}
\end{aligned}
$$

For the denominator to be positive, we assume that $\left(\sigma_{k}-1\right)^{2}>\left(\gamma_{k}-\sigma_{k}\right)\left(\xi_{k}-\left(\sigma_{k}-1\right)\right)$. A positive denominator nests the case of monopolistic competition as in Melitz (2003) and Chaney (2008), where $\gamma_{k}=\sigma_{k}$.

Derivative of the weight $w_{i j k}$ :

$$
\begin{aligned}
w_{i j k}= & \left(\frac{\sigma_{k}\left(\frac{z_{i j k}^{a_{k}}}{f_{i j k}}+\triangle_{i j k}^{f}-1\right)}{\triangle_{i j k}^{d}\left(\triangle_{i j k}^{\tau}\right)^{1-\sigma_{k}} z_{i j k}^{\left(\sigma_{k}-1\right)\left(1-t_{k}\right)}-1}\right)^{\frac{-\xi_{k}}{\sigma_{k}-1}} \\
\frac{\partial \log w_{i j k}}{\partial \log z_{i j k}}= & \frac{-\xi_{k}}{\sigma_{k}-1} \\
& \left(\frac{a_{k} z_{i j k}^{a_{k}}}{z_{i j k}^{a_{k}}+f_{i j k}^{z}-f_{i j k}}-\left(\sigma_{k}-1\right)\left(1-t_{k}\right) \frac{\triangle_{i j k}^{d}\left(\triangle_{i j k}^{\tau}\right)^{1-\sigma_{k}} z_{i j k}^{\left(\sigma_{k}-1\right)\left(1-t_{k}\right)}}{\triangle_{i j k}^{d}\left(\triangle_{i j k}^{\tau}\right)^{1-\sigma_{k}} z_{i j k}^{\left(\sigma_{k}-1\right)\left(1-t_{k}\right)}-1}\right)
\end{aligned}
$$

Derivative of $s_{i j k}$ :

$$
s_{i j k}=1-w_{i j k}^{1-\frac{\sigma_{k}-1}{\xi_{k}}}+w_{i j k}^{1-\frac{\sigma_{k}-1}{\xi_{k}}} \triangle_{i j k}^{d}\left(\triangle_{i j k}^{\tau}\right)^{1-\sigma_{k}} z_{i j k}^{\left(\sigma_{k}-1\right)\left(1-t_{k}\right)}
$$




$$
\begin{aligned}
\frac{\partial \log s_{i j k}}{\partial \log z_{i j k}}= & \frac{\left(1-\frac{\sigma_{k}-1}{\xi_{k}}\right) w_{i j k}^{1-\frac{\sigma_{k}-1}{\xi_{k}}}\left(\triangle_{i j k}^{d}\left(\triangle_{i j k}^{\tau}\right)^{1-\sigma_{k}} z_{i j k}^{\left(\sigma_{k}-1\right)\left(1-t_{k}\right)}-1\right)}{1+w_{i j k}^{1-\frac{\sigma_{k}-1}{\xi_{k}}}\left(\triangle_{i j k}^{d}\left(\triangle_{i j k}^{\tau}\right)^{1-\sigma_{k}} z_{i j k}^{\left(\sigma_{k}-1\right)\left(1-t_{k}\right)}-1\right)} \frac{\partial \log w_{i j k}}{\partial \log z_{i j k}} \\
& +\frac{w_{i j k}^{1-\frac{\sigma_{k}-1}{\xi_{k}}}\left(1-t_{k}\right)\left(\sigma_{k}-1\right) \triangle_{i j k}^{d}\left(\triangle_{i j k}^{\tau}\right)^{1-\sigma_{k}} z_{i j k}^{\left(\sigma_{k}-1\right)\left(1-t_{k}\right)}}{1+w_{i j k}^{1-\frac{\sigma_{k}-1}{\xi_{k}}}\left(\triangle_{i j k}^{d}\left(\triangle_{i j k}^{\tau}\right)^{1-\sigma_{k}} z_{i j k}^{\left(\sigma_{k}-1\right)\left(1-t_{k}\right)}-1\right)}
\end{aligned}
$$

Note that the numerator is positive because $z_{i j k}>1$ and $\triangle_{i j k}^{d}\left(\triangle_{i j k}^{\tau}\right)^{1-\sigma_{k}}>1$.

In the paper, we ask how an increase in $z_{i j k}$ affects the margins of trade absent any harmonization effects, i.e. $\triangle_{i j k}^{f}=\triangle_{i j k}^{d}=\triangle_{i j k}^{\tau}=0$. This simplifies equations 71 and 73 :

$$
\begin{aligned}
& \frac{\partial \log w_{i j k}}{\partial \log z_{i j k}}=\frac{-\xi_{k}}{\sigma_{k}-1}\left(a_{k}-\left(\sigma_{k}-1\right)\left(1-t_{k}\right) \frac{z_{i j k}^{\left(\sigma_{k}-1\right)\left(1-t_{k}\right)}}{z_{i j k}^{\left(\sigma_{k}-1\right)\left(1-t_{k}\right)}-1}\right) \\
& \frac{\partial \log s_{i j k}}{\partial \log z_{i j k}}=\frac{\left(1-\frac{\sigma_{k}-1}{\xi_{k}}\right) w_{i j k}^{1-\frac{\sigma_{k}-1}{\xi_{k}}}\left(z_{i j k}^{\left(\sigma_{k}-1\right)\left(1-t_{k}\right)}-1\right)}{1+w_{i j k}^{1-\frac{\sigma_{k}-1}{\xi_{k}}}\left(z_{i j k}^{\left(\sigma_{k}-1\right)\left(1-t_{k}\right)}-1\right)} \frac{\partial \log w_{i j k}}{\partial \log z_{i j k}} \\
& +\frac{w_{i j k}^{1-\frac{\sigma_{k}-1}{\xi_{k}}}\left(1-t_{k}\right)\left(\sigma_{k}-1\right) z_{i j k}^{\left(\sigma_{k}-1\right)\left(1-t_{k}\right)}}{1+w_{i j k}^{1-\frac{\sigma_{k}-1}{\xi_{k}}}\left(z_{i j k}^{\left(\sigma_{k}-1\right)\left(1-t_{k}\right)}-1\right)}
\end{aligned}
$$

To check whether the derivative of $s_{i j k}$ is negative, the following condition must be satisfied (i.e. the composition effect of shifting the weight must be stronger than the direct effect of increasing $\left.z_{i j k}\right)$ :

$$
\left(1-t_{k}\right)\left(\sigma_{k}-1\right) z_{i j k}^{\left(\sigma_{k}-1\right)\left(1-t_{k}\right)}<-\left(1-\frac{\sigma_{k}-1}{\xi_{k}}\right)\left(z_{i j k}^{\left(\sigma_{k}-1\right)\left(1-t_{k}\right)}-1\right) \frac{\partial \log w_{i j k}}{\partial \log z_{i j k}}
$$

We can substitute for $\frac{\partial \log w_{i j k}}{\partial \log z_{i j k}}$ and obtain the following inequality:

$$
\begin{aligned}
\left(1-t_{k}\right)\left(\sigma_{k}-1\right) z_{i j k}^{\left(\sigma_{k}-1\right)\left(1-t_{k}\right)}< & \frac{\xi_{k}}{\sigma_{k}-1}\left(1-\frac{\sigma_{k}-1}{\xi_{k}}\right)\left(z_{i j k}^{\left(\sigma_{k}-1\right)\left(1-t_{k}\right)}-1\right) \\
& \left(a_{k}-\left(\sigma_{k}-1\right)\left(1-t_{k}\right) \frac{z_{i j k}^{\left(\sigma_{k}-1\right)\left(1-t_{k}\right)}}{z_{i j k}^{\left(\sigma_{k}-1\right)\left(1-t_{k}\right)}-1}\right)
\end{aligned}
$$

We can simplify the previous equation:

$$
\frac{\xi_{k}\left(1-t_{k}\right)\left(\sigma_{k}-1\right)}{a_{k}\left(\xi_{k}-\left(\sigma_{k}-1\right)\right)}<\frac{z_{i j k}^{\left(\sigma_{k}-1\right)\left(1-t_{k}\right)}-1}{z_{i j k}^{\left(\sigma_{k}-1\right)\left(1-t_{k}\right)}}
$$

This condition is satisfied for high values of the sunk investment cost parameter $a_{k}$ as well as high values of the marginal cost parameter $t_{k}$. High values of these parameters disincentivize the investment into the standard and lead to a smaller weight $w_{i j k}$ and a 
decrease in $s_{i j k}$. As a consequence, the extensive margin decreases:

$$
\frac{\partial \log s_{i j k}}{\partial \log z_{i j k}}<0 \text { implies } \frac{\partial \log P_{i j k}}{\partial \log z_{i j k}}>0 \text { and therefore } \frac{\partial \log M_{i j k}}{\partial \log z_{i j k}}<0
$$

The derivative with respect to average prices is given by

$$
\begin{aligned}
\frac{\partial \log \tilde{p}_{i j k}}{\partial \log z_{i j k}} & =-\frac{\gamma_{k}-\sigma_{k}}{\sigma_{k}-1} \frac{\partial \log P_{i j k}}{\partial \log z_{i j k}}-\frac{1}{\sigma_{k}-1} \frac{\partial \log s_{i j k}}{\partial \log z_{i j k}} \\
& =\frac{\xi\left(\gamma_{k}-\sigma_{k}\right)-\left(\sigma_{k}-1\right)^{2}}{\left(\sigma_{k}-1\right)\left[\left(\sigma_{k}-1\right)^{2}-\left(\gamma_{k}-\sigma_{k}\right)\left(\xi_{k}-\left(\sigma_{k}-1\right)\right)\right]} \frac{\partial \log s_{i j k}}{\partial \log z_{i j k}} .
\end{aligned}
$$

The derivative with respect to average quantities is given by

$$
\begin{aligned}
\frac{\partial \log \tilde{c}_{i j k}}{\partial \log z_{i j k}}= & \frac{\gamma_{k}-\sigma_{k}}{\sigma_{k}-1} \frac{\partial \log P_{i j k}}{\partial \log z_{i j k}}+\frac{\sigma_{k}}{\sigma_{k}-1} \frac{\partial \log s_{i j k}}{\partial \log z_{i j k}} \\
& =\frac{-\xi\left(\gamma_{k}-\sigma_{k}\right) \sigma_{k}+\gamma_{k}\left(\sigma_{k}-1\right)^{2}}{\left(\sigma_{k}-1\right)\left[\left(\sigma_{k}-1\right)^{2}-\left(\gamma_{k}-\sigma_{k}\right)\left(\xi_{k}-\left(\sigma_{k}-1\right)\right)\right]} \frac{\partial \log s_{i j k}}{\partial \log z_{i j k}}
\end{aligned}
$$

If we assume $\left(\sigma_{k}-1\right)^{2}>\xi\left(\gamma_{k}-\sigma_{k}\right)$, then we have

$$
\frac{\partial \log s_{i j k}}{\partial \log z_{i j k}}<0 \text { and therefore } \frac{\partial \log \tilde{p}_{i j k}}{\partial \log z_{i j k}}>0 \text { and } \frac{\partial \log \tilde{c}_{i j k}}{\partial \log z_{i j k}}<0 .
$$

\section{Derivatives w.r.t. the wedges $\left(\triangle_{i j k}^{f}, \triangle_{i j k}^{d}\right.$ and $\left.\triangle_{i j k}^{\tau}\right)$}

The gravity margin is given by

$$
\begin{aligned}
X_{i j k}= & \underbrace{\left(\frac{\sigma_{k}}{\sigma_{k}-1} \tau_{i j k}\left(\frac{\sigma_{k} f_{i j k}}{A_{i j k}}\right)^{\frac{1}{\sigma_{k}-1}}\right)^{-\xi_{k}} M_{i k}}_{\text {Extensive margin }} \\
& \underbrace{\Gamma_{1 k} f_{i j k}\left(1-w_{i j k}^{1-\frac{\sigma_{k}-1}{\xi_{k}}}+w_{i j k}^{1-\frac{\sigma_{k}-1}{\xi_{k}}} \triangle_{i j k}^{d}\left(\triangle_{i j k}^{\tau}\right)^{1-\sigma_{k}} z_{i j k}^{\left(\sigma_{k}-1\right)\left(1-t_{k}\right)}\right)}_{\text {Intensive margin }} .
\end{aligned}
$$

The share of firms producing the standardized variety is

$$
w_{i j k}=\left(\frac{\sigma_{k}\left(\frac{z_{i j k}^{a_{k}}}{f_{i j k}}+\triangle_{i j k}^{f}-1\right)}{\triangle_{i j k}^{d}\left(\triangle_{i j k}^{\tau}\right)^{1-\sigma_{k}}\left(z_{i j k}^{\left(\sigma_{k}-1\right)\left(1-t_{k}\right)}-1\right)}\right)^{\frac{-\xi_{k}}{\sigma_{k}-1}}
$$


and the corresponding expressions for the average quantity and price of firms

$$
\begin{aligned}
\tilde{p}_{i j k}= & \Gamma_{2, k}\left(d_{i j k} A_{i j k}\right)^{\frac{1}{\sigma_{k}-1}} f_{i j k}^{\frac{1}{1-\sigma_{k}}} \\
& \left(1-w_{i j k}^{1-\frac{\sigma_{k}-1}{\xi_{k}}}+w_{i j k}^{1-\frac{\sigma_{k}-1}{\xi_{k}}} \triangle_{i j k}^{d}\left(\triangle_{i j k}^{\tau}\right)^{1-\sigma_{k}} z_{i j k}^{\left(1-t_{k}\right)\left(\sigma_{k}-1\right)}\right)^{\frac{1}{1-\sigma_{k}}} \\
\tilde{c}_{i j k}= & \Gamma_{3, k}\left(d_{i j k} A_{i j k}\right)^{\frac{1}{1-\sigma_{k}}} f_{i j k}^{\frac{\sigma_{k}}{\sigma_{k}-1}} \\
& \left(1-w_{i j k}^{1-\frac{\sigma_{k}-1}{\xi_{k}}}+w_{i j k}^{1-\frac{\sigma_{k}-1}{\xi_{k}}} \triangle_{i j k}^{d}\left(\triangle_{i j k}^{\tau}\right)^{1-\sigma_{k}} z_{i j k}^{\left(1-t_{k}\right)\left(\sigma_{k}-1\right)}\right)^{\frac{\sigma_{k}}{\sigma_{k}-1}} .
\end{aligned}
$$

Derivatives w.r.t. $\triangle_{i j k}^{d}$

The derivatives of the extensive margin depend on the price index:

$$
\frac{\partial \log \left(\bar{\varphi}_{i j k}\right)^{-\xi_{k}}}{\partial \log \triangle_{i j k}^{d}}=-\frac{\xi_{k}\left(\gamma_{k}-\sigma_{k}\right)}{\sigma_{k}-1} \frac{\partial \log P_{i j k}}{\partial \log \triangle_{i j k}^{d}}
$$

Derivative of the price index:

$$
\frac{\partial \log P_{i j k}}{\partial \log \triangle_{i j k}^{d}}=\frac{-\left(\sigma_{k}-1\right)}{\left(\sigma_{k}-1\right)^{2}-\left(\gamma_{k}-\sigma_{k}\right)\left(\xi_{k}-\left(\sigma_{k}-1\right)\right)} \frac{\partial \log s_{i j k}}{\partial \log \triangle_{i j k}^{d}}
$$

Derivative of the weight $w_{i j k}$ :

$$
\frac{\partial \log w_{i j k}}{\partial \log \triangle_{i j k}^{d}}=\frac{-\xi_{k}}{\sigma_{k}-1}\left(-\frac{\triangle_{i j k}^{d}\left(\triangle_{i j k}^{\tau}\right)^{1-\sigma_{k}} z_{i j k}^{\left(\sigma_{k}-1\right)\left(1-t_{k}\right)}}{\triangle_{i j k}^{d}\left(\triangle_{i j k}^{\tau}\right)^{1-\sigma_{k}} z_{i j k}^{\left(\sigma_{k}-1\right)\left(1-t_{k}\right)}-1}\right)>0
$$

An increase in demand increases the share of firms that produce the standardized good. Derivative of $s_{i j k}$ :

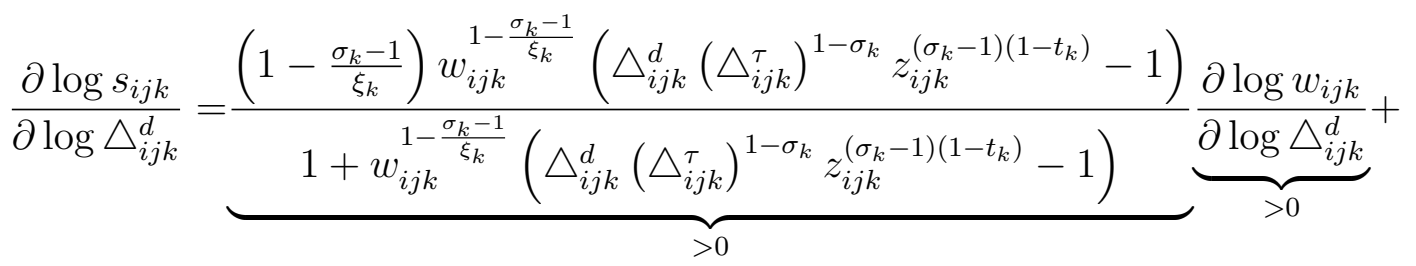

$$
\begin{aligned}
& +\underbrace{\frac{w_{i j k}^{1-\frac{\sigma_{k}-1}{\xi_{k}}}}{\triangle_{i j k}^{d}\left(\triangle_{i j k}^{\tau}\right)^{1-\sigma_{k}} z_{i j k}^{\left(\sigma_{k}-1\right)\left(1-t_{k}\right)}}}_{>0}>0
\end{aligned}
$$

Note that the numerator is positive. This implies that the extensive margin is increasing because

$$
\frac{\partial \log s_{i j k}}{\partial \log \triangle_{i j k}^{d}}>0 \text { implies } \frac{\partial \log P_{i j k}}{\partial \log \triangle_{i j k}^{d}}<0 \text { and therefore } \frac{\partial \log M_{i j k}}{\partial \log \triangle_{i j k}^{d}}>0 .
$$


The derivative of the intensive margin is given by

$$
\frac{\partial \log \bar{x}_{i j k}}{\partial \log \triangle_{i j k}^{d}}=\frac{\partial \log s_{i j k}}{\partial \log \triangle_{i j k}^{d}}>0
$$

The derivative of the average price is

$$
\frac{\partial \log \tilde{p}_{i j k}}{\partial \log \triangle_{i j k}^{d}}=-\frac{\gamma_{k}-\sigma_{k}}{\sigma_{k}-1} \frac{\partial \log P_{i j k}}{\partial \log \triangle_{i j k}^{d}}-\frac{1}{\sigma_{k}-1} \frac{\partial \log s_{i j k}}{\partial \log \triangle_{i j k}^{d}}<0 .
$$

The derivative of the average quantity is

$$
\frac{\partial \log \tilde{c}_{i j k}}{\partial \log \triangle_{i j k}^{d}}=\frac{\gamma_{k}-\sigma_{k}}{\sigma_{k}-1} \frac{\partial \log P_{i j k}}{\partial \log \triangle_{i j k}^{d}}+\frac{\sigma_{k}}{\sigma_{k}-1} \frac{\partial \log s_{i j k}}{\partial \log \triangle_{i j k}^{d}}>0 .
$$

Derivatives w.r.t. $\triangle_{i j k}^{\tau}$

The derivatives of the extensive margin depend on the price index:

$$
\frac{\partial \log \left(\bar{\varphi}_{i j k}\right)^{-\xi_{k}}}{\partial \log \triangle_{i j k}^{\tau}}=-\frac{\xi_{k}\left(\gamma_{k}-\sigma_{k}\right)}{\sigma_{k}-1} \frac{\partial \log P_{i j k}}{\partial \log \triangle_{i j k}^{\tau}}
$$

Derivative of the price index:

$$
\frac{\partial \log P_{i j k}}{\partial \log \triangle_{i j k}^{\tau}}=\frac{-\left(\sigma_{k}-1\right)}{\left(\sigma_{k}-1\right)^{2}-\left(\gamma_{k}-\sigma_{k}\right)\left(\xi_{k}-\left(\sigma_{k}-1\right)\right)} \frac{\partial \log s_{i j k}}{\partial \log \triangle_{i j k}^{\tau}}
$$

Derivative of the weight $w_{i j k}$ :

$$
\frac{\partial \log w_{i j k}}{\partial \log \triangle_{i j k}^{\tau}}=\frac{-\xi_{k}}{\sigma_{k}-1}\left(\left(\sigma_{k}-1\right) \frac{\triangle_{i j k}^{\tau}\left(\triangle_{i j k}^{\tau}\right)^{1-\sigma_{k}} z_{i j k}^{\left(\sigma_{k}-1\right)\left(1-t_{k}\right)}}{\triangle_{i j k}^{\tau}\left(\triangle_{i j k}^{\tau}\right)^{1-\sigma_{k}} z_{i j k}^{\left(\sigma_{k}-1\right)\left(1-t_{k}\right)}-1}\right)<0
$$

Derivative of $s_{i j k}$ :

$$
\begin{aligned}
& \frac{\partial \log s_{i j k}}{\partial \log \triangle_{i j k}^{\tau}}=\frac{\left(1-\frac{\sigma_{k}-1}{\xi_{k}}\right) w_{i j k}^{1-\frac{\sigma_{k}-1}{\xi_{k}}}\left(\triangle_{i j k}^{d}\left(\triangle_{i j k}^{\tau}\right)^{1-\sigma_{k}} z_{i j k}^{\left(\sigma_{k}-1\right)\left(1-t_{k}\right)}-1\right)}{1+w_{i j k}^{1-\frac{\sigma_{k}-1}{\xi_{k}}}\left(\triangle_{i j k}^{d}\left(\triangle_{i j k}^{\tau}\right)^{1-\sigma_{k}} z_{i j k}^{\left(\sigma_{k}-1\right)\left(1-t_{k}\right)}-1\right)} \frac{\partial \log w_{i j k}}{\partial \log \triangle_{i j k}^{\tau}}- \\
& -\frac{\left(\sigma_{k}-1\right) w_{i j k}^{1-\frac{\sigma_{k}-1}{\xi_{k}}} \triangle_{i j k}^{d}\left(\triangle_{i j k}^{\tau}\right)^{1-\sigma_{k}} z_{i j k}^{\left(\sigma_{k}-1\right)\left(1-t_{k}\right)}}{1+w_{i j k}^{1-\frac{\sigma_{k}-1}{\xi_{k}}}\left(\triangle_{i j k}^{d}\left(\triangle_{i j k}^{\tau}\right)^{1-\sigma_{k}} z_{i j k}^{\left(\sigma_{k}-1\right)\left(1-t_{k}\right)}-1\right)}<0
\end{aligned}
$$

Note that the numerator is positive. This implies that the extensive margin is decreasing because

$$
\frac{\partial \log s_{i j k}}{\partial \log \triangle_{i j k}^{\tau}}<0 \text { implies } \frac{\partial \log P_{i j k}}{\partial \log \triangle_{i j k}^{\tau}}>0 \text { and therefore } \frac{\partial \log M_{i j k}}{\partial \log \triangle_{i j k}^{\tau}}<0 .
$$


The derivative of the intensive margin is given by

$$
\frac{\partial \log \bar{x}_{i j k}}{\partial \log \triangle_{i j k}^{\tau}}=\frac{\partial \log s_{i j k}}{\partial \log \triangle_{i j k}^{\tau}}<0
$$

The derivative of the average price is

$$
\frac{\partial \log \tilde{p}_{i j k}}{\partial \log \triangle_{i j k}^{\tau}}=-\frac{\gamma_{k}-\sigma_{k}}{\sigma_{k}-1} \frac{\partial \log P_{i j k}}{\partial \log \triangle_{i j k}^{\tau}}-\frac{1}{\sigma_{k}-1} \frac{\partial \log s_{i j k}}{\partial \log \triangle_{i j k}^{\tau}}>0 .
$$

The derivative of the average quantity is

$$
\frac{\partial \log \tilde{c}_{i j k}}{\partial \log \triangle_{i j k}^{\tau}}=\frac{\gamma_{k}-\sigma_{k}}{\sigma_{k}-1} \frac{\partial \log P_{i j k}}{\partial \log \triangle_{i j k}^{\tau}}+\frac{\sigma_{k}}{\sigma_{k}-1} \frac{\partial \log s_{i j k}}{\partial \log \triangle_{i j k}^{\tau}}<0 .
$$

Derivatives w.r.t. $\triangle_{i j k}^{f}$

The derivatives of the extensive margin depend on the price index:

$$
\frac{\partial \log \left(\bar{\varphi}_{i j k}\right)^{-\xi_{k}}}{\partial \log \triangle_{i j k}^{f}}=-\frac{\xi_{k}\left(\gamma_{k}-\sigma_{k}\right)}{\sigma_{k}-1} \frac{\partial \log P_{i j k}}{\partial \log \triangle_{i j k}^{f}}
$$

Derivative of the price index:

$$
\frac{\partial \log P_{i j k}}{\partial \log \triangle_{i j k}^{f}}=\frac{-\left(\sigma_{k}-1\right)}{\left(\sigma_{k}-1\right)^{2}-\left(\gamma_{k}-\sigma_{k}\right)\left(\xi_{k}-\left(\sigma_{k}-1\right)\right)} \frac{\partial \log s_{i j k}}{\partial \log \triangle_{i j k}^{f}}
$$

Derivative of the weight $w_{i j k}$ :

$$
\frac{\partial \log w_{i j k}}{\partial \log \triangle_{i j k}^{f}}=\frac{-\xi_{k}}{\sigma_{k}-1}\left(\frac{\triangle_{i j k}^{f}}{\frac{z_{i j k}^{a}}{f_{i j k}}+\triangle_{i j k}^{f}-1}\right)<0
$$

Derivative of $s_{i j k}$ :

$$
\frac{\partial \log s_{i j k}}{\partial \log \triangle_{i j k}^{f}}=\frac{\left(1-\frac{\sigma_{k}-1}{\xi_{k}}\right) w_{i j k}^{1-\frac{\sigma_{k}-1}{\xi_{k}}}\left(\triangle_{i j k}^{d}\left(\triangle_{i j k}^{\tau}\right)^{1-\sigma_{k}} z_{i j k}^{\left(\sigma_{k}-1\right)\left(1-t_{k}\right)}-1\right)}{1+w_{i j k}^{1-\frac{\sigma_{k}-1}{\xi_{k}}}\left(\triangle_{i j k}^{d}\left(\triangle_{i j k}^{\tau}\right)^{1-\sigma_{k}} z_{i j k}^{\left(\sigma_{k}-1\right)\left(1-t_{k}\right)}-1\right)} \frac{\partial \log w_{i j k}}{\partial \log \triangle_{i j k}^{f}}
$$

Note that the numerator is positive. This implies that the extensive margin is decreasing because

$$
\frac{\partial \log s_{i j k}}{\partial \log \triangle_{i j k}^{f}}<0 \text { implies } \frac{\partial \log P_{i j k}}{\partial \log \triangle_{i j k}^{f}}>0 \text { and therefore } \frac{\partial \log M_{i j k}}{\partial \log \triangle_{i j k}^{f}}<0 .
$$


The derivative of the intensive margin is given by

$$
\frac{\partial \log \bar{x}_{i j k}}{\partial \log \triangle_{i j k}^{f}}=\frac{\partial \log s_{i j k}}{\partial \log \triangle_{i j k}^{f}}<0
$$

The derivative of the average price is

$$
\frac{\partial \log \tilde{p}_{i j k}}{\partial \log \triangle_{i j k}^{f}}=-\frac{\gamma_{k}-\sigma_{k}}{\sigma_{k}-1} \frac{\partial \log P_{i j k}}{\partial \log \triangle_{i j k}^{f}}-\frac{1}{\sigma_{k}-1} \frac{\partial \log s_{i j k}}{\partial \log \triangle_{i j k}^{f}}>0 .
$$

The average quantity is

$$
\frac{\partial \log \tilde{c}_{i j k}}{\partial \log \triangle_{i j k}^{f}}=\frac{\gamma_{k}-\sigma_{k}}{\sigma_{k}-1} \frac{\partial \log P_{i j k}}{\partial \log \triangle_{i j k}^{f}}+\frac{\sigma_{k}}{\sigma_{k}-1} \frac{\partial \log s_{i j k}}{\partial \log \triangle_{i j k}^{f}}<0 .
$$




\section{B Appendix: ICS}

Table 17: International classification of standards (ICS)

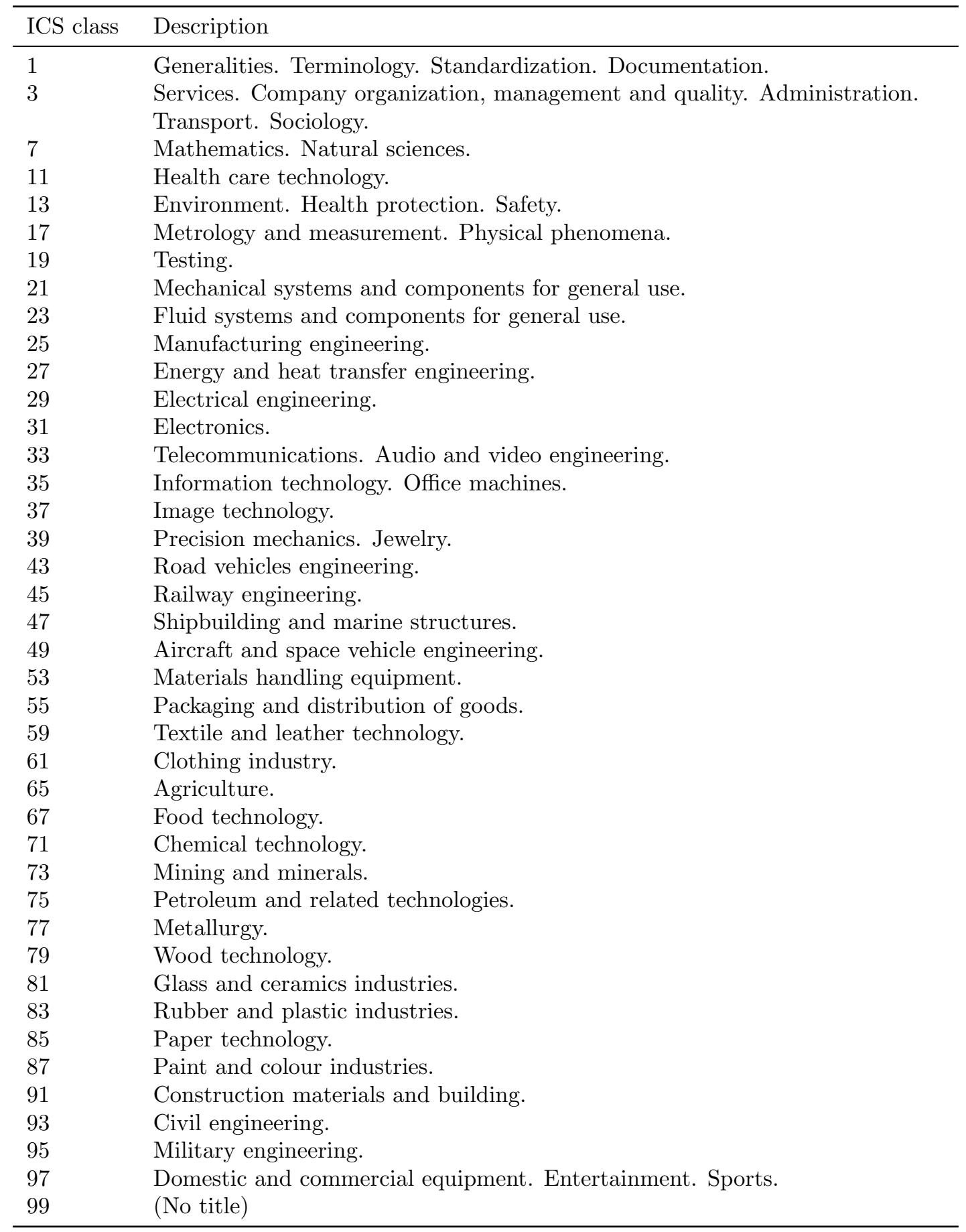

Source: ISO 


\section{Appendix: Database construction}

The original dataset comprises individual standards for which the date of release, the ICS class, the nationality of the standard-setting organization (SSO) as well as the duplicate versions in other SSOs are known ("links" to other standards). We denote these duplicates as "equivalences". The nationality of an SSO can either be a country ("national") or a European or international SSO ("international").

\section{Linking all equivalent standards to one another}

The original Perinorm dataset explicitly comprises a column where standard equivalences are listed; these essentially represent accreditations of a previously released standard by another SSO or the simultaneous release of a standard by more than one SSO. However, due to misreporting or chronological reporting, a single standard observation does not necessarily reveal all equivalences. In the case of chronological reporting, only equivalences known at the time of the release are listed and subsequent equivalences are only reported for newly released standards. For these reasons, one may for example encounter the following situation:

Table 18: Example of incomplete equivalences

\begin{tabular}{llll}
\hline Standard ID & Release date & Nationality of SSO & Equivalence \\
\hline A & $01 / 01 / 2000$ & FR & B \\
B & $05 / 06 / 2005$ & DE & A, C \\
C & $31 / 07 / 2012$ & FR & \\
D & $04 / 08 / 2008$ & AT & B \\
\hline
\end{tabular}

All four standards, A, B, C and D, are equivalent, but this is not obvious when examining standards individually due to the incompleteness of the equivalence listings (which is most likely due to the fact that they were recorded in chronological order, i.e. when standard B was released, standard D did not yet exist, which is why it is not explicitly listed under its equivalences). For the purpose of identifying the originating country, we need to have the full information on these equivalences to determine which of the standards A, B, C or D was first released (standard A in the above example), and thus represents the original standard. All other standards, B, C and D, are then classified as accreditations of standard A. ${ }^{35}$

We use graph theory to identify all standards that belong to one group by assigning them the same group identifier. ${ }^{36}$ In particular, we use the following breadth-first search algorithm (which we specifically adapt to the structure of the dataset) to connect all standards by exploring their equivalences:

\footnotetext{
${ }^{35}$ The accreditation of standard A due to the release of standard $\mathrm{C}$ is irrelevant information for our research question, as it concerns a within-country accreditation; we will thus drop the observation on standard $\mathrm{C}$ in the final dataset.

${ }^{36}$ We particularly thank François Farago for helping us with this procedure.
} 
1. Initialize the group identifier, equal to a standard's row number in the dataset, for each standard.

2. Starting with $n=1$, store the group identifier of standard $n$ in the database (i.e. A).

3. Add the group identifiers of the equivalent standards, i.e. B, to the vector of stored group identifiers.

4. Note the smallest element of the vector of stored group identifiers.

5. Modify the group identifiers of standard $n$ and its equivalent standards by assigning them the value identified in step 4 (i.e. A and B will have the same group identifier).

6. Delete the stored group identifiers.

7. Go on to the next standard $n+1$ and repeat from step 2 onwards.

In order to minimize the computing power needed to run the algorithm, we use a simple hash function to build a dictionary of all standards whose IDs, which are strings, are mapped one-to-one to numeric values.

\section{Identifying "originating country" and "accrediting country"}

Once all equivalent standards have been grouped together, we identify the "originating country" by the nationality of the SSO who first released the standard. The nationalities of SSOs who released equivalent standards at a later date are used to classify the "accrediting countries". As such, a standard should have one originating country and one or several accrediting countries.

However, it is also possible that two or more SSOs release a standard at the same date. ${ }^{37}$ International SSOs also constitute a "country" (country code "IX" in figure 7). If two countries each released a standard at the same time, the respective standard is counted both as an original standard as well as an accreditation. However, if an international SSO and a national SSO release a standard at the same time, we consider that this standard originated in the international SSO (as it is very likely that the national SSO is a member organization of the international SSO and simply accredits standards of the international SSO at the same date as the latter one releases the standard). If two national SSOs are releasing a standard at the same time, both nationalities are registered as originating and accrediting countries.

\footnotetext{
${ }^{37}$ This situation arises most obviously when the date of the release is exactly the same. However, for some standards, only the year of the release is known, and in this case, two standards with the same release year will also be considered to have been released at the same date despite the fact that we cannot rule out the possibility that they were released at different dates over the course of the same year.
} 


\section{Obtaining the relevant sub-sample}

We eliminate the following standards to obtain the relevant subsample of all standard harmonizations:

1. Standards that exist by themselves and are not linked to any other standard, meaning there is no other equivalent standard in the database.

2. Standards that constitute pure within-country accreditations or accreditations of a foreign standard after it was already accredited by another SSO of the same nationality.

3. Original national standards that were subsequently only released by SSOs of the same nationality.

Table 19: Procedure to define subset of data

\begin{tabular}{lr}
\hline Initial number of standards & 2148822 \\
Standards that are not linked to other standards (step 1) & 1026339 \\
Duplicate accreditations within one country (step 2) & 397678 \\
Remaining national standards (step 3) & 29081 \\
Remaining standards in database & 695724 \\
of which: original bilateral standards & 10541 \\
of which: accreditations of bilateral standards & 45493 \\
of which: by national SSOs & 39885 \\
of which: by international SSOs & 5608 \\
of which: original international standards & 98987 \\
of which: accreditations of international standards & 540703 \\
\hline
\end{tabular}

Figure 7 (a) displays the country distribution of the raw data. We note the strong representation of Austrian, German and US standards. Besides the non-excludable possibility that these countries are very active in the standard-setting process, this could be due to more comprehensive reporting for the SSOs of these countries as well as the duplicate release of the same standard within one country due to institutional practices. Figure 7 (b) displays the country distribution of the relevant subset for our analysis and shows that the dominance of Austrian, German and US standards vanishes in the subsample.

The data presented in figure 7 show that a large number of standards documents are released by international SSOs. A large amount of this international dimension of standard harmonization is due to the European integration process and the accompanying dominance of European SSOs among international SSOs. Table 20 lists the largest international SSOs (in terms of original standards). As their names reveal, many of these SSOs are European ones. However, it should be noted that many of these SSOs were founded as part of the European integration process, but also produce international standards and are comprised of non-European members (one such example is ETSI). 
Figure 7: Country distribution before and after cleaning

(a) Raw data

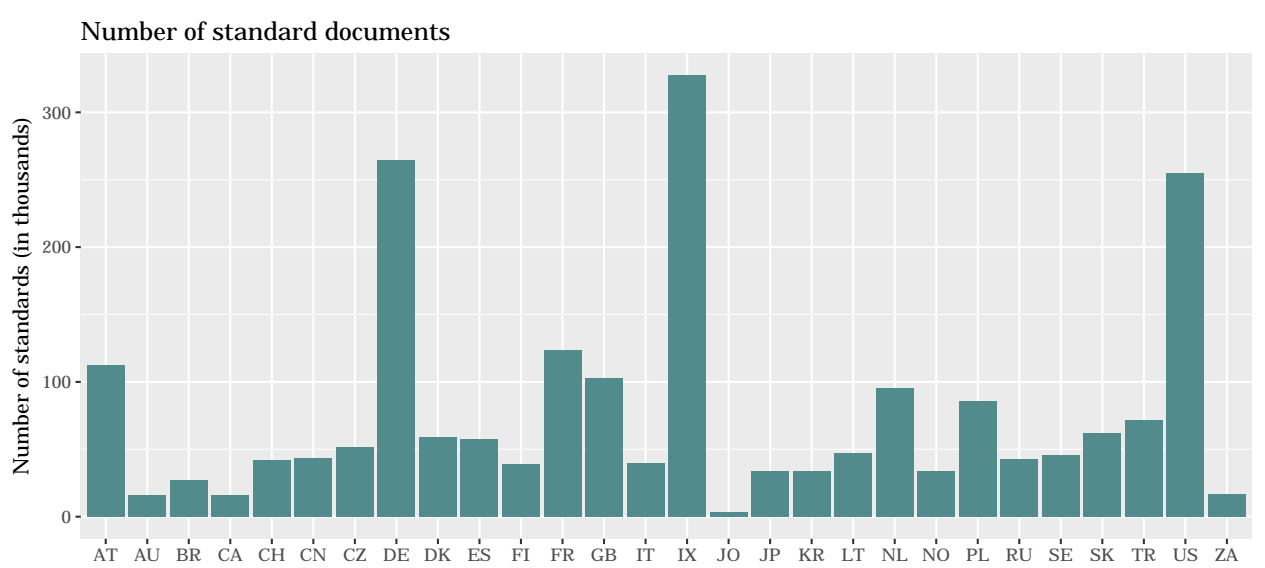

(b) Relevant subset

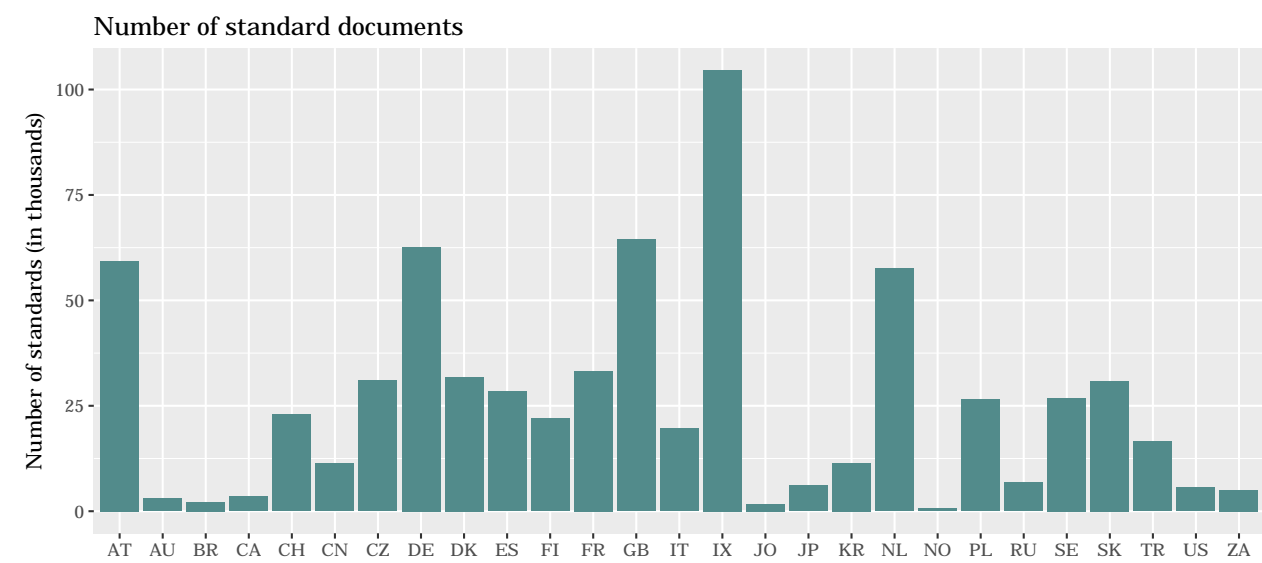

Notes: The figure displays the number of standards, broken down by the nationality of the respective SSO. The data are summed over the years 1960-2018 and all ICS classes. Panel a displays the distribution based on the original dataset, while panel $b$ displays the distribution after the data have been cleaned according to the criteria described in this appendix.

Table 20: Top ten international SSOs (release of original standards)

\begin{tabular}{lrr}
\hline SSO & Number & $\%$ \\
\hline CEN - European Committee for Standardization & 33276 & 33.6 \\
ISO - International Organization for Standardization & 28428 & 28.7 \\
IEC - International Electrotechnical Commission & 19158 & 19.4 \\
CENELEC - European Committee for Electrotechnical Standardization & 8762 & 8.9 \\
ETSI - European Telecommunications Standards Institute & 5643 & 5.7 \\
ASD - AeroSpace and Defence Industries Association of Europe & 1964 & 2.0 \\
ITU - International Telecommunication Union & 535 & 0.5 \\
ECMA - European Asso. for Standardizing Info. and Comm. Systems & 218 & 0.2 \\
ECSS - European Cooperation for Space Standardization & 122 & 0.1 \\
EC - European Communities/European Union & 110 & 0.1 \\
Other & 771 & 0.8 \\
\hline Sum & 98987 & 100 \\
\hline
\end{tabular}

Notes: The table displays the number of original standards of international SSOs, broken down by SSO. A standard can be released by more than one SSO per year and can thus be counted several times. The data are summed over the years 1960-2015 and all ICS classes. 


\section{Construction of identifiers for harmonization events}

A standard document can either be a national standard, meaning that it was released by a national SSO and never accredited by an SSO of another nationality (such as standards $\mathrm{A}$ and $\mathrm{F}$ in figure 8), or a harmonized standard, meaning that at least two versions of the same unique standard have been released by at least two SSOs of different nationalities (such as standards B, C, D and E in figure 8).

Figure 8: Terminology

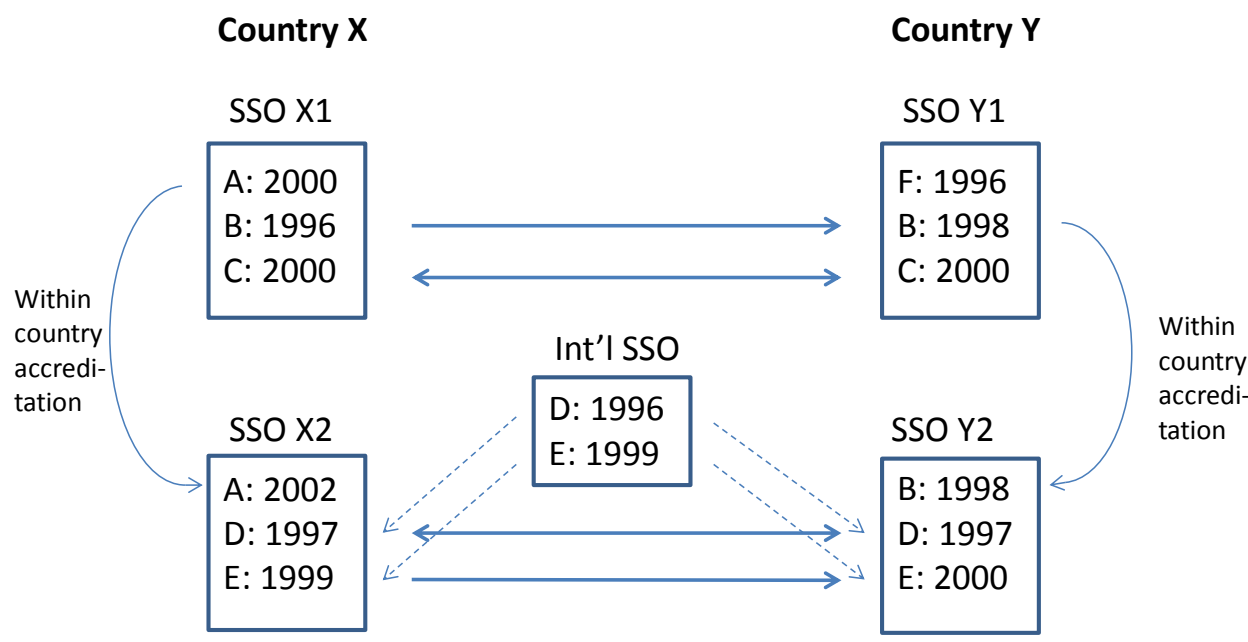

We consider a standard harmonization event to take place whenever the importer of a product accredits a standard that was already released or is being released in the same year by the exporter. As demonstrated in figure 8, this can be the case when country Y accredits the standard B in 1998 that was originally released by country X in 1996. A harmonization event also takes place whenever two countries accredit a standard that was originally released by an international SSO. In the example in figure 8, this is the case for standards D and E.

Table 21: Coding of harmonization events

\begin{tabular}{llllll}
\hline Exporter & Importer & Year & Harm. events & Dummy & Time lag \\
\hline $\mathrm{X}$ & $\mathrm{Y}$ & 1996 & - & 0 & 0 \\
$\mathrm{X}$ & $\mathrm{Y}$ & 1997 & $\mathrm{D}$ & 1 & 0 \\
$\mathrm{X}$ & $\mathrm{Y}$ & 1998 & $\mathrm{~B}$ & 1 & 2 \\
$\mathrm{X}$ & $\mathrm{Y}$ & 1999 & - & 0 & 0 \\
$\mathrm{X}$ & $\mathrm{Y}$ & 2000 & $\mathrm{C}+\mathrm{E}$ & 1 & $(0+1) / 2=0.5$ \\
$\mathrm{Y}$ & $\mathrm{X}$ & 1996 & - & 0 & 0 \\
$\mathrm{Y}$ & $\mathrm{X}$ & 1997 & $\mathrm{D}$ & 1 & 0 \\
$\mathrm{Y}$ & $\mathrm{X}$ & 1998 & - & 0 & 0 \\
$\mathrm{Y}$ & $\mathrm{X}$ & 1999 & - & 0 & 0 \\
$\mathrm{Y}$ & $\mathrm{X}$ & 2000 & $\mathrm{C}$ & 1 & 0 \\
\hline
\end{tabular}

In table 21, we show how we code the harmonization events as well as the variable that measures the time lag of harmonization. The year of the harmonization is the point in 
time when the importing country accredits the standard, i.e. 1998 for the case of standard $\mathrm{B}$ in the example of figure 8. When the two countries accredit the same standard in the same year, as is the case of standard $\mathrm{C}$ in the example, we record it as a harmonization event both when considering exports from $\mathrm{X}$ to $\mathrm{Y}$ in the year 2000 as well as exports from $\mathrm{Y}$ to $\mathrm{X}$ in the year 2000. 


\section{Appendix: Concordance table}

One of the key identification issues in quantifying the impact of standard harmonization on international trade is linking the standard documents to their corresponding products. The International Standard Classification (ICS) system groups standards according to economic sector, the underlying technology or activity, such as environmental protection, safety assurance or protection of public health. On the other hand, products in international trade data are categorized according to the Harmonized System (HS) established by the World Customs Organization (WCO).

The HS nomenclature follows trade policy concerns such as tariffs and not necessarily the production characteristics of the product. The non-existence of a concordance is one of the main reasons why previous papers in the literature cover only certain industries; see Moenius (2006), Reyes (2011) or Fontagné et al. (2015). This paper tackles the concordance issue in two ways. First, we use a newly developed concordance table from the WTO with the drawback that some links between key standard categories and products are missing. As a second step, we develop an alternative all-industry concordance table using keyword-matching techniques. We briefly describe both approaches below.

\section{Concordance table based on WTO's TBT IMS database}

The WTO concordance table is based on the Technical Barriers to Trade Information Management System (TBT IMS) database of the WTO. The TBT IMS is a publicly available database of transparency information provided by WTO members in relation to technical regulations, conformity assessment procedures and standards. ${ }^{38}$ A typical notification of a member country consists of an explanation of why it imposes a technical barrier to trade, which partner country is affected, the ICS classification of the TBT and, in some instances, it also includes the 4-digit HS code (in some instances the 2-digit or the 6 -digit code) for the products on which the measure is applied.

All the notified relationships between HS and ICS classes for the period 2000 to 2016 amount to 3775 notifications, of which several mention one or more HS and ICS classes. There are a total of 2391 links between HS and ICS, and these make up $0.5 \%$ of all possible links. Of the identified relationships, $32 \%$ cover multiple relationships and lead to a many-to-many concordance. One of the drawbacks of this concordance table is potential underreporting because there will only be links for those HS-ICS relationships for which there was actually a notification at the WTO. In addition, there might be biased reporting, as WTO members have different incentives to report to the WTO depending on the importance of the export and import flows pertaining to a particular product.

\footnotetext{
${ }^{38}$ The table is available at https://i-tip.wto.org/goods/Forms/Methodology.aspx.
} 


\section{Concordance table based on keyword matching}

We use a rich set of fixed effects to tackle the issues mentioned above. However, identification concerns of neglecting key standard-product links remain. To mitigate this concern, we construct another concordance table based on keyword-matching techniques described in a companion paper (Han et al., 2019). The main idea is to use keywords describing individual standards (obtained from the German Institute for Standardization DIN, Deutsches Institut für Normung e.V.) and match them with keywords extracted from the descriptions of the product categories in the Harmonized System.

The first step reduces the set of keywords via a stemming algorithm. We consider only the present tense of a verb and the singular of a noun. After having unified each word, a keyword algorithm extracts all the keywords from the HS and ICS classification and attaches an importance weight to each of them. The importance weight is determined by the inverse-document frequency (how distinctive the word is in the overall classification scheme). We then calculate the combined weight for each HS 4-digit and ICS 5-digit category and normalize this combined weight by the number of keywords in each classification scheme. We then choose a threshold below which we consider the respective HS-ICS links as irrelevant. This threshold value is chosen to keep as many of the links that appear in the WTO concordance table as possible while reducing the total number of links.

We obtain a concordance table with 994 links between the ICS 5-digit and HS 4-digit categories. Given that the quality of the match is not as good as the one by the WTO (which is based on human knowledge), we use this table as a robustness check. The advantage of the keyword-matching algorithm is that it is unbiased and comprehensive. 


\section{E Appendix: Additional empirical results}

\section{Multiple harmonization events}

In contrast to most difference-in-difference set-ups, each exporter-importer-product triplet can be subject to multiple treatments over the time period in question. The baseline specification estimates the marginal effect of a standard harmonization on trade flows relative to non-harmonized flows, assuming that this effect is constant. However, the positive effects of standard harmonization might take time to materialize. For this reason, we consider a non-parametric specification, where we allow the marginal effect to depend on the number of times a product experienced a harmonization event. The corresponding regression specification looks as follows, where the subscript $n$ indexes the $n$-th harmonization:

$$
\log \left(X_{i j k t}\right)=\sum_{n}^{20} \beta_{n} h_{n, i j k t}+f_{i k t}+f_{j k t}+f_{i j t}+f_{i j k}+\varepsilon_{i j k t}
$$

The dummy $h_{n, i j k t}$ equals 1 if a product was harmonized $n$ times and zero otherwise. The variable measures the difference in the average trade flow of a product that was harmonized $n$ times compared to a product that was never harmonized.

Figure 9 plots the coefficients $\beta_{n}$ from the above-specified regression set-up together with the 95 percent confidence interval. Panel a shows that the marginal effect of standard harmonization on trade flows is more or less constant in the number of harmonization events (up to 12-13 events), with each subsequent harmonization contributing a similar positive amount to overall trade flows. Afterwards the additional effect declines slightly, but the overall effect remains positive. The effects for the extensive margin (panel b), the intensive margin (panel c) and quantities (panel e) mirror the baseline results. The price response shows a steadily negative response. 
Figure 9: Cumulative effect of multiple harmonization events

(a) Total flows

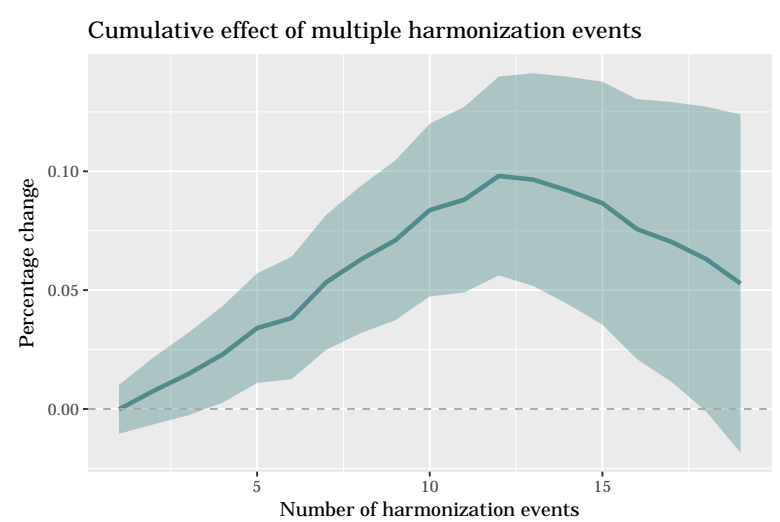

(b) Extensive margin

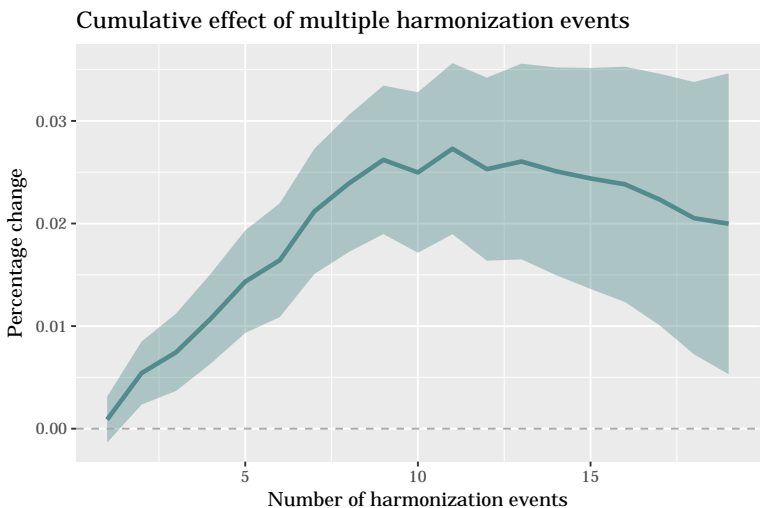

(d) Price

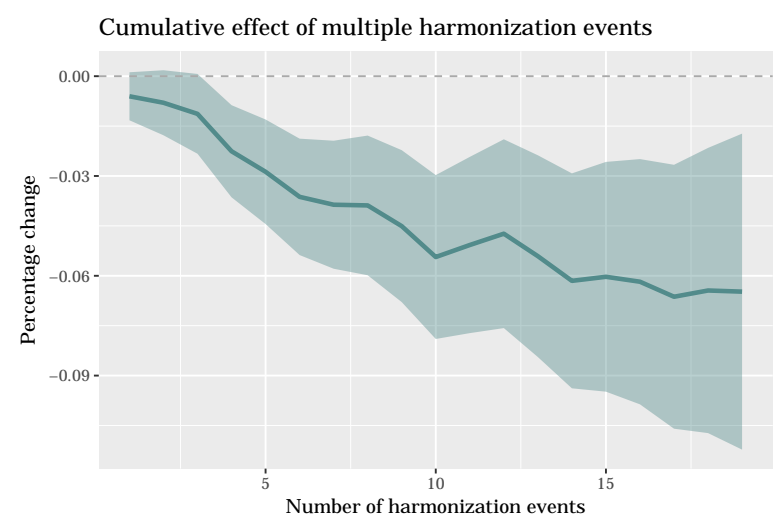

(c) Intensive margin

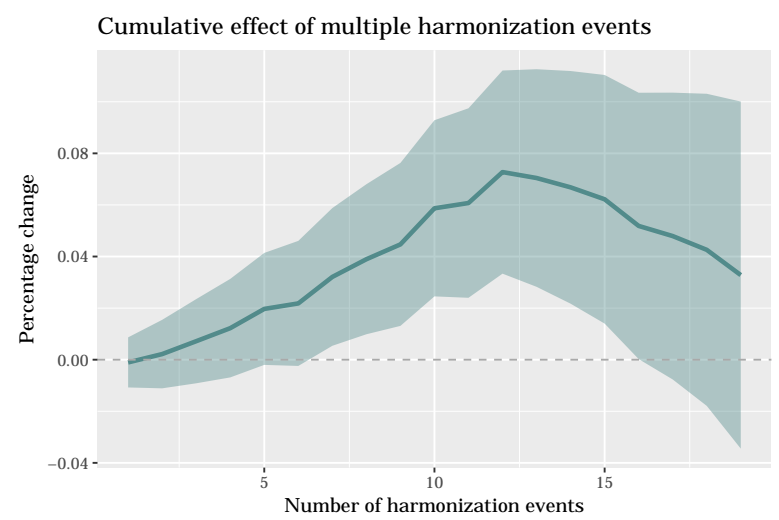

(e) Quantity

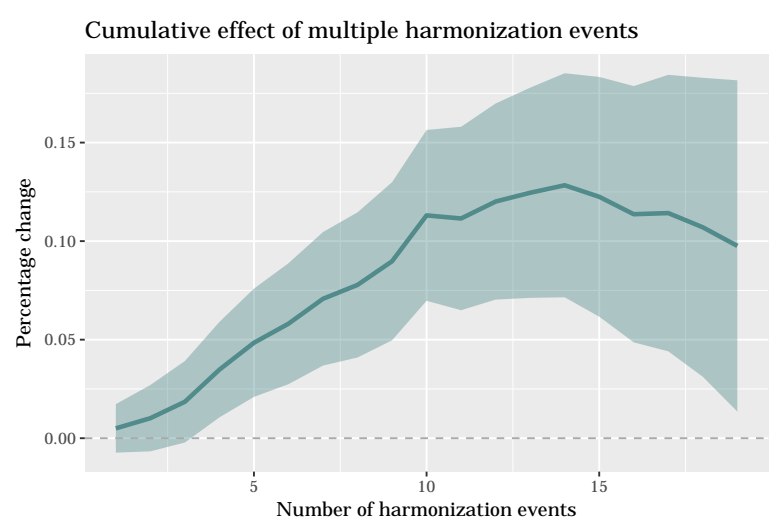

Notes: The figure displays the coefficient estimates of a regression of the respective dependent variable (designated in figure subtitles) on dummies for each subsequent harmonization within an exporter-importer-product triplet (regression specification 113). Shaded regions represent $95 \%$ confidence intervals.

\section{Intensive and extensive margin à la Hummels and Klenow}

As a robustness check to the decomposition of trade flows in their different margins as implemented in the baseline specification, we use the cross-sectional decomposition developed by Hummels and Klenow (2005). The main difference is to weigh the extensive margin by the importance of the trade flow rather than assuming that each 6-digit HS product has the same importance weight within a HS 4-digit category. Hummels and 
Klenow (2005) argue that this adjustment reduces concerns about the level of aggregation of the classification scheme and the grouping of product categories according to non-economic characteristics. We define the extensive margin as

$$
N_{i j k t}=\frac{\sum_{l \in \Omega_{i j k t}} p_{s j l t} q_{s j l t}}{\sum_{l \in \Omega_{k}} p_{s j l t} q_{s j l t}}
$$

and the intensive margin as

$$
\frac{X_{i j k t}}{N_{i j k t}}=\bar{x}_{i j k t}=\frac{\sum_{l \in \Omega_{i j k t}} p_{i j l t} q_{i j l t}}{\sum_{l \in \Omega_{i j k t}} p_{s j l t} q_{s j l t}}
$$

where $s$ is the reference country, i.e. the rest of the world. The share of overall exports can then be decomposed into an intensive and extensive margin:

$$
\frac{\sum_{l \in \Omega_{i j k t}} p_{i j l t} q_{i j l t}}{\sum_{l \in \Omega_{k}} p_{s j l t} q_{s j l t}}=\bar{x}_{i j k t} N_{i j k t}
$$

It is also possible to decompose the intensive margin into a price effect as well as a quantity effect (see Hummels and Klenow, 2005). This takes the form

$$
\bar{x}_{i j k t}=P_{i j k t} Q_{i j k t},
$$

where the price index, $P_{i j k t}$, is defined as

$$
P_{i j k t}=\prod_{l \in N_{i j k t}}\left(\frac{p_{i j l t}}{p_{s j l t}}\right)^{w_{i j l t}} .
$$

The exponent $w_{i j l t}$ is the logarithmic mean of the shares of HS6-category $l$ in country $i$ 's and country $s$ 's exports to $j$ at time $t s_{i j l t}$ :

$$
\begin{aligned}
s_{i j l t} & =\frac{p_{i j l t} q_{i j l t}}{\sum_{l \in \Omega_{i j k t}} p_{i j l t} q_{i j l t}} \quad, \quad s_{s j l t}=\frac{p_{s j l t} q_{s j l t}}{\sum_{l \in \Omega_{i j k t}} p_{s j l t} q_{s j l t}} \\
w_{i j l t} & =\frac{\frac{s_{i j l t}-s_{s j l t}}{\ln s_{i j l t}-\ln s_{s j l t}}}{\sum_{l \in \Omega_{i j k t} \frac{s_{i j l t}-s_{s j l t}}{\ln s_{i j l t}-\ln s_{s j l t}}}}
\end{aligned}
$$

The quantity index, $Q_{i j k t}$, is obtained by dividing the intensive margin by the price index. 
Table 22: Regression results / HK decomposition

\begin{tabular}{lccccc}
\hline & $(1)$ & $(2)$ & $(3)$ & $(4)$ & $(5)$ \\
& Total & Ext. margin & Int. margin & Price & Quantity \\
\hline Harm. & $0.00662^{* * *}$ & 0.00079 & $0.00582^{* * *}$ & $-0.00282^{* *}$ & $0.00855^{* * *}$ \\
& {$[0.000]$} & {$[0.235]$} & {$[0.001]$} & {$[0.011]$} & {$[0.000]$} \\
\hline Observations & 5843027 & 5843027 & 5843027 & 5848855 & 5843027 \\
$R^{2}$ & 0.88 & 0.68 & 0.84 & 0.60 & 0.81 \\
Adjusted $R^{2}$ & 0.85 & 0.59 & 0.79 & 0.49 & 0.76 \\
\hline
\end{tabular}

Notes: Regression of the respective dependent variable (designated in column headers) on harmonization indicator. Fixed effects are included as described in the regression specification 1. Standard errors are clustered at the exporter-product level. P-values are reported in brackets. ${ }^{* * *},{ }^{* *}$ and $*$ indicate respectively $1 \%, 5 \%$ and $10 \%$ significance levels.

Results are displayed in table 22. The estimated coefficients very much mirror the results from table 3. Total exports expand; this increase is driven by the intensive margin which is in turn driven by larger quantities being sold. However, the extensive margin is not significant, as in the baseline regression in table 3 .

\section{Results using the keyword-matching table}

All results in the main part of the paper are obtained using the concordance table extracted from the WTO's TBT IMS database. As a further robustness check, we run the regression on the dataset using the concordance table obtained via keyword-matching techniques. Results for the baseline regression specification 1 are displayed in table 23 and show similar, though slightly smaller coefficients. In comparison to the results in table 3 , the responses of the extensive margin and prices are not significant.

Table 23: Regression results / Concordance based on keyword matching

\begin{tabular}{lccccc}
\hline & $(1)$ & $(2)$ & $(3)$ & $(4)$ & $(5)$ \\
& Total & Ext. margin & Int. margin & Price & Quantity \\
\hline Harm. & $0.00406^{* *}$ & -0.00016 & $0.00422^{* *}$ & -0.00165 & $0.00587^{* * *}$ \\
& {$[0.035]$} & {$[0.693]$} & {$[0.019]$} & {$[0.189]$} & {$[0.009]$} \\
\hline Observations & 4260286 & 4260286 & 4260286 & 4260286 & 4260286 \\
$R^{2}$ & 0.88 & 0.90 & 0.86 & 0.85 & 0.87 \\
Adjusted $R^{2}$ & 0.85 & 0.87 & 0.83 & 0.81 & 0.83 \\
\hline
\end{tabular}

Notes: Regression of the respective dependent variable (designated in column headers) on harmonization indicator. Fixed effects are included as described in the regression specification 1. Standard errors are clustered at the exporter-product level. P-values are reported in brackets. $* * *, * *$ and $*$ indicate respectively $1 \%, 5 \%$ and $10 \%$ significance levels.

\section{Lagged effects}

Another way to investigate the robustness of the results is to include lags of the independent variable. The estimation equation takes the following form:

$$
\log \left(X_{i j k t}\right)=\beta h_{i j k, t-l}+f_{i k t}+f_{j k t}+f_{i j t}+f_{i j k}+\varepsilon_{i j k t},
$$


where $h_{i j k, t-l}$ designates the harmonization dummy lagged by $l$ years. Results are displayed in table 24 and show that the effect fades out over time, but remains significant.

Table 24: Regression results / Lagged effects

\begin{tabular}{lcccc}
\hline & $(1)$ & $(2)$ & $(3)$ & $(4)$ \\
& Total & Total & Total & Total \\
\hline Harm. (t-1) & & & & -0.00007 \\
& & & {$[0.980]$} \\
Harm. (t-2) & $0.00616^{* * *}$ & & 0.00300 \\
& {$[0.001]$} & & {$[0.263]$} \\
Harm. (t-3) & & $0.00500^{* * *}$ & & -0.00073 \\
& & {$[0.007]$} & & {$[0.782]$} \\
Harm. (t-4) & & & $0.00397^{* *}$ & 0.00091 \\
& & & {$[0.038]$} & {$[0.718]$} \\
\hline Observations & 5332782 & 5065797 & 4798734 & 4798734 \\
$R^{2}$ & 0.89 & 0.89 & 0.89 & 0.89 \\
Adjusted $R^{2}$ & 0.85 & 0.86 & 0.86 & 0.86 \\
\hline
\end{tabular}

Notes: Regression of log total trade flows on lagged values of the harmonization indicator. Fixed effects are included as described in the regression specification 121. Standard errors are clustered at the exporter-product level. P-values are reported in brackets. ${ }^{* * *},{ }^{* *}$ and $*$ indicate respectively $1 \%, 5 \%$ and $10 \%$ significance levels. 